Aus der Klinik für Neurologie

(Prof. Dr. med. M. Bähr)

der Medizinischen Fakultät der Universität Göttingen

\title{
Live-Imaging von Kalzium-induzierter axonaler Degeneration in transgenen Mausmodellen des Morbus Parkinson
}

\author{
INAUGURAL-DISSERTATION \\ zur Erlangung des Doktorgrades \\ der Medizinischen Fakultät der \\ Georg-August-Universität zu Göttingen
}

vorgelegt von

Julius Christian Steenken

aus

Oberhausen

Göttingen 2020 
Dekan:

Referent/in

Ko-Referent/in:

Drittreferent/in:

Datum der mündlichen Prüfung:

Prof. Dr. med. W. Brück

PD Dr. med. J. C. Koch 
Die vorliegende Dissertation wurde unter der Betreuung von Prof. Dr. med. P. Lingor und nachfolgend von PD Dr. med. J. C. Koch angefertigt. 
Hiermit erkläre ich, Julius Christian Steenken, die Dissertation mit dem Titel "Live-Imaging von Kalzium-induzierter axonaler Degeneration in transgenen Mausmodellen des Morbus Parkinson" eigenständig angefertigt und keine anderen als die von mir angegebenen Quellen und Hilfsmittel verwendet zu haben.

Göttingen, den 23. Juli 2020

(Unterschrift) 


\section{Inhaltsverzeichnis}

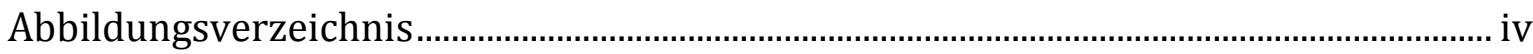

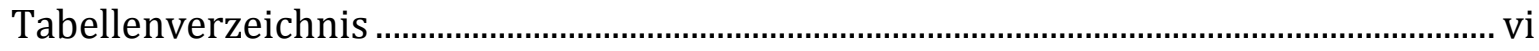

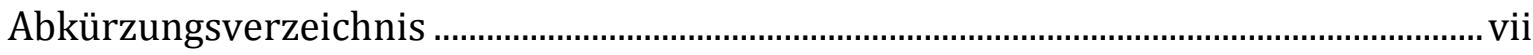

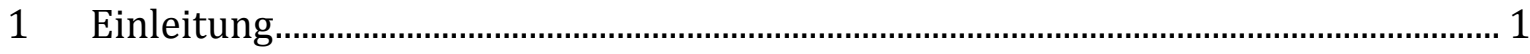

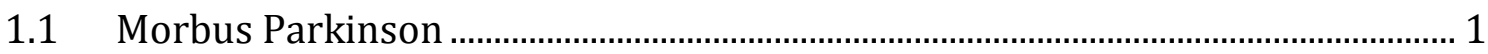

1.1.1 Epidemiologie und klinisches Bild ................................................................ 1

1.1.2 Neuropathologische Beobachtungen ................................................................ 1

1.2 Zellbiologische Mechanismen in der Pathogenese des Morbus Parkinson ...... 3

1.2.1 Bedeutung axonaler Degeneration beim Morbus Parkinson und akute

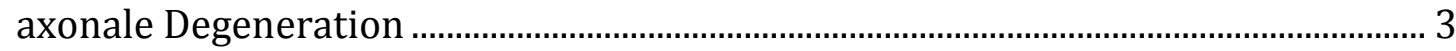

1.2.2 Genetik des Morbus Parkinson - im Fokus: $\alpha$-Synuclein ............................... 5

1.3 Die Erforschung des Morbus Parkinson im Tiermodell ............................................. 7

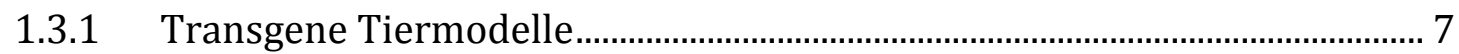

1.3.2 Der optische Nerv als Modell zur Erforschung des Morbus Parkinson ..... 8

$1.4 \quad$ Fragestellung und Zielsetzung der Arbeit............................................................... 10

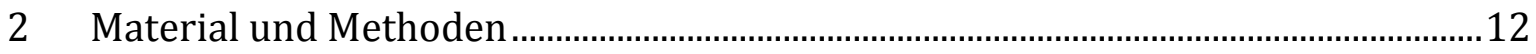

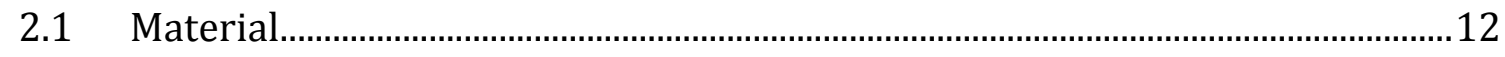

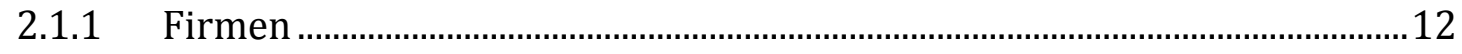

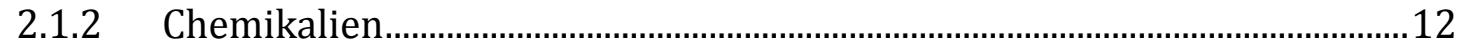

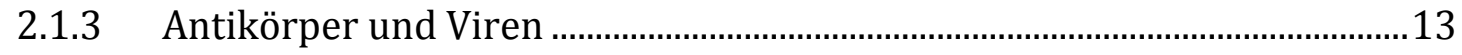

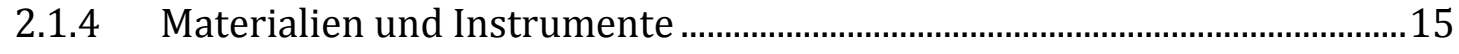

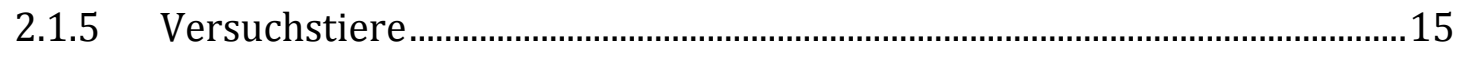

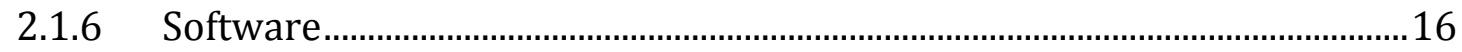

2.1.7 Puffer und Lösungen................................................................................... 16

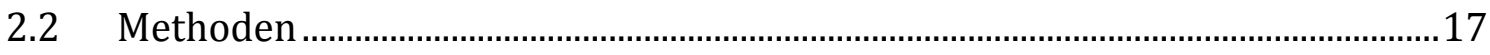


2.2.1 Versuchstiernarkose

2.2.2 In-vivo-Live-Imaging axonaler Degeneration des optischen Nervs...........18

2.2.3 Western Blot 26

2.2.4 Immunohistochemische Färbung von Gewebeschnitten optischer Nerven auf humanes $\alpha$-Synuclein 28

2.2.5 Retina-Flat-Mounts 29

2.2.6 Nervenquerschnitte 29

3 Ergebnisse 31

3.1 Nachweis der Transduktion retinaler Ganglienzellen mit AAV-EGFP 31

3.2 Expression von $\alpha$-Synuclein im optischen Nerv transgener Versuchstiere.....34

3.3 Ergebnisse der Live-Imaging-Experimente 38

3.3.1 Weiterentwicklung des Live-Imaging-Verfahrens 38

3.3.2 Dynamik der Bulb-Formierung im optischen Nerv nach Applikation von Kalzium-Ionophor .40

4 Diskussion 61

4.1 Zusammenfassung der Ergebnisse 61

4.2 Diskussion der Ergebnisse. 62

4.2.1 Die Transduktion retinaler Ganglienzellen mit AAV-EGFP führte zu einer verlässlichen fluoreszenzmikroskopischen Darstellung von Axonen im optischen Nerv.

4.2.2 [A53T] $\alpha \mathrm{SYN}$ - und [A30P] $\alpha \mathrm{SYN}$-Mäuse exprimierten humanes $\alpha \mathrm{SYN}$ im optischen Nerv. .64

4.2.3 Die Applikation von Kalzium-Ionophor führte zur axonalen Degeneration. .65

4.2.4 [A53T] $\alpha \mathrm{SYN}$-Tiere zeigten ein höheres Ausmaß an axonaler Degeneration als $[\mathrm{A} 30 \mathrm{P}] \alpha \mathrm{SYN}$-Tiere und Wildtyp-Tiere .66

4.2.5 Das Alter der Versuchstiere beeinflusste nicht das Ausmaß und den Ablauf der axonalen Degeneration 69

4.3 Ausblick . .70 


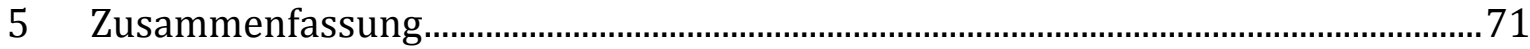

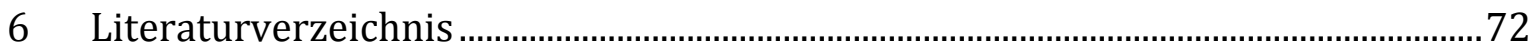




\section{Abbildungsverzeichnis}

Abbildung 1: Plasmidkarte des Virus AAV 1/2 9(5)-hSyn-EGFP-CytBAS

Abbildung 2: Zeitlicher Ablauf der experimentellen Schritte des Live-Imagings ......19

Abbildung 3: Schemazeichnung einer Glaskapillare zur intravitrealen Injektion.....19

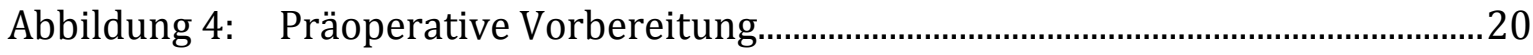

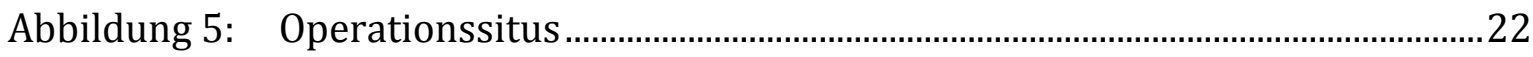

Abbildung 6: Auswertung der Live-Imaging-Daten ......................................................25

Abbildung 7: Fluoreszenzmikroskopische Aufnahme eines Retina-Flat-Mounts zwei Wochen nach Transduktion der RGZ mit AAV-EGFP .32

Abbildung 8: Fluoreszenzmikroskopische Aufnahme des ON einer Maus im Querschnitt zwei Wochen nach Transduktion der RGZ mit AAV-EGFP. 33

Abbildung 9: Nachweiß der Genexpression von $\alpha$ SYN im ON transgener Mäuse mittels Western Blot .35

Abbildung 10: IHC-gefärbte Kryogewebeschnitte von ON transgener und Wildtypmäuse .37

Abbildung 11: Die Applikation von Kalzium-Ionophor auf den freigelegten optischen Nerv führte zur Ausbildung axonaler Bulbs.

Abbildung 12: Exemplarische Additionsbilder aus Live-Imagings von WT- und transgenen Mäusen $([\mathrm{A} 30 \mathrm{P}] \alpha \mathrm{SYN},[\mathrm{A} 53 \mathrm{~T}] \alpha \mathrm{SYN})$ im Alter von 3-5 Monaten vom Zeitpunkt vor Applikation von Kalzium-Ionophor bis 90 Minuten danach 43

Abbildung 13: Exemplarische Additionsbilder aus Live-Imagings von WT- und transgenen Mäusen ([A30P] $\alpha \mathrm{SYN},[\mathrm{A} 53 \mathrm{~T}] \alpha \mathrm{SYN})$ im Alter von 3-5 Monaten im Zeitraum 120-300 Minuten nach Applikation von Kalzium-Ionophor 44

Abbildung 14: Exemplarische Additionsbilder aus Live-Imagings von WT- und transgenen Mäusen $([\mathrm{A} 30 \mathrm{P}] \alpha \mathrm{SYN},[\mathrm{A} 53 \mathrm{~T}] \alpha \mathrm{SYN})$ im Alter von 7-9 Monaten vom Zeitpunkt vor Applikation von Kalzium-Ionophor bis 90 Minuten danach 45

Abbildung 15: Exemplarische Additionsbilder aus Live-Imagings von WT- und transgenen Mäusen ([A30P] $\alpha$ SYN, [A53T] $\mathrm{SSYN})$ im Alter von 7-9 Monaten im Zeitraum 120-300 Minuten nach Applikation von Kalzium-Ionophor 46 


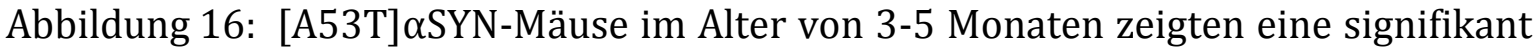
stärkere Erhöhung der Bulb-Verteilungsdichte als Wildtypmäuse desselben Alters..48

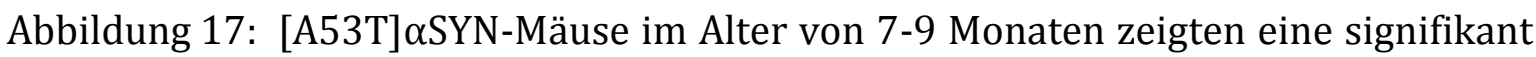
stärkere Erhöhung der Bulb-Verteilungsdichte als Wildtypmäuse desselben Alters..49 Abbildung 18: Das Ausmaß der Bulb-Formierung von [A30P] $\alpha$ SYN-Mäusen im Alter von 3-5 Monaten unterschied sich nicht signifikant von demjenigen der Wildtypmäuse desselben Alters 50

Abbildung 19: Das Ausmaß der Bulb-Formierung von [A30P] $\alpha$ SYN-Mäusen im Alter von 7-9 Monaten unterschied sich nicht signifikant von demjenigen der Wildtypmäuse desselben Alters 51

Abbildung 20: Das Alter der Versuchstiere beeinflusste nicht den Verlauf der BulbFormierung bei den Genotypen [A53T] $\mathrm{SYYN},[\mathrm{A} 30 \mathrm{P}] \alpha \mathrm{SYN}$ und WT 53

Abbildung 21: In Betrachtung des Bulb-Durchmessers ergaben sich bei jungen und alten Versuchstieren signifikante Unterschiede zwischen den Genotypen [A53T] $\alpha$ SYN, $[\mathrm{A} 30 \mathrm{P}] \alpha \mathrm{SYN}$ und WT. 56

Abbildung 22: Verteilung der Bulb-Durchmesser 90 und 120 Minuten nach der Applikation von Kalzium-Ionophor 57

Abbildung 23: Verteilung der Bulb-Durchmesser 180 und 240 Minuten nach der Applikation von Kalzium-Ionophor.

Abbildung 24: Verteilung der Bulb-Durchmesser 300 Minuten nach der Applikation von Kalzium-Ionophor

Abbildung 25: Zusammengefasste Verteilung der Bulb-Durchmesser aller Zeitpunkte. 


\section{Tabellenverzeichnis}

Tabelle 1: Mit dem Auftreten von Morbus Parkinson assoziierte Gene. ........................... 5

Tabelle 2: Stichprobengrößen zur Analyse des Bulb-Durchmessers..................................54 


\section{Abkürzungsverzeichnis}

[A30P] $]$ SYN $[\mathrm{A} 53 \mathrm{~T}] \alpha \mathrm{SYN}$

AAD

BCA

BD.

BSA

CPI

DAPI

DTT

ERG

IHC.

ILB

JNK

$\mathrm{kDa}$

LB

LN

mfERG

MP.

OCT

ON.

PBS

PFA

PVDF

RGZ

S.c.

SDS

SDS-PAGE

SNpc

Tris

VEP

$\alpha \mathrm{SYN}$
Alpha-Synuclein-Variante mit der Mutation A30P Alpha-Synuclein-Variante mit der Mutation A53T akute axonale Degeneration bicinchroninic acid assay ...Becton Dickinson (Firma) bovines Serumalbumin complete protease inhibitor .4',6-Diamidino-2-Phenylindol .. Dithiothreitol Elektroretinogramm Immunhistochemie incidental lewy body disease ...-Jun- $\mathrm{N}$-terminale Kinase Kilo-Dalton . Lewy-Körperchen (Lewy Body) Lewy Neurite multifokales Elektroretinogramm Morbus Parkinson Optische Kohärenztomografie optischer Nerv ...phosphate-buffered saline ...Paraformaldehyd Polyvinylidendifluorid ...retinale Ganglienzelle subkutan ..Natriumdodecylsulfat SDS-Polyacrylamidgelelektrophorese Substantia nigra pars compacta 2-Amino-2-hydroxymethyl-propan-1,3-diol . visuell evoziertes Potential .Alpha-Synuclein 


\section{$1 \quad$ Einleitung}

\section{$1.1 \quad$ Morbus Parkinson}

\subsubsection{Epidemiologie und klinisches Bild}

Die Bewohner der westlichen Industriestaaten erreichen dank einer zunehmend optimierten medizinischen Versorgung ein immer höheres Lebensalter. Da unsere Gesellschaft einem demographischen Alterungsprozess unterworfen ist, betreffen altersassoziierte, meist chronische Erkrankungen immer größere Anteile der Bevölkerung und stellen nicht zuletzt eine Belastung für das Gesundheitssystem dar.

Auch der Morbus Parkinson (MP) zählt zu diesen Erkrankungen. Während in den Industrieländern die Prävalenz des MP 0,3 \% der Gesamtbevölkerung beträgt, steigt der Anteil der Erkrankten bei den über 60-Jährigen auf 1 \% (de Lau und Breteler 2006; Dexter und Jenner 2013). Damit ist der MP nach der Alzheimer-Demenz die zweithäufigste neurodegenerative Erkrankung. Das Lebenszeitrisiko, an MP zu erkranken, beträgt 1,5\% (Lees et al. 2009).

Die Kardinalsymptome sind Bewegungsarmut (Bradykinese), ein Zittern in Ruhe (Tremor), eine Versteifung der Muskulatur (Rigor) und eine Fallneigung (posturale Instabilität). Daneben können sich auch nicht-motorische Symptome einstellen, die teilweise schon früher im Krankheitsverlauf auftreten. Dazu gehören Schlafstörungen, autonome Störungen (z. B. Dranginkontinenz, orthostatische Dysregulation), sowie psychiatrische Erkrankungen wie Demenz und Depression (Dauer und Przedborski 2003; Dexter und Jenner 2013). Die Erkrankung führt ab dem Zeitpunkt der Diagnose im Mittel innerhalb von 15 Jahren zum Tod (Lees et al. 2009).

\subsubsection{Neuropathologische Beobachtungen}

Begleitend zum klinischen Symptomkomplex fallen beim MP spezifische neuropathologische Veränderungen auf. In der Substantia nigra pars compacta (SNpc) kommt es zu einem Verlust dopaminerger, Neuromelanin-haltiger Neurone. In den betroffenen Regionen konnten intrazelluläre Einschlusskörperchen beobachtet werden, die so genannten lewy bodies (LB) und lewy neurites (LN) (Damier et al. 1999), die einen hohen Gehalt an aggregiertem $\alpha$-Synuclein ( $\alpha \mathrm{SYN}$ ) aufweisen (Wakabayashi et al. 2007). 
Neben der SNpc sind auch andere Hirnregionen von pathologischen Veränderungen betroffen. Das Auftreten von neuronalem Zellverlust und LB-Pathologie folgt dabei einem gewissen anatomischen Ausbreitungsmuster, das chronologisch mit der klinischen Symptomatik zu korrelieren scheint. Nach Braak lassen sich 6 Stadien differenzieren (Braak et al. 2003a): Zuerst sind zwei Regionen betroffen: der Bulbus olfactorius und der dorsale motorische Kern des Nervus vagus (Pearce et al. 1995; Del Tredici et al. 2002). Im zweiten Stadium treten Läsionen im Raphe-Kern, Locus coeruleus und Nucleus reticularis gigantocellularis auf (Holstege 1992; Holstege 1996; Nieuwenhuys 1996; Braak et al. 2000), gefolgt von pathologischen Veränderungen in der Amygdala, im basalen Telencephalon (u. a. Nucleus basalis Meynert) und in der SNpc in Stadium 3. Schließlich sind auch kortikale Regionen betroffen, beginnend mit dem anteromedialen und temporalen Mesocortex (Stadium 4), gefolgt vom Neocortex (somatosensorischer und präfrontaler Cortex) in Stadium 5. In Stadium 6 sind schließlich auch der motorische und prämotorische Cortex betroffen (Braak et al. 2002; Braak et al. 2003b).

Im Kontext dieses Ausbreitungsmusters mit einer Progression der $\alpha$ SYN-Pathologie von kaudal nach rostral bzw. von peripher nach zentral wird das Vorhandensein eines exogenen Pathogens diskutiert (Braak et al. 2003a), das im Sinne einer „DualHit“-Hypothese für die Initiierung des Krankheitsprozesses in olfaktorischen und vegetativen Nervenzellen des Darms verantwortlich sein könnte (Hawkes et al. 2007; Hawkes et al. 2009). Nervenzellen anderer peripherer Regionen wie des Rückenmarks sind erst nach Befall des Gehirns betroffen, sie scheiden daher als mögliche Route zum ZNS aus (Hawkes et al. 2007; Del Tredici und Braak 2016).

Klinische Beobachtungen und histologische Untersuchungen unterstützen die Braakund „Dual-Hit“-Hypothese. So sind beim MP Beeinträchtigungen des Geruchsinns und Beschwerden des Gastrointestinaltrakts (wie Nausea, Dysphagie und Obstipation) bekannt und treten bereits Jahre vor den motorischen Symptomen auf (Pfeiffer 2011; Cersosimo und Benarroch 2012; Doty 2012). Korrespondierend dazu wurden in Neuronen des olfaktorischen Trakts und des enterischen Nervensystems (Meissner- und Auerbach-Plexus) LBs nachgewiesen (Braak et al. 2006; Beach et al. 2009).

Bei den beschriebenen pathologischen Veränderungen und ihrer Verbreitung von der Peripherie zum ZNS spielt $\alpha$ SYN eine Schlüsselrolle, wobei die genauen Mechanismen 
der Ausbreitung und der Neurotoxizität nach wie vor nicht bekannt sind. Verschiedene Mechanismen zur Verbreitung von fehlgefaltetem $\alpha$ SYN werden diskutiert.

Es wurde gezeigt, dass neuronale Zellen zur Exkretion von $\alpha$ SYN fähig sind. $\alpha$ SYN in Form von Mono- und Oligomeren sowie Fibrillen wird mittels Kalzium-abhängiger Exozytose oder mittels Exosomen aus der Zelle geschleust (Lee 2005; Emmanouilidou et al. 2010; Danzer et al. 2012; Pan-Montojo et al. 2012). Freies oder Exosomgebundenes $\alpha$ SYN kann durch Endozytose auch wieder in die Zellen aufgenommen werden. Während Oligomere und Fibrillen des $\alpha$ SYN lysosomal degradiert werden, bleibt monomeres $\alpha$ SYN vom Abbau ausgenommen. Nach Aufnahme kann $\alpha$ SYN entlang des Axons transportiert und an andere Neurone weiter gegeben werden (Lee H-J et al. 2008; Desplats et al. 2009; Danzer et al. 2012). Es konnte gezeigt werden, dass exogene $\alpha$ SYN -Fibrillen die Formierung von LBs in exponierten Neuronen bewirken (Desplats et al. 2009), indem sie endogenes $\alpha$ SYN rekrutieren und in die Bildung der LBs mit einbeziehen (Luk et al. 2009; Hansen et al. 2011).

\subsection{Zellbiologische Mechanismen in der Pathogenese des Morbus Parkinson}

\subsubsection{Bedeutung axonaler Degeneration beim Morbus Parkinson und akute axonale Degeneration}

Es konnte gezeigt werden, dass MP-Patienten schon beim Auftreten erster klinischer Symptome einen Verlust dopaminerger Neurone von 48-68 \% in der SNpc aufwiesen verglichen mit altersentsprechenden gesunden Personen (Fearnley und Lees 1991). Diese Neurone projizieren in das Striatum. Mittels dopaminerger Marker konnte nachgewiesen werden, dass der Verlust dieser dopaminergen Projektionen den Verlust der nigralen neuronalen Somata zahlenmäßig deutlich übersteigt (Bernheimer et al. 1973; Kish et al. 1988; Scherman et al. 1989). Lässt sich dieses Degenerationsmuster auch in früheren Krankheitsstadien oder bei asymptomatischen Patienten beobachten? Patienten mit incidental lewy body disease (ILB) sind klinisch unauffällig, weisen jedoch typische histopathologische Veränderungen in Form von LBs auf und stellen wahrscheinlich ein präklinisches Krankheitsstadium des MP dar (DelleDonne et al. 2008; Iacono et al. 2015). Diese Patienten zeigten einen Verlust von nigralen, dopaminergen Neuronen von 17 \% (Ross et al. 2004), jedoch ebenfalls eine noch stärkere Reduktion des dopaminergen Markers Tyrosinhydroxylase im Striatum von 
50 \% verglichen mit altersadjustierten Kontrollen, was auf einen Verlust von Axonen der dopaminergen Neurone der Substantia nigra hinweist (Beach et al. 2008).

Die aktuelle Studienlage stützt also die Hypothese, dass die Degeneration von Axonen nicht nur früh im Verlauf neurodegenerativer Erkrankungen auftritt, sondern auch dem Zugrundegehen dazugehöriger Zellsomata vorausgeht. Eine Erkenntnis, die als therapeutischer Ansatz weitergedacht, ein frühes Eingreifen in den Krankheitsprozess in Aussicht stellt. Der Misserfolg experimenteller neuroprotektiver Therapien ohne speziellen Fokus auf das Axon (Lingor et al. 2012) legt nahe, dass es sich beim Axon um eine Funktionseinheit mit einer sich vom Soma unterscheidenden Pathologie handelt.

Die akute axonale Degeneration (AAD) wurde als Folge einer traumatischen Schädigung des Axons beschrieben, tritt aber wahrscheinlich auch nach anderen akuten Schädigungsmustern auf. Sie ist durch eine innerhalb weniger Stunden ablaufende Desintegration des Axons in einem Bereich von 300-400 $\mu \mathrm{m}$ um die Läsion charakterisiert.

Das Studium der AAD eröffnet die Möglichkeit, auch in vivo innerhalb eines überschaubaren Zeitfensters Degenerationsprozesse im zentralen Nervensystem am Tiermodell zu beobachten. So gelang es mittels in-vivo-Live-Imaging-Technik, morphologische Veränderungen nach traumatischer Schädigung von Axonen im Rückenmark (Kerschensteiner et al. 2005) und im optischen Nerv (ON) (Knöferle et al. 2010) zu erfassen.

\subsubsection{Verlauf der akuten axonalen Degeneration}

In den ersten 30-40 Sekunden nach Axon-Schädigung kommt es zu einem massiven Kalzium-Einstrom, der eine molekulare Signalkaskade in Gang setzt. Wird dieser initiale Kalzium-Einstrom durch den Einsatz von Kalzium-Kanal-Blockern verhindert, wird die AAD inhibiert (Knöferle et al. 2010; Ribas et al. 2016).

Nach etwa 10 Minuten werden erste strukturelle Veränderungen sichtbar. Es kommt zu zytoskelettalen Veränderungen, wie der Desintegration von Mikrotubuli und der Zusammenlagerung und Fehlausrichtung von Neurofilamenten (Knöferle et al. 2010). Es wird vermutet, dass die fortschreitende Desintegration des Zytoskleletts zunehmend axonale Transportvorgänge behindert. So konnten Ansammlungen von Zellor- 
ganellen beobachtet werden, die häufig an lokalen Schwellungen der Axone zu finden sind (Knöferle et al. 2010; Koch et al. 2010).

Während des Degenerationsprozesses erhöht sich stetig die Anzahl von Autophagosomen. Schließlich erfolgt die Fragmentierung des Axons proximal und distal der Läsion. Die Pharmakologische Inhibierung der Autophagie schwächt die AAD ab, allerdings nicht so effektiv wie die bereits erwähnte Blockade des KalziumEinstroms (Knöferle et al. 2010; Koch et al. 2010; Ribas et al. 2016).

\subsubsection{Genetik des Morbus Parkinson - im Fokus: $\alpha$-Synuclein}

Die Beobachtung, dass 15-20 \% der Patienten mit MP eine positive Familienanamnese aufweisen, deutet auf einen bedeutsamen genetischen Faktor in der Ätiologie der Erkrankung hin (Nuytemans et al. 2010). Vor diesem Hintergrund wurden einige Genmutationen beschrieben, die mit dem Auftreten von MP assoziiert sind. Dabei ergibt sich für Mutationen in den folgenden Genen nach aktueller Studienlage (Nuytemans et al. 2010) am wahrscheinlichsten ein Kausalzusammenhang mit der Pathogenese des MP:

Tabelle 1: Auswahl mit dem Auftreten von Morbus Parkinson assoziierter Gene.

$\begin{array}{lll}\text { Protein } & \text { Gen } & \text { Erstbeschreibung } \\ \alpha \text {-Synuclein } & \text { SNCA } & \text { (Polymeropoulos et al. } \\ \text { parkin } & \text { PARK2 } & \text { (Kitada et al. 1998) } \\ \text { Daisuke-Junko-1 } & \text { PARK7 } & \text { (Bonifati et al. 2003) } \\ \text { PTEN-induced putative kinase 1 } & \text { PINK1 } & \text { (Valente et al. 2004) } \\ \text { leucine-rich repeat kinase 2 } & \text { LRRK2 } & \text { (Zimprich et al. 2004) }\end{array}$

Das SNCA-Gen war das erste Gen, das im Zusammenhang mit MP beschrieben wurde. In mehreren Familien, bei denen MP gehäuft auftrat, wurde eine Mutation nachgewiesen, die im kodierten Protein $\alpha$ SYN einen Alanin-Threonin-Austausch an Position 53 (A53T-Mutation) zur Folge hat. Dieses Protein wird in der Folge bezeichnet als [A53T] $\alpha$ SYN. Heterozygote Träger dieser Mutation entwickelten mit einer Penetranz von $85 \%$ einen MP in jungen Jahren (mittleres Erkrankungsalter: $46 \pm 13$ Jahre) (Polymeropoulos et al. 1997). Zu homozygoten Trägern der [A53T] $\alpha S Y N-M u t a t i o n$ finden sich keine Studien. 
Mutationen im SNCA-Gen sind selten. Sie wurden in 2,5 \% der Krankheitsfälle nachgewiesen (Nuytemans et al. 2010) Dabei ist neben der A53T-Mutation auch eine A30P-Mutation ([A30P] $\alpha$ SYN) bei MP-Patienten nachgewiesen worden. Hier erkrankte der Indexpatient im Alter von 52 Jahren an MP, seine Mutter im Alter von 56 Jahren, wobei der Erbgang auf eine autosomal-dominante Vererbung mit unvollständiger Penetranz schließen lässt (Krüger et al. 1998). Wieder lassen sich keine Fallbeschreibungen homozygoter Träger der Mutation finden. Auch Multiplikationen vom Wildtyp des SNCA-Gens wurden bei MP-Patienten gehäuft beobachtet (Singleton et al. 2003), auch bei jenen ohne auffällige Familienanamnese (Ahn et al. 2008).

Viele Aspekte der physiologischen und pathologischen Rolle des $\alpha$ SYN sind nach wie vor unbekannt und Gegenstand der Forschung. Der folgende Abschnitt beschränkt sich in erster Linie auf für die Dissertation relevante Aspekte.

$\alpha$ SYN besteht aus 140 Aminosäure(AS)-resten. Die ersten N-terminalen AS 1-95 bilden zwei amphipathische $\alpha$-Helices aus und vermitteln die Interaktion des Proteins mit Lipidmembranen (Davidson et al. 1998; Bussell und Eliezer 2003; Bussell et al. 2005). Interessanterweise liegen alle nachgewiesenen Punktmutationen, die mit Synucleinopathien assoziiert sind (A53T, A30P, E46K u. a.) im Bereich der Lipidbindenden Domäne (AS 1-95) (Polymeropoulos et al. 1997; Krüger et al. 1998; Zarranz et al. 2004; Proukakis et al. 2013; Pasanen et al. 2014). Für die A53TMutation konnte gezeigt werden, dass der Austausch einer AS zur Unterbrechung der zuvor beschriebenen $\alpha$-helikalen Struktur und zur vermehrten Ausbildung von $\beta$ Faltblattstrukturen im $\alpha$ SYN-Molekül führt. Diese strukturelle Veränderung unterstützt die Aggregration des Proteins mit anderen $\alpha$ SYN-Molekülen (Coskuner und Wise-Scira 2013). Vergleichbare strukturelle Veränderungen treten auch bei anderen Punktmutationen im SNCA-Gen auf, wie der A30P- und E46K-Mutation (Wise-Scira et al. 2013a; Wise-Scira et al. 2013b). Die C-terminale Domäne (AS 96-140) enthält viele organische Säuregruppen und liegt unstrukturiert vor (Davidson et al. 1998; Bussell und Eliezer 2003; Ulmer et al. 2005). Vermutlich vermittelt sie die Interaktion mit anderen Proteinen. Darüber hinaus scheint sie anti-aggregative Eigenschaften zu besitzen (Park et al. 2002; Hoyer et al. 2004).

$\alpha$ SYN wird im gesamten zentralen Nervensystem exprimiert und liegt besonders konzentriert an Präsynapsen vor (Jakes et al. 1994). Dies und seine Vergesellschaftung 
mit dem Reserve-Pool synaptischer Vesikel (Lee S-J et al. 2008; Zhang et al. 2008) verweisen auf eine funktionelle Verknüpfung mit dem Vesikel-Kreislauf in neuronalen Endknöpfchen. Ebenso lassen Einschränkungen der synaptischen Funktion bei fehlender Expression (Abeliovich et al. 2000), aber auch bei Überexpression von aSYN (Decressac et al. 2012) die Notwendigkeit eines strengen Gleichgewichts der $\alpha S Y N-E x p r e s s i o n$ für die synaptische Funktion vermuten.

$\alpha$ SYN-Monomere können sich verbinden und dabei Oligomere, Protofibrillen und Fibrillen bilden. Am Ende dieses Aggregationsprozesses steht der LB (Ishizawa et al. 2003), ein Korrelat charakteristischer histopathologischer Ablagerungen und Namensgeber einer Gruppe von neurologischen Erkrankungen. Zu dieser Gruppe der lewy body diseases gehört auch der MP. Dabei scheinen besonders präfibrilläre Oligomere eine toxische Wirkung zu entfalten (Conway et al. 2000). Unter anderem beeinflussen Poren-artige Oligomere die neuronale Membranpermeabilität und setzen so über einen Kalziumeinstrom einen proapoptotischen Stimulus (Danzer et al. 2007).

\subsection{Die Erforschung des Morbus Parkinson im Tiermodell}

\subsubsection{Transgene Tiermodelle}

Basierend auf den oben beschriebenen hereditären MP-Fällen sind transgene Tiermodelle etabliert worden. Zwei Modelle mit Fokussierung auf die Mutationen des aSYN (A53T und A30P) sind Gegenstand der hier vorliegenden Arbeit und werden an dieser Stelle näher vorgestellt.

Transgene Tiere der Studie von Giasson et al. 2002 mit der A53T-Mutation ((MoPrP)$\mathrm{h}[\mathrm{A} 53 \mathrm{~T}] \alpha \mathrm{SYN}$ ) entwickelten eine schwere Synucleinopathie mit Neurodegeneration und LB-Pathologie. Ab dem Alter von 8 Monaten traten erste Anzeichen einer motorischen Beeinträchtigung auf: initial das Vernachlässigen der Fellpflege, Gewichtsverlust und allgemeine Bewegungsarmut, gefolgt von schweren motorischen Defiziten (Rigor-artige Versteifung der Muskulatur bei passiver Bewegung, Teilparesen der Extremitäten, kurzzeitiges „Einfrieren“ des Hinterlaufs). Die Paresen begannen meist an den hinteren Extremitäten, nach 4 Tagen lag eine Tetraplegie vor. Die Tiere konnten sich nicht mehr selbstständig aufrichten und wiesen einen charakteristisch gekrümmten Rücken auf. 10-21 Tage nach Symptombeginn mussten die betroffenen Tiere euthanasiert werden, um weiteres Leiden zu verhindern (Giasson et al. 2002). 
Die behavioralen Veränderungen korrelierten mit dem Auftreten von $\alpha$ SYNAggregaten und LBs (Giasson et al. 2002). In der Lokalisation der Hirn-Läsionen ähneln sich A53T-Tiere und Patienten mit LB-Erkrankungen. So weisen beide Veränderungen in einigen Kerngebieten auf, wie dem Locus coeruleus und dem Raphe-Kern. Auch Hirnstamm, Rückenmark und der Neocortex sind bei beiden betroffen (Shoji 2000; Duda et al. 2002; Giasson et al. 2002; Lee et al. 2002).

Für die A30P-Mutation des $\alpha$ SYN existieren mehrere transgene Tiermodelle. Das hier verwendete Tiermodell wurde von Kahle et al. 2000 etabliert. Die Expression von humanem $\alpha$ SYN wird in diesem Modell reguliert durch den Promotor Thy-1. Er gilt als besonders spezifisch für neuronale, aber auch gliale Zellpopulationen (Kemshead et al. 1982) und wird daher in Tiermodellen neurodegenerativer Erkrankungen wie dem Morbus Alzheimer (Moechars et al. 1999) und dem MP (Kahle et al. 2000; Gerstenberger et al. 2016) verwendet. Individuen dieses Tiermodells ((Thy-1)$\mathrm{h}[\mathrm{A} 30 \mathrm{P}] \alpha \mathrm{SYN}$ ) weisen LB-artige pathohistologische Veränderungen auf und zeigen sowohl Verhaltensänderungen als auch motorische Dysfunktionen (Kahle et al. 2000; Masliah et al. 2000; van der Putten et al. 2000). In diesem [A30P] $\alpha$ SYN-Modell konnten $\alpha \mathrm{SYN}$-Aggregate in zahlreichen neuronalen Strukturen nachgewiesen werden, darunter auch in der Retina (Kahle et al. 2000). Es war intrazellulär präsynaptisch, innerhalb von Neuriten und dem neuronalen Soma lokalisiert. Zudem wurden intrazelluläre Aggregate aus mutiertem $\alpha$ SYN nachgewiesen (Kahle et al. 2000). Dabei konnte gezeigt werden, dass sowohl die histopathologischen Veränderungen als auch die Auffälligkeiten in Verhalten und motorischer Beeinträchtigung altersabhängig zunehmen (Neumann et al. 2002; Freichel et al. 2007; Fagerqvist et al. 2013).

\subsubsection{Der optische Nerv als Modell zur Erforschung des Morbus Parkinson}

\subsubsection{Die Bedeutung des optischen Systems beim Morbus Parkinson}

Bei MP-Patienten konnten funktionelle Beeinträchtigungen des visuellen Systems objektiviert werden. Mit der Ableitung sogenannter visuell evozierter Potentiale (VEP) können Funktionsstörungen der retinalen Erregungsentstehung oder Erregungsleitungsstörungen des visuellen Systems detektiert werden. Dabei kann eine Störung jede Struktur zwischen Retina und Cortex betreffen. Bei MP-Patienten zeigte sich eine Abschwächung der VEPs und eine interokuläre Asymmetrie der PotentialAmplitude (Bodis-Wollner, I. et al. 1981). Das Elektroretinogramm (ERG) und multi- 
fokale Elektroretinogramm (mfERG) leiten die elektrischen Potentiale der RGZ direkt am Augapfel ab. Mit diesen Untersuchungsmethoden lässt sich also spezifisch die Funktion der RGZ beurteilen. Während das klassische ERG ein panretinales Potential ableitet, löst das mfERG das Potential nach Netzhautregionen auf. Beeinträchtigungen, die auf die Fovea beschränkt sind, werden so sensitiver erfasst. In beiden Untersuchungsmethoden zeigten sich Abschwächungen der Potentialstärke bei MPPatienten, sogar bei Patienten in frühen Krankheitsstadien ohne subjektive visuelle Beeinträchtigung (Peppe et al. 1992; Ikeda et al. 1994; Tagliati et al. 1996; Palmowski-Wolfe et al. 2006; Sartucci et al. 2006; Moschos et al. 2011). In diesen Studien offenbarten sich auch Störungen des Farb- und Kontrastsehens.

Neben einer Beeinträchtigung der Funktion konnten mittels der optischen KohärenzTomografie (OCT) strukturelle Veränderungen an der Retina von MP-Patienten nachgewiesen werden. Eine Verschmälerung der Nervenfaserschicht, wie in älteren Studien gezeigt (Inzelberg et al. 2004; Altintaş et al. 2008), konnte in neueren Studien nicht bestätigt werden (Roth et al. 2014). Stattdessen zeigte sich eine Verschmälerung der retinalen Photorezeptorschicht und inneren Körnerschicht (Roth et al. 2014).

Histologische Studien an Augen von älteren Patienten zeigten intrazelluläre Ablagerungen von $\alpha$ SYN und Ubiquitin in der inneren Körnerschicht und Ablagerungen des tau-Proteins in der Photorezeptorschicht und im Soma der RGZ als Teil des physiologischen Alterungsprozesses (Leger et al. 2011). Fibrillen aus Serin-129phosphoryliertem $\alpha \mathrm{SYN}$, dass bisher nur bei Patienten mit Synucleinopathien nachgewiesen wurde, konnte in den inneren Retinaschichten (Nervenfaserschicht, Ganglienzellschicht, innere Plexiforme Schicht) von MP-Patienten und Patienten mit LBDemenz nachgewiesen werden und deuten auf eine retinale Synucleinopathie bei diesen Patienten hin (Beach et al. 2014). Speziell für die Ganglienzellschicht wurde eine sowohl intra- als auch extrazelluläre Akkumulation von $\alpha \mathrm{SYN}$ nachgewiesen (BodisWollner et al. 2014).

In der Zusammenschau der oben dargestellten Studien wird die Beteiligung retinaler Strukturen an Synucleinopathien wie dem MP deutlich. Auch die RGZ, deren Axone sich im ON fortsetzen, scheinen an der Pathologie beteiligt. Der ON ist daher als Modell zur Erforschung des MP interessant. 


\subsubsection{Modellierung axonaler Degeneration im optischen Nerv}

Per intravitrealer Injektion konnte die Transduktion von RGZ mittels viraler Vektoren etabliert werden (Martin et al. 2002). Dabei findet die Integration beliebiger Gene in das Genom der RGZ statt. Durch die Integration des Gens für das Enhanced-greenfluorescent-protein (EGFP) können die Axone der RGZ im ON mittels eines Fluoreszenzmikroskops im lebenden Tier dargestellt werden, wenn der ON zuvor operativ freigelegt wurde. Mittels dieser Methode des so genannten Live-Imagings konnte erstmals am lebenden Tier nachvollzogen werden, dass eine traumatische Schädigung des $\mathrm{ON} \mathrm{zu}$ axonaler Degeneration führt, ausgelöst durch einen massiven KalziumEinstrom (Knöferle et al. 2010).

In der Pathogenese neurodegenerativer Erkrankungen ist jedoch ein kontinuierlicher und langsamer Kalzium-Einstrom wahrscheinlicher (Surmeier 2007). Deshalb eignet sich das mechanische Läsions-Modell eher zur Darstellung der akut-traumatischen Nervenschädigung. Um diesen Gegebenheiten Rechnung zu tragen, etablierten wir ein chemisches Läsions-Modell, in dem eine topische Applikation des Kalzium-Ionophors A23187 auf den ON erfolgte. Diese Substanz maskiert die Ladung von Kalzium-Ionen und ermöglicht die Passage durch die axonale Zellmembran. Dieser KalziumEinstrom führte im Vergleich zur mechanischen Läsion zu schwächer ausgeprägten morphologischen Veränderungen.

Das Kalzium-Ionophor A23187 ist ein bakterielles Molekül, das divalente Kationen durch biologische Membranen schleusen kann (Pressman 1976). Dazu bilden je zwei Moleküle ein Dimer, das einen Komplex mit dem divalenten Kation bildet. Dadurch wird die Ladung des Kations verborgen und es ist ihm möglich, lipophile Membranen wie die Zellmembran zu durchqueren. Die Stabilität dieser Komplexe hängt vom jeweiligen Kation ab und verhält sich wie folgt: $\mathrm{Mn}^{2+}>>\mathrm{Ca}^{2+} \approx \mathrm{Mg}^{2+}>>\mathrm{Sr}^{2+}>\mathrm{Ba}^{2+}$ (Chaney et al. 1976).

\subsection{Fragestellung und Zielsetzung der Arbeit}

In der Pathogenese des MP spielt die Degeneration von Axonen eine Schlüsselrolle. $\alpha$ SYN und seine mutierten Formen [A53T]- und [A30P] $\alpha$ SYN sind bekanntermaßen an diesem degenerativen Prozess beteiligt. Das bessere Verständnis der mechanistischen Zusammenhänge dieser axonalen Degenerationsprozesse ermöglicht innovative Strategien in der Therapie des MP. 
Basierend auf der Arbeit von Knöferle et al. 2010 in Ratten wurde hier eine Mausadaptierte Live-Imaging-Technik und neue Läsionstechnik etabliert, um den Prozess der Kalzium-induzierten akuten axonalen Degeneration im ON am lebenden Tier zu visualisieren. Mittels transgener MP-Mausmodelle untersuchten wir, ob [A53T]- und [A30P] $\alpha$ SYN in vivo Einfluss auf den Ablauf und das Ausmaß der axonalen Degeneration haben. Im Einzelnen wurden folgende Fragestellungen untersucht:

- Kommt es im ON der untersuchten transgenen Tiere zu einer Überexpression von $\alpha \mathrm{SYN}$ ?

- Bestehen hinsichtlich der morphologischen Charakteristika und des zeitlichen Verlaufs der axonalen Degeneration nach Applikation des KalziumIonophors Unterschiede zwischen Wildtyp-Mäusen und den transgenen (MoPrP)-h[A53T] $\alpha$ SYN- und (Thy-1)-h[A30P] $\alpha$ SYN-Tiermodellen?

- Werden zeitlicher Verlauf und/oder Morphologie der axonalen Degeneration durch das Alter der Versuchstiere beeinflusst?

Es konnte in der vorliegenden Arbeit gezeigt werden, dass die $\alpha \mathrm{SYN}$-Mutationen den Ablauf der axonalen Degeneration nach Kalzium-Einstrom signifikant und spezifisch beeinflussen. Die Ergebnisse zeigen damit spezifische Pathomechanismen von einzelnen $\alpha \mathrm{SYN}$-Mutanten auf, die bei der Pathogenese des MP eine entscheidende Rolle spielen könnten. 


\section{$2 \quad$ Material und Methoden}

\subsection{Material}

\subsubsection{Firmen}

Abcam (Cambridge, Großbritannien); Abbott (Chicago, Illinois, USA) Agfa (Köln, Deutschland); Applichem (Darmstadt, Deutschland); BANDELIN electronic GmbH \& Co. $\boldsymbol{K G}$ (Berlin, Deutschland); Becton Dickinson (Franklin Lakes, New Jersey, USA); BIO-RAD (München, Deutschland); Braun (Melsungen, Deutschland); Canon (Krefeld, Deutschland); Carl Zeiss Microimaging (Göttingen, Deutschland); Charles River (Sulzfeld, Deutschland); Covance (Princeton, New Jersey, USA); DAKO (Hamburg, Deutschland); David Kopf Instruments (Tujunga, USA); Dianova (Hamburg, Deutschland); Dremel (Leinfelden-Echterdingen, Deutschland); Eppendorf (Wesseling-Berzdorf, Deutschland); GE Healthcare (Chalfont St. Gilles, Großbritannien); GraphPad Software Inc. (La Jolla, USA); Hitachi GmbH (Düsseldorf, Deutschland); Hoffmann-La Roche (Basel, Schweiz); Invitrogen von ThermoFisher Scientific (Waltham, USA); IVC, Tecniplast (Hohenpeißenberg, Deutschland); Jackson ImmunoResearch Laboratory Inc. (Suffolk, Großbritannien); Kent Scientific (Torrington, Connecticut, USA); Leica Microsystems (Mannheim, Deutschland); Medistar (Ascheberg, Deutschland); Menzel (Braunschweig, Deutschland); Merck (Darmstadt, Deutschland); Millipore (Darmstadt, Deutschland); N.I.H. (Bethesda, USA); Nikon Instruments (Düsseldorf, Deutschland); Precellys by Peqlab (Erlangen, Deutschland); Proxxon (Föhren, Deutschland) Roth (Karlsruhe, Deutschland); Sarstedt (Nümbrecht, Deutschland); Sigma Aldrich (Taufkirchen, Deutschland); ThermoFisher Scientific (Waltham, USA); World Precision Intruments (Berlin, Deutschland)

\subsubsection{Chemikalien}

$30 \% \mathrm{H}_{2} \mathrm{O}_{2}$ (Applichem)

Bepanthen (Braun)

BSA (Applichem)

Buprenorphinhydrochlorid (Sigma)

$\mathrm{CaCl}_{2}($ Merck)

Kalzium-Ionophore A23187 (Sigma)

Citronensäuremonohydrat (Sigma)

CPI (Roche) 
DAPI (Sigma)

Dual Proteine Standard (BIO-RAD)

DTT (Sigma)

Glucose (Merck)

Glycin (Applichem)

$\mathrm{HCl}$ (Roth)

Isofluran (Abbott)

Ketamin (Medistar)

Luminol (Calbiochem)

Methanol (Applichem, Roth)

Milchpulver: non-fat dried milk (Applichem)

Mineralöl (Sigma)

Mowiol-488 (Merck, Sigma)

$\mathrm{NaCl}$ (Merck)

$\mathrm{NaOH}$ (Applichem)

p-Cumarsäure (Applichem)

PFA (Applichem, Roth)

PBS (Applichem, Roth)

Pierce $^{\mathrm{TM}}$ BCA Protein Assay Kit (ThermoFisher scientific), Katalognummer: 23227

PhosStop (Roche)

PVDF-Membran (ThermoFisher Scientific)

RIPA-Puffer (ThermoFisher Scientific)

SDS (Applichem)

Sterofundin (Braun)

Sucrose (Applichem)

Tris (Applichem)

TritonX 100 (Applichem)

Tween20 (Applichem)

\subsubsection{Antikörper und Viren}

\subsubsection{Primärantikörper}

Mouse anti $\alpha$ SYN (human) (Covance), Katalognummer: Sig-39726

Mouse anti $\alpha$ SYN (rat \& mouse \& human) (BD), Katalognummer: 610786 
Mouse anti ß-Tubulin (Sigma), Katalognummer: T4026

\subsubsection{Sekundärantikörper}

Goat anti mouse IgG F(ab)2 Cy3 (Dianova), Katalognummer: 115165006

\subsubsection{Viren}

AAV 1/2 9(5)-hSyn-EGFP-CytBAS, Konz.: 5,6 x 107 transforming unit/ $\mu$ l (produziert und freundlicherweise zur Verfügung gestellt von Herrn Professor Uwe Michel, Klinik für Neurologie, Universitätsmedizin Göttingen). Gen-Bank ID: HQ416702.

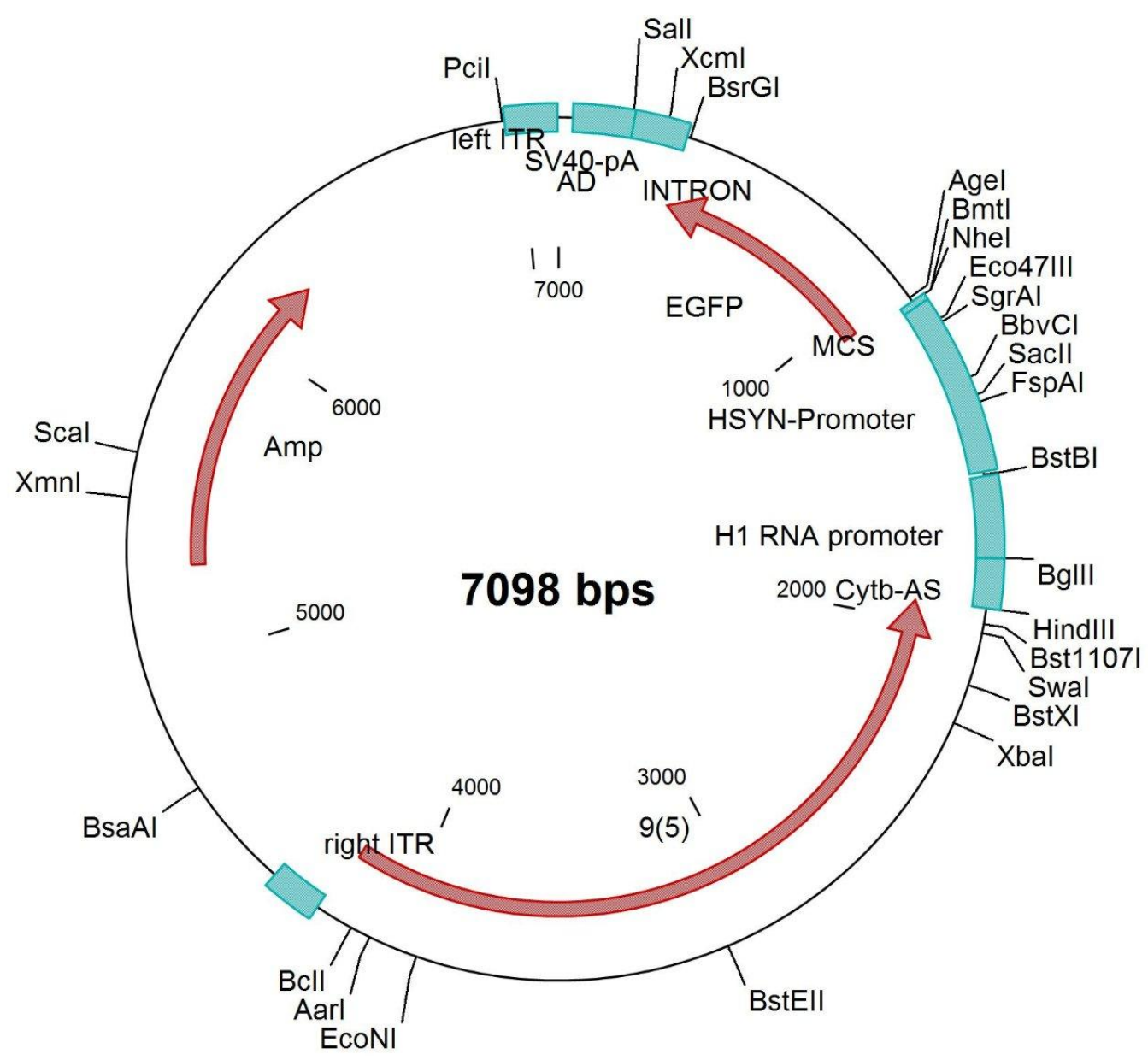

Abbildung 1: Plasmidkarte des Virus AAV 1/2 9(5)-hSyn-EGFP-CytBAS. 


\subsubsection{Materialien und Instrumente}

96 well micro test plate (Sarstedt)

Tierkäfige (IVC, Tecniplast)

Mikroskop (IHC): Zeiss Axioplan, ausgerüstet mit einer 16-bit grayscale CCD Kamera

(Carl Zeiss Microimaging)

Mikroskop (Live-Imaging): Zeiss Axio Examiner (Carl Zeiss Microimaging)

Bead mill homogenizer, Precellys 24® (Precellys by Peqlab)

Bohrer: MICROMOT-Netzgerät NG 2/S, Aufsatz: 0,8 mm (Proxxon)

Camera Legria, HFM36 (Canon)

Cover slides 24x60mm (Menzel)

Cryostat, CM 3050S (Leica)

Cryomatrix (Thermo Scientific)

Curix 60 Developer (Agfa)

Deckgläser, Durchmesser 18 mm (Menzel)

Electrophoresekammer (Bio-RAD)

Electrophoresis power supply (GE Healthcare)

Glass plates/Short plates (Bio-RAD)

Glasskapillaren (World Precision Intruments)

Headholder für Mäuse (David Kopf Instruments)

Isofluran-Vernebler (Abbott)

Micro4-based controller (World Precision Intruments)

Mikrozentrifuge, 5415R (Eppendorf)

Micro injector, Nanoliter 2000 pump head (World Precision Intruments)

Sonifikator: Sonopuls HD2070.2 (BANDELIN)

Wärmematte: Right Temp Warming Pad (Kent Scientific)

Whatman Gel Blotting-Papier (GE Healthcare)

\subsubsection{Versuchstiere}

Die Mauslinie mit der Bezeichnung B6.Cg-Tg(THY1-SNCA*A30P)TS2Sud/J trägt eine mutierte Form des Gens für humanes $\alpha$ SYN namens A30P, bei der im Gen für $\alpha$ SYN die an der Position 30 befindliche AS Alanin durch die AS Prolin ausgetauscht ist (Kahle et al. 2000). Die Linie mit der Bezeichnung B6.C3-Tg(PrnpSNCA*A53T)83Vle/J trägt ebenfalls eine mutierte Form des Gens für humanes $\alpha$ SYN (Giasson et al. 2002), bei der im Gen für $\alpha$ SYN die an der Position 53 befindliche AS 
Alanin durch die AS Threonin ausgetauscht ist. Beide Mutationen, A30P und A53T, sind auch bei Menschen bekannte familiäre Mutationen, die zum MP führen. Die verwendeten Wildtyptiere stammen aus einer Linie namens C57Bl/6J. Alle Versuchstiere stammen aus eigener Zucht in der Zentralen Tierexperimentellen Einrichtung (ZTE) der Universitätsmedizin Göttingen. Die Ursprungstiere für die Zucht stammen von der Firma Jackson Laboratory Inc.

Für alle Experimente wurde von der zuständigen Behörde, dem Niedersächsischen Landesamt für Verbraucherschutz und Lebensmittelsicherheit (LAVES), nach ausführlicher Prüfung die Genehmigung erteilt (Tierversuchsantrag Nummer: 14/1551).

\subsubsection{Software}

AxioVision 4.6 (Carl Zeiss Microimaging)

GraphPad Prism Demo 7.0 (GraphPad Software Inc.)

Image $1.47 \mathrm{v}$ (N.I.H.)

(Fiji Is Just) ImageJ $1.47 \mathrm{v}$ (N.I.H.)

Zen (Carl Zeiss Microimaging)

\subsubsection{Puffer und Lösungen}

Blockier- und Antikörper-Lösung für IHC: 2,5 \% DS, 1 \% immunglobulinfreies BSA. Blockierlösung für IHC: 10 \% NHS, 5 \% BSA, 0,3 \% Triton, 25 mM Glycin in PBS.

Blockiermilch für Westernblot: 5 g Milchpulver in $100 \mathrm{ml}$ TBS-T, 0,1 \% TritonX, $100 \mathrm{ml}$ in PBS.

Citratpuffer: $100 \mathrm{ml}: 10 \mathrm{mM}$ Citronensäure (Monohydrat 0,21g) in $\mathrm{H}_{2} \mathrm{O}$ gelöst, pHWert mit NaOH auf 6,0 eingestellt, $50 \mu \mathrm{l}(0,05 \%)$ Tween 20.

DAPI Lösung: $1 \mu \mathrm{g} / \mathrm{ml}$ DAPI in PBS.

ECL-1: $10 \mu \mathrm{l} / \mathrm{ml} 250 \mathrm{mM}$ Luminol, 4,4 $\mu \mathrm{l} / \mathrm{ml} 90$ mM p-Cumarsäure, $100 \mu \mathrm{l} / \mathrm{ml} 1 \mathrm{M}$ Tris pH 8,5 in destilliertem $\mathrm{H}_{2} \mathrm{O}$.

ECL-2: $0,9 \mu \mathrm{l} / \mathrm{ml} 30 \% \mathrm{H}_{2} \mathrm{O}_{2}, 100 \mu \mathrm{l} 1 \mathrm{M}$ Tris pH 8,5 in destilliertem $\mathrm{H}_{2} \mathrm{O}$.

Elektrophorese-Puffer: 250 mM Tris, 1,0 M Glycin, 1,0 \% SDS.

Lysepuffer für Western Blots (500 $\mu \mathrm{l}$ ): $455 \mu \mathrm{l}$ Ripa, $25 \mu \mathrm{l}$ Phospho-Stopp, $20 \mu \mathrm{l}$ CPI. Laemmli-Puffer ( $p H$ 8,3): TRIS (25 mM), Glycin (192 mM) und SDS (0,1\% m/V) Laemmli-DTT-Puffer für Western Blot $(200 \mu l): 180 \mu \mathrm{l}$ 5-fach Laemmli-Puffer $+20 \mu \mathrm{l}$ DTT.

Mowiol: 6 g Glycerin, 2,4 g Mowiol, $6 \mathrm{ml} \mathrm{H} 2 \mathrm{O}, 12 \mathrm{ml} \mathrm{0,2} \mathrm{M} \mathrm{Tris} \mathrm{pH} \mathrm{7.2.}$ 
PBS: $9,5 \mathrm{mg} / \mathrm{ml}$ PBS in destilliertem $\mathrm{H}_{2} \mathrm{O}$.

PFA-Lösung (4\%): $40 \mathrm{mg} / \mathrm{ml} \mathrm{PFA,} \mathrm{9,55} \mathrm{mg/ml} \mathrm{PBS} \mathrm{in} \mathrm{destilliertem} \mathrm{H}_{2} \mathrm{O}, \mathrm{pH}$ 7,4 mit $\mathrm{NaOH}$ eingestellt.

TBS: $10 \mathrm{mM}$ Tris HCL, $150 \mathrm{mM} \mathrm{NaCl}$ in destilliertem $\mathrm{H}_{2} \mathrm{O}$.

TBS-T: 0,1 \% Tween20 in TBS, pH 7,6.

Transfer-Puffer: 25 mM Tris-Base, 192 mM Glycin, 20 \% Methanol).

Tris-HCl: 10 mM TBS, pH 8,3.

\section{$2.2 \quad$ Methoden}

Im Folgenden werden die der vorliegende Arbeit zugrunde liegenden Methoden beschrieben.

Sämtliche Tierversuche inklusive Virusinjektion, Präparation des optischen Nervs und Live Imaging wurden von Herrn Steenken immer nur in Assistenz und unter der persönlichen Supervision von Dr. Böcker, Prof. Dr. Lingor oder PD Dr. Koch durchgeführt. Die Narkose wurde von Dr. Böcker, Prof. Dr. Lingor oder PD Dr. Koch durchgeführt und überwacht.

\subsubsection{Versuchstiernarkose}

Für die Operation und den postoperativen Zeitraum von insgesamt ca. $6 \mathrm{~h}$ wurde das Versuchstier mittels einer intraperitonealen Injektionsnarkose betäubt, für die intravitreale Injektion von AAV-EGFP dagegen mittels Inhalation von Isofluran.

\subsubsection{Supportive Maßnahmen}

Während der Live-Imaging-Experimente erfolgten als supportive Maßnahmen während der Narkose zum einen die Platzierung des Versuchstiers auf einer Wärmematte mit rektalem Körpertemperatursensor. Damit lag die Körpertemperatur des Versuchstiers konstant bei $36,5^{\circ} \mathrm{C}$. Zum anderen erfolgte eine subkutane (s.c.) Flüssigkeitsgabe in die Nackenfalte (Sterofundin, $250 \mu$ s.c.) alle 2 h.

\subsubsection{Intraperitoneale Injektionsnarkose}

Die Narkoseeinleitung erfolgte per i. p. Injektion von $100 \mu$ l einer Mischung aus Medetomidin und Ketamin (1 ml Injektionslösung enthielten $60 \mu \mathrm{g}$ Medetomidin und 12 mg Ketamin in 0,9 \% NaCl). Zuvor wurden die Tiere durch die Inhalation mit Isofluran in einer Inhalationsbox betäubt (Dosis: $5 \%$ Isoflurangas in reinem $\mathrm{O}_{2}$, Flow: 2L/min). Die Steuerung der Narkosetiefe und die Erhaltung der Narkose über den 
gesamten Operations- und Imagingzeitraum (0,5-1 h Operation + 5 h Imaging) erfolgte ebenfalls mittels i. p. Injektion derselben Narkotika, wobei sich die Injektionsdosis am klinischen Eindruck der Narkosetiefe orientierte. Dazu wurde eine Schmerzreaktionstestung mittels Kneifen in den Hinterlauf durchgeführt. Trat eine sichtbare Schmerzreaktion auf (Bewegung des Hinterlaufs), wurde körpergewichtsunabhängig $30 \mu \mathrm{l}$ der Narkoselösung i. p. nachinjiziert. Dieser Vorgang aus Schmerzreaktionstestung (Testung 10-15 Minuten nach letzter Injektion) und Nachinjektion wurde bis zum Ausbleiben der Schmerzreaktion wiederholt. Typischerweise benötigte das Versuchstier etwa 2 h nach der initialen Narkotikagabe die erste Erhaltungsdosis von 30 $\mu \mathrm{l}$, danach stündlich eine weitere Dosis von $30 \mu \mathrm{l}$ bis zum Versuchsende. Zur Analgesie erhielt das Versuchstier initial und nach 3 h je $100 \mu$ l Buprenorphin (Verdünnung 1:10) subkutan.

\subsubsection{Inhalative Narkose}

Die inhalative Narkose erfolgte bei der Durchführung der intravitrealen Injektion von AAV-EGFP. Nach der Betäubung mit Isofluran in einer Isofluran-Box erfolgte die Platzierung eines Gummischlauchs an der Schnauze des Tiers über das Isofluran 2-5 \% bei $2 \mathrm{~L} /$ min Flow inhaliert wurde. Der Gummischlauch wurde vor der Schnauze des Tiers platziert und mit Klebeband abgedichtet. Zur Analgesie wurde den Versuchstieren bei Narkoseeinleitung $100 \mu$ l Buprenorphin-Lösung (Konzentration: $30 \mu \mathrm{g} / \mathrm{ml}$ ) subkutan injiziert.

\subsubsection{In-vivo-Live-Imaging axonaler Degeneration des optischen Nervs}

Die Methode des Live-Imagings dient der Untersuchung axonaler Degenerationsprozesse in vivo. Hierbei wurde die axonale Degeneration am ON - als Teil des zentralen Nervensystems - induziert. Der zeitliche Verlauf der resultierenden morphologischen Veränderungen von Fluoreszenz-markierten Axonen wurde anschließend am lebenden Tier unter einem Fluoreszenz-Mikroskop beobachtet.

Das Experiment hatte den folgenden Ablauf: Zwei Wochen vor dem eigentlichen Imaging wurde den Tieren der Virus AAV-EGFP zur Transduktion der RGZ in den linken Augapfel injiziert. Zwei Wochen später erfolgte unter adäquater Narkose die operative Freilegung des ON. Mit der Applikation von Kalzium Ionophor A23187 begann das fünf-stündige live-Imaging. Am Ende wurde die Maus Mittels $\mathrm{CO}_{2}$-Intoxikation und Genickbruch euthanasiert. 
Injektion von

AAV.EGFP

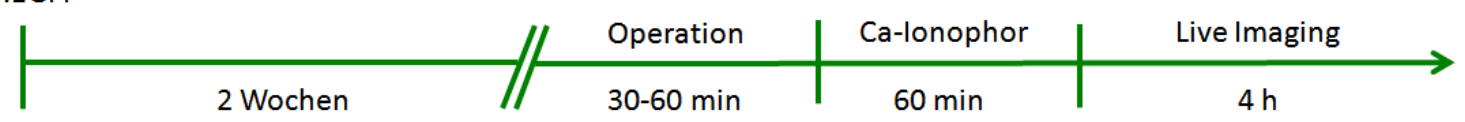

\section{Abbildung 2: Zeitlicher Ablauf der experimentellen Schritte des Live-Imagings.}

\subsubsection{Tierhaltung}

Die Versuchstiere wurden in Gruppen von maximal fünf Tieren in individuell belüfteten Käfigen in einem 12 h-Tag-12 h-Nacht-Rhythmus mit freiem Zugang zu Futter und Wasser gehalten und wogen bei Experimentbeginn je nach Alter zwischen 20 und $30 \mathrm{~g}$.

Für die Versuche wurden ausschließlich homozygote Tiere im Alter von 3-5 und 7-9 Monaten verwendet. Die Genotypisierung anhand qPCR wurde nach dem Protokoll der Jackson Laboratory Inc. von Frau Dr. rer. nat. Eleonora Carboni durchgeführt.

\subsubsection{Intravitreale Injektion von AAV-EGFP zur Fluoreszenzmarkierung der Axone des optischen Nervs}

Zwei Wochen vor dem geplanten Imaging wurde den Versuchstieren jeweils $2 \mu \mathrm{l}$ eines Virus (AAV1/2 9(5)-hSyn-EGFP-CytBAS, Konz.: 5,6 x $10^{7}$ transforming units/ $\mu$ l) mittels eines Mikroinjektors in den Glaskörper des linken Auges injiziert. Das Virus transduziert RGZ vermittelt die Expression des Fluoreszenz-Proteins EGFP im Zytosol der Axone des ON.

Der Mikroinjektor wurde mit einer selbstgezogenen und an der Spitze zu einem Schliff gebrochenen Glaskapillare versehen, welche mit Mineralöl gefüllt war. Im Anschluss wurden etwa $1 \mu \mathrm{l}$ Luft und anschließend $2 \mu$ l Virus aufgezogen. Die Luft diente zur Trennung von Virus und Mineralöl. Letzteres induziert beim Versuchstier eine Entzündungsreaktion und darf nicht mit injiziert werden.

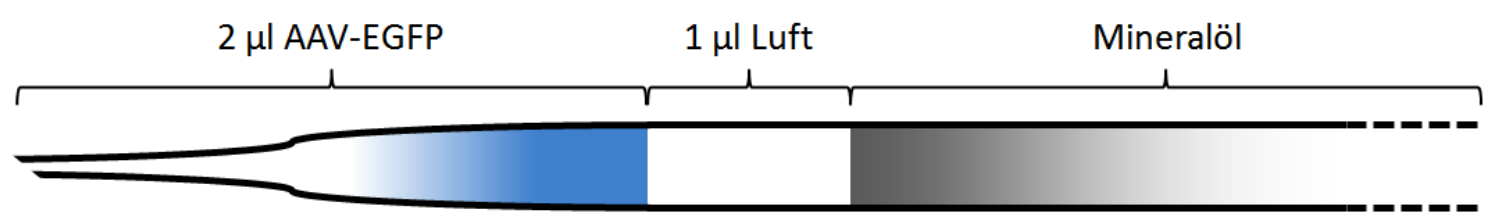

Abbildung 3: Schemazeichnung einer Glaskapillare zur intravitrealen Injektion. In die mit Mineralöl ausgefüllte Kapillare wurden nacheinander $1 \mu \mathrm{l}$ Luft und $2 \mu \mathrm{l}$ des Virus' AAV-EGFP aufgezogen. 
Ziel war in erster Linie eine Transduktion der Ganglienzellen des kranialen RetinaAbschnitts, da deren Axone unter dem Fluoreszenzmikroskop am besten zu beurteilen sind. Nachdem die Maus durch Isofluran-Inhalation (4-5 \%, $1 \mathrm{~L} / \mathrm{min}_{2}$ ) ausreichend narkotisiert war (ausbleibende Schmerzreaktion bei Kneifen in die Hinterpfote), wurde im Bereich des kranialen Augenabschnitts an der Ora serrata senkrecht mit der Glaskapillare eingestochen. Dabei zeigte der Schliff in Richtung des Sehnervenaustritts. Dann erfolgte die Injektion von $2 \mu \mathrm{l}$ Virus innerhalb von 1 Minute. Nach erfolgter Injektion wurde für mindestens 30 Sekunden verharrt, bevor die Kapillare zurück gezogen wurde, um ein Auslaufen des Virus zu minimieren.

Zum Abschluss erhielt die Maus $100 \mu$ l Buprenorphin (Verdünnung 1:10) s.c. als postoperative Schmerztherapie und Bepanthen-Augensalbe auf beide Augen zur Unterstützung der Wundheilung und Pflege.

\subsubsection{Operative Freilegung des optischen Nervs}

Es erfolgte die Einleitung der intraperitonealen Narkose wie vorherig beschrieben. Die Fixierung des Kopfes erfolgte mittels eines selbst hergestellten „Head-Holders“. Dazu wurde der Kopf nach gründlicher Rasur der Schädelpartie mittels zweier Ohrstecker im äußeren Gehörgang, sowie mit einem Stift zwischen Ober- und Unterkiefer eingespannt.
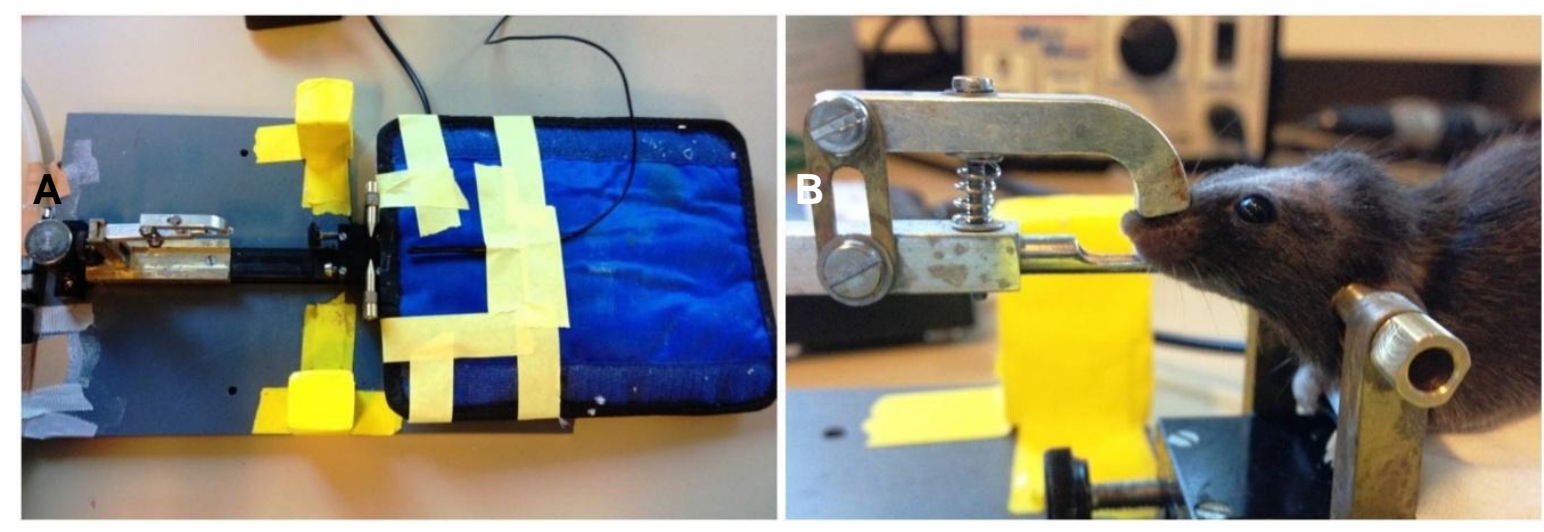

Abbildung 4: Präoperative Vorbereitung. A: Headholder mit Wärmematte rechts im Bild, B: Die Maus wird mit Schnauze und beiden Ohren fixiert (3-Punkt-Fixation).

Der Hautschnitt begann mittig zwischen den Augen und folgte etwa einen Zentimeter lang einer sagittalen Schnittführung median über der Schädelkalotte. Die Haut entlang des Schnitts wurde mit Haken auseinandergespreizt. Dabei lagen sich in der Schnittmitte zwei Haken gegenüber und zogen in $90^{\circ}$-Richtung zur Schnittführung. 
Zwei weitere Haken wurden an den Schnitträndern positioniert und zogen die Haut nach links/vorne bzw. links/hinten (aus der Perspektive des Versuchstiers) (siehe Abbildung 5A).

Nun bestand Aufsicht auf die linke Orbitakante, noch umgeben von Bindegewebe. Dieses wurde streng am knöchernen Rand der Orbita per Elektrokoagulation entfernt.

Der darunter gelegene Bindegewebssack enthält sowohl die Tränendrüse als auch einen meist gut durchbluteten Venenplexus. Bei der Eröffnung des Sacks kam es in der Folge nicht selten zu Blutungen, die entweder spontan sistierten oder durch Kompression mit Wattetupfern gestillt wurden.

Nach Eröffnung und eventueller Blutstillung wurde die Tränendrüse nach medial mobilisiert, ohne sie dabei aus der Orbita heraus zu ziehen. Der Nervus supraorbicularis wurde durchtrennt.

Der nun sichtbare M. rectus superior wurde mittels Pinzette am Ursprung durchtrennt, nach vorn geklappt und mit dem vorderen der vier Haken fixiert. Dieser Haken hielt nun den Muskelansatz zusammen mit der Haut. So wurde eine teilweise Luxation des Augapfels aus der Orbita erreicht. Der ON wurde anschließend vom perinervalen Fettgewebe stumpf freipräpariert. Um nun die den Nerv umgebende Durascheide zu eröffnen, wurde diese vorsichtig einen Millimeter vom distalen Ende des Nervs gepackt und in Richtung des Augapfels gezogen, um sie zu zerreißen und von der Nervenoberfläche zu entfernen. Der blanke Nerv präsentierte sich nach erfolgreicher Freilegung weiß und silbrig glänzend. 

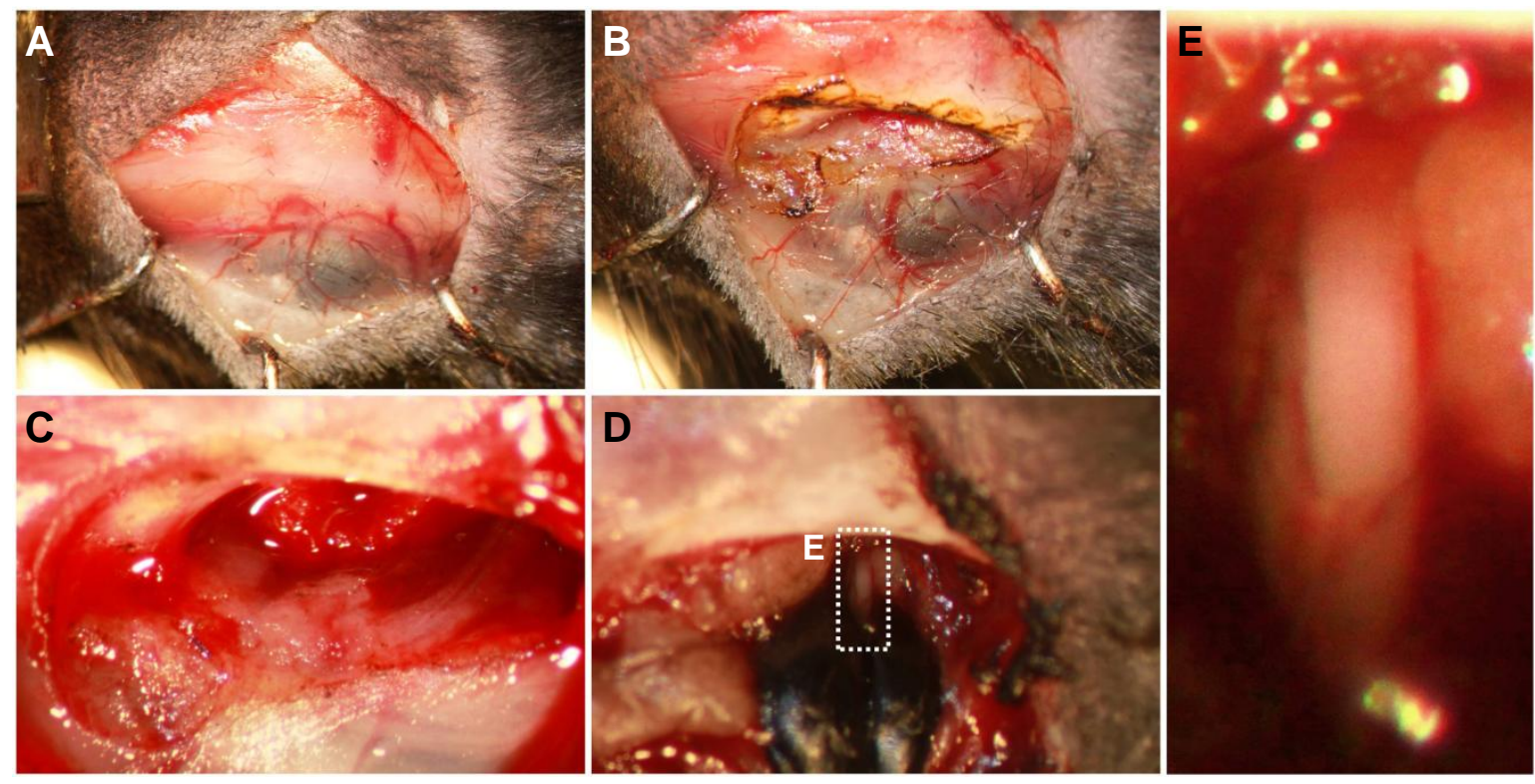

Abbildung 5: Operationssitus. A: Aufsicht auf die Orbitakante nach Hautschnitt und Hakenfixation von Cutis und Subcutis, B: Nach Koagulation des Bindegewebes stellt sich die knöcherne Orbitakante dar, C: Präparation des M. rectus superior. In der Tiefe ein Tupfer zur Blutstillung, D: Nach Anteroluxation des M. rectus superior und Entfernung von intraorbitalem Fettgewebe stellt sich der N. opticus dar. Weißes Rechteck zeigt die Ausschnittsvergrößerung in E, E: Nahansicht des N. opticus, Dura mater im hinteren Anteil bereits teilweise entfernt.

\subsubsection{Einstellung des optischen Nervs unter dem Fluoreszenz-Mikroskop}

Ziel der Einstellungsphase war die möglichst parallele Ausrichtung des ON, die somit möglichst longitudinale Darstellung der fluoreszenzmarkierten Axone. Als Bereich besonders geeignet schien dafür der Nervenaustrittspunkt aus dem Augapfel. Zur Adjustierung bestand die Möglichkeit, entweder die Stellung und den Zug der Haken zu variieren, oder an der Orbitakante Knochenmaterial zu entfernen. War der Nervenaustrittspunkt zufriedenstellend dargestellt, $d$. h. viele Axone ließen sich über eine längere Strecke nachverfolgen, wurde eine erste Aufnahme angefertigt. Die Aufnahmen wurden angefertigt unter Verwendung des Zeiss-Axio-Examiner-Mikroskops. Die Aufnahmen erfolgten bei 400-facher Vergrößerung (Objektiv: 40x, Fotookular: 10x). Die Aufnahmen wurden mit der Software „Zen“ erstellt und sowohl als cvi-Datei lokal als auch auf einer externen Festplatte gespeichert. Ein „Bild“ entsprach dabei einer Reihe von Aufnahmen („Z-Stacks“) in unterschiedlichen Tiefenebenen. So konnte der dreidimensionale Verlauf der Axone nachvollzogen werden. 


\subsubsection{Induktion axonaler Degeneration durch lokale Applikation des Kalzium-} Ionophors A23187

Zur Initiation axonaler Degeneration wurde nach Beendigung der Operation und nach Platzierung des Versuchstiers unter dem Fluoreszenz-Mikroskop das KalziumIonophor A23187 (Konzentration: $250 \mu \mathrm{M}$ ) auf den Nerv aufgebracht, sodass er komplett umspült war (aufgebrachtes Volumen ca. $1 \mathrm{ml}$ ) und eine Stunde dort belassen. Der Degenerationsprozess wurde fünf Stunden lang verfolgt, indem $\mathrm{zu}$ folgenden Zeitpunkten je ein Bild angefertigt wurde: Zum Zeitpunkt 0 Minuten vor Applikation des Kalzium-Ionophors und 30, 60, 90, 120, 180, 240 sowie 300 Minuten nach Applikation.

Während des Imagings musste die Narkosetiefe überwacht werden, indem regelmäßig die Reaktion auf einen Schmerzreiz (Kneifen in den Hinterlauf) überprüft wurde. Wenn eine Schmerzreaktion ausgelöst werden konnte, wurde die Isoflurankonzentration schrittweise erhöht, bis keine Schmerzreaktion mehr erfolgte.

\subsubsection{Euthanasieverfahren und Gewinnung von Gewebeproben}

Nach Abschluss des Imagings erfolgte die Tötung der Versuchstiere mittels $\mathrm{CO}_{2}$ Intoxikation bis zum Atemstillstand und anschließendem Genickbruch.

\subsubsection{Auswertung}

Die Auswertung erfolgte mit dem Bildbearbeitungsprogramm ImageJ. Zur Quantifizierung der axonalen Degeneration musste ein Verfahren zur Auswertung der Bilddaten gefunden werden. Der axonale Verfall äußerte sich in der Bildung axonaler Ausstülpungen, im Folgenden Bulbs genannt, die im Bild als helle Punkte sichtbar wurden (siehe Abbildung 6B). Je mehr Bulbs ein Axon ausbildete, desto größer der axonale Schaden. Allerdings konnten sichtbare Bulbs nicht sicher bestimmten Axonen zugeordnet werden, u. a. weil die Axone besonders zu späten Zeitpunkten aufgrund eines vermehrten Ausbleichens des EGFP durch die wiederholte Belichtung (Bleaching) nicht mehr abgrenzbar waren oder ihr Verlauf schwer nachzuvollziehen war. Einzelne Axone waren besonders im Initialbild vor Applikation des Kalzium-Ionophors voneinander und gegenüber dem Hintergrund unterscheidbar. Deshalb wurden Anzahl und Länge aller beobachteten Axone im Initialbild quantifiziert. Abbildung 6A zeigt ein solches Initialbild. Es ist noch keine Degeneration erkennbar, die einzelnen Axone können jedoch klar als helle Linien identifiziert werden. Das gelbe Rechteck 
definiert das Messareal. Es liegt in jedem Einzelbild des Z-Stacks und bei den Z-Stacks aller gemessener Zeitpunkte an derselben Stelle des ON. Es ist so platziert, dass eine Seite (in diesem Fall die kurze Seite) parallel zur Axonverlaufsrichtung liegt. Ihre Länge entspricht also näherungsweise der Länge aller Axonabschnitte innerhalb des Rechtecks. Dies beruht auf der vereinfachten Annahme, dass alle Axone parallel zu dieser Seite verlaufen. Tatsächlich werden die meisten Axone leicht schräg verlaufen. Den Weg, den sie durch den Messbereich nehmen, wird daher länger sein, eine Ungenauigkeit, die bei dieser Methode in Kauf genommen werden muss. Die andere Seite des Rechtecks (in diesem Fall die lange Seite) verläuft senkrecht zu den Axonen. Der Annahme folgend, dass die Axone im Messbereich parallel zur kurzen Seite velaufen, schneiden alle Axone im Messbereich die lange Seite und können so gezählt werden. Um Fehler bei der Zählung zu vermeiden, wurden die Axone im 0h-Bild und im 0,5 hBild gezählt und das arithmetische Mittel gebildet. Wird nun die Anzahl der Axone im Messbereich mit der Länge der kurzen Seite (die der Länge der Axonabschnitte im Messbereich entspricht) multipliziert, erhält man die Axongesamtlänge des Messbereichs (Einheit: $\mu \mathrm{m}$ ). So wird das Problem umgangen, dass einige Axone nicht sicher in ihrem Verlauf verfolgt werden können. Im Verlauf des Imagings wurden nun innerhalb des Rechtecks Bulbs sichtbar. Diese wurden gezählt und ihre Anzahl durch die Axongesamtlänge dividiert. Der so erzeugte Messwert gibt die BulbVerteilungsdichte an und dient als Maß für die axonale Schädigung. Zur besseren Anschaulichkeit geben wir die Bulb-Verteilungsdichte als Bulb-Anzahl pro $100 \mu \mathrm{m}$ Axonlänge an:

$$
\text { Dichte der Bulbs }=\frac{\text { Anzahl der Bulbs }}{100 \mu \mathrm{m} \text { Axonlänge }} \quad[/ 100 \mu \mathrm{m}]
$$



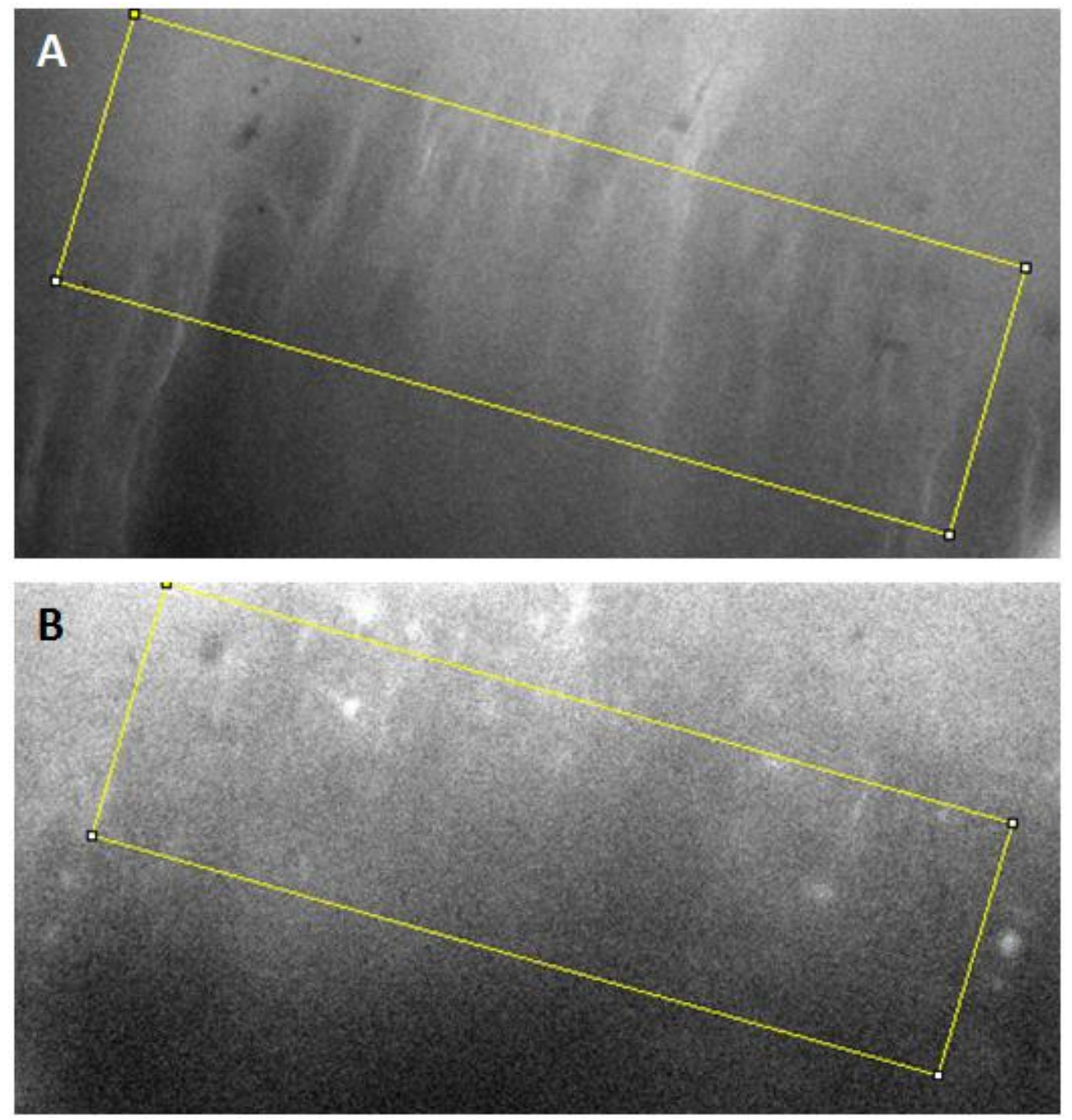

Abbildung 6: Auswertung der Live-Imaging-Daten. Der Bildausschnitt zeigt ein Areal des N. opticus vor (A) und einige Stunden nach Applikation von KalziumIonophor. $\mathrm{Zu}$ erkennen sind Bulbs als helle Flecken. Darüber hinaus sind einzelne Axone nicht mehr differenzierbar (B). Der Messbereich liegt innerhalb des gelb markierten Rechtecks.

\subsubsection{Erstellung von repräsentativen Abbildungen zum Degenerationsverlauf}

Da es sich bei den Z-Stacks um eine Reihe von Bildern mit unterschiedlichen Fokussierungsebenen handelte, in denen immer nur ein kleiner Teil des ausgewählten Areals scharf abgebildet wurde, mussten Additionsbilder aus dem Z-Stack-Bildmaterial erstellt werden. Denn, wie auch in Abbildung $6 \mathrm{zu}$ sehen, eignen sich die Z-Stacks zwar zur Auswertung, nicht aber zur repräsentativen Visualisierung der BulbFormierung in der vorliegenden Arbeit. Die einzelnen Schritte der Bildbearbeitung mit dem Programm „(Fiji Is Just) ImageJ“ werden im Folgenden dargelegt.

Zunächst wurde von den jeweiligen repräsentativen Z-Stacks Substacks erstellt, es wurden dabei alle Bilder verworfen, die den interessanten Bereich nicht scharf abbil- 
deten (Image $\rightarrow$ Stacks $\rightarrow$ Tools $\rightarrow$ Make Substack). Innerhalb dieses Substacks wurden alle Einzelbilder verworfen, die durch Atembewegungen des Versuchstiers o.ä. ebenfalls unscharf waren (Image $\rightarrow$ Stacks $\rightarrow$ Delete Slice). Mit den übrigen Stacks wurde nun ein Additionsbild erstellt, in dem über einen Filter vorrangig Areale mit maximaler Leuchtintensität berücksichtigt wurden, um eine möglichst gute Abgrenzung der hell leuchtenden Axone und Bulbs von der Umgebung zu erreichen (Image $\rightarrow$ Stacks $\rightarrow$ Z-Project, Filter: Maximum Intensity). Die übrigen Filter erwiesen sich als suboptimal, da sich entweder ein sehr kontrastarmes Additionsbild ergab, oder Bulbs und/oder Axone heraus gerechnet wurden. Für eine bessere Kontrastierung wurden die Additionsbilder entsprechend nachbearbeitet (Process $\rightarrow$ Sharpen/Substract Background/Enhance local contrast). Diese Bearbeitungsschritte wurden bei allen gezeigten Additionsbildern in dieser Arbeit gleich angewandt, um eine optimale Vergleichbarkeit zu gewährleisten.

\subsubsection{Western Blot}

Um $\alpha$ SYN in den Neuronen des ON nachzuweisen, wurden Western Blots angefertigt. Die verwendeten Primärantikörper waren dabei spezifisch für humanes und endogenes, murines $\alpha$ SYN: Mouse anti $\alpha$ SYN (BD) und für ß-Tubulin: Mouse anti ß-Tubulin (Sigma). Sekundärantikörper: Goat anti mouse IgG F(ab)2 Cy3 (Dianova).

Beim untersuchten Gewebe handelte es sich um die ON der Versuchstiere aus den Imaging-Experimenten, die nach Tötung der Tiere entnommen und mittels Flüssigstickstoff kryokonserviert wurden.

\subsubsection{Herstellung der Gewebelysate}

Die Gewebeproben wurden mit jeweils $40 \mu$ l Lyse-Puffer mittels Plastikpastille durch Dreh- und Stoßbewegungen mechanisch homogenisiert. Zum Ansetzen von $500 \mu \mathrm{l}$ Lyse-Puffer wurden verwendet: $455 \mu \mathrm{l}$ Ripa, $25 \mu$ l PhosStop, $20 \mu \mathrm{l}$ CPI. Anschließend wurde das Lysat zwei Mal für jeweils 20 Sekunden sonifiziert (40\% Intensität). Abschließend erfolgte eine Zentrifugation für 20 Minuten bei $4{ }^{\circ} \mathrm{C}$ mit 16000 Umdrehungen pro Minute. Der Überstand wurde in ein neues Eppendorf-Reaktionsgefäß überführt.

\subsubsection{SDS-Polyacrylamid-Gel-Elektrophorese (SDS-PAGE)}

Die SDS-PAGE dient der Auftrennnung von Proteinen aus Gewebe- oder Zell-Lysaten anhand der Molekülgröße mithilfe eines elektrischen Feldes in einer Gel-Matrix. Es 
wurde ein $15 \%$-iges Trenngel verwendet. Zusammensetzung des $15 \%$-igen Trenngels: 4,25 ml Acryamidbisacryl; 2,13 ml 4x Tris/SDS pH 8,8; 2,13 ml $\mathrm{H}_{2} \mathrm{O} ; 42,5 \mu \mathrm{l} 10 \%$ APS; 4,25 $\mu$ l TEMED.

Zunächst erfolgte eine Bestimmung der Proteinkonzentration der Lysate mittels des Pierce $^{\mathrm{TM}}$ BCA Protein Assay Kits (ThermoFisher Scientific) nach Herstellerprotokoll. Bovines Serumalbumin (BSA) wurde als Standartprobe für die Kalibierungskurve verwendet. Die Proben wurden bei einer Wellenlänge von $562 \mathrm{~nm}$ in einem 96-wellplate-reader ausgelesen.

Jede Probe wurde mit 11,5 $\mu$ l Puffer (200 $\mu$ Puffer enthielten $180 \mu$ l 5-fach LaemmliPuffer + $20 \mu \mathrm{l}$ DTT) für 5 Minuten bei $95{ }^{\circ} \mathrm{C}$ inkubiert. Anschließend wurde das Volumenäquivalent von $7 \mu \mathrm{g}$ Lysat-Protein in die jeweiligen Taschen des Sammelgels gefüllt. Zusammensetzung des Sammelgels: 0,325 ml $30 \%$ Acryamidbisacryl; 0,625 ml 4x Tris/SDS pH 6,8; 1,515 ml H${ }_{2} 0 ; 12,5 \mu \mathrm{l} 10 \%$ APS; 2,5 $\mu \mathrm{l}$ TEMED; $10 \mu \mathrm{l}$ 0,5 \% Bromphenolblau. Zwei Taschen enthielten einen Elektrophorese-Marker (Dual Proteine Standard, BioRad). Das Gel befand sich in einem Elektrophorese-Puffer (500 ml Puffer enthielten 15,12 g 250 mM Tris, 71,25 g 1,0 M Glycin, 5 g 1,0 \% SDS).

Es wurde eine Spannung von 50 Volt angesetzt, bis die Probe in das Trenngel vorgedrungen war. Danach wurde die Spannung auf 100 Volt erhöht.

\subsubsection{Immunoblotting und Banden-Visualisierung}

Um die Proteine vom Gel auf eine PVDF-Membran zu übertragen, wurde die Membran (zuvor für 30s in Methanol aktiviert) in einer Kassette platziert, umgeben von zwei Whatman Filterpapieren und zwei Kunstoff-Schaumpads. Whatman-Filterpapiere und Kunststoff-Schaumpads wurden zuvor in Transfer-Puffer (1000 ml TransferPuffer enthielten 3,025 g 25 mM Tris-base, 14,4 g 192 mM Glycin, 200 ml 20 \% Methanol) getränkt. Die Kassette wurde in eine Elektrophoresekammer eingespannt. Das Blotting erfolgte bei einer Spannung von 100 Volt für 1,25 h.

Nach erfolgreichem Blotting wurden die Membranen mit 5 \%-iger Blockier-Milch (100 ml TBS-T enthielten $5 \mathrm{~g}$ Milchpulver) für $1 \mathrm{~h}$ blockiert. Anschließend wurde die Membran mit dem Primärantikörper gegen $\alpha$ SYN (verdünnt 1:500 in Milch) und gegen Tubulin (verdünnt 1:8000 in Milch) über Nacht bei $4{ }^{\circ} \mathrm{C}$ inkubiert. Nach dreimaligem Waschen in TBS-T für jeweils 10 Minuten erfolgte das Auftragen des Sekundär- 
Antikörpers (verdünnt 1:1000 in Milch), ein Antikörper, an den eine Peroxidase gebunden war. Nach einstündiger Inkubation bei Raumtemperatur und nachfolgender Waschung (3 mal 10 Minuten in TBST) wurde die Membran mit einer Mischung der ECL-Lösungen 1 und 2 inkubiert. Die ECL-Lösungen enthielten: $100 \mu$ l Luminol 250 $\mathrm{mM}, 44 \mu \mathrm{l}$ p-Coumarsäure $90 \mathrm{mM}, 1 \mathrm{ml}$ Tris $1 \mathrm{M} \mathrm{pH} \mathrm{8,5,} \mathrm{8,85} \mathrm{ml} \mathrm{dest.} \mathrm{H}_{2} \mathrm{O}$ (Lösung 1) und $6 \mu \mathrm{H}_{2} \mathrm{O}_{2} 30 \%, 1 \mathrm{ml}$ Tris $1 \mathrm{M} \mathrm{pH} \mathrm{8,5,} 9 \mathrm{ml}$ dest. $\mathrm{H}_{2} \mathrm{O}$ (Lösung 2). Die Mischung der beiden Lösungen erfolgte im Verhältnis 1:1. Es kam zu einer ChemolumineszenzReaktion, die zur Belichtung von Filmen genutzt wurde. Zum Entwickeln der Filme wurde ein Curix 60 Developer verwendet.

\subsubsection{Immunohistochemische Färbung von Gewebeschnitten optischer Nerven auf humanes $\alpha$-Synuclein}

\subsubsection{Gewinnung der Gewebeproben und Anfertigung von Kryoschnitten}

Nach erfolgtem Imaging und nach Euthanasie des Versuchstiers wurde auf der nichtoperierten Seite der Augapfel samt Teilstück des ON entnommen, über Nacht in PFA fixiert und bei $-20{ }^{\circ} \mathrm{C}$ eingefroren.

Im Verlauf wurde dem Gewebestück mittels einer 30 \%-igen Sucrose-Lösung Flüssigkeit entzogen. Je nach Größe des Gewebestücks dauerte dies 1-2 Tage. Die ausreichende Dehydrierung wurde durch ein Absinken des Gewebestücks in der SucroseLösung angezeigt. Anschließend wurde das Gewebestück in Cryomatrix eingebettet und bei $-20^{\circ} \mathrm{C}$ zu einem Block eingefroren.

Mittels des Cryostats, CM 3050S wurden $16 \mu$ m-dicke Schnitte in Längsrichtung des ON angefertigt. Die Temperatur der Kühlkammer betrug dabei $-20{ }^{\circ} \mathrm{C}$. Die Schnitte wurden auf Objektträger aufgebracht und trockneten ohne Abdeckung bei $37{ }^{\circ} \mathrm{C}$ für $1 \mathrm{~h}$. Anschließend wurden sie bei $-20^{\circ} \mathrm{C}$ gelagert.

\subsubsection{Immunohistochemische Färbung der Gewebeschnitte}

Die Gewebeschnitte wurden zunächst für 30 Minuten bei $80{ }^{\circ} \mathrm{C}$ in Citratpuffer inkubiert und kühlten anschließend 30-60 Minuten auf Raumtemperatur ab. Nun zweimalige fünfminütige Waschung mit PBS, Inkubation für 20 Minuten in $25 \mathrm{mM}$ Glycin in PBS, Wiederholung der Waschung (2 mal 5 Minuten in PBS). Im Anschluss 1,5 h Inkubation bei Raumtemperatur in der Feuchtkammer mit 100-200 $\mu$ l Blockierungslösung pro Schnitt. 
Die Gewebeschnitte wurden mit dem anti $\alpha$ SYN-Primärantikörper (Covance) in einer Verdünnung von 1:500 in Blockierlösung über Nacht bei $4^{\circ} \mathrm{C}$ inkubiert.

Nach dreimaliger Waschung in PBS für 15 Minuten erfolgte das Auftragen der Sekundärantikörper (gt anti-mo Cy3 (Dianova), 1:250 verdünnt in Blockierungslösung) und die anschließende Inkubation bei Raumtemperatur für 1,5 h in der Feuchtkammer.

Nach 3 mal 10-minütiger Waschung in PBS folgte das Auftragen von DAPI (Inkubation für 2 Minuten bei Raumtemperatur) und Waschung zweimal für 10 Minuten in PBS. Nach dem Trocknen wurden die Schnitte mit Mowiol eingedeckelt.

Die Aufnahmen erfolgten mit dem Mikroskop Zeiss-Axioplan bei 200-facher Vergrößerung für die Übersichtsaufnahmen (Objektiv: 20x, Fotookular: 10x) und bei 400facher Vergrößerung für die Detailaufnahmen (Objektiv: 40x, Fotookular: 10x).

\subsubsection{Retina-Flat-Mounts}

Nach erfolgtem Imaging und nach Euthanasie des Versuchstiers wurde der Augapfel samt Teilstück des ON auf der operierten Seite entnommen und in PFA über Nacht fixiert.

Am Folgetag wurde das fixierte Gewebe vom Bindegewebe befreit und der Augapfel entlang der Ora serrata aufgeschnitten. Die Retina wurde in toto entnommen, auf einem Objektträger ausgebreitet und mit 10 \%-igem Glycerol eingedeckelt.

Nach erfolgter Präparation wurden mithilfe eines Fluoreszenzmikroskops (ZeissAxioplan) Bilder der mit AAV-EGFP transduzierten RGCs und Axone der Retina angefertigt als Kompositaufnahme bei 400-facher Vergrößerung (Objektiv: 40x, Fotookular: 10x).

\subsubsection{Nervenquerschnitte}

Die Gewinnung der Gewebeproben und die Anfertigung der Kryoschnitte erfolgten wie in Abschnitt 2.2.3.1. mit dem Unterschied, dass erstens die ON der Seite verwendet wurden, auf der zuvor geimaged wurde und zweitens die Schnittrichtung dabei quer und nicht längs erfolgte. Wie bei den Retina-Flat-Mounts waren auch hier keine weiteren immunhistochemischen Färbungen notwendig. 
Die Aufnahmen erfolgten mit dem Mikroskop Zeiss-Axioplan in 200-facher Vergrößerung (Objektiv: 20x, Fotookular: 10x). 


\section{$3 \quad$ Ergebnisse}

\subsection{Nachweis der Transduktion retinaler Ganglienzellen mit AAV- EGFP}

Für die Durchführung der Live-Imaging-Experimente ist die Expression von EGFP insbesondere in RGZ des kranialen Retinaabschnitts entscheidend. Zur Evaluation der erfolgreichen Transduktion der RGZ wurden Retina-Flat-Mounts $(n=5)$ und Kryoquerschnitte des ON ( $n=7)$ angefertigt.

In der Fluoreszenzmikroskopie der Retina-Flat-Mounts (siehe exemplarisch Abbildung 7) konnte die erfolgreiche Transduktion von RGZ mit AAV-EGFP nachgewiesen werden. An einem Ort der Netzhautperipherie (mutmaßlich der kraniale Abschnitt, der mit der Spitze der Injektionsnadel gezielt angesteuert wurde; genaue Zuordnung im Flat-Mount jedoch nicht möglich) zeigte sich das Fluoreszenzsignal verstärkt. Zudem zeigte sich eine verstärkte Transduktion in Netzhautbereichen um die retinalen Gefäße.

Die Fluoreszenzmikroskopie der Nervenquerschnitte (siehe exemplarisch Abbildung 8) bestätigte die Expression von EGFP in den Axonen des ON. Eine Betonung der Transduktion in einem peripheren, mutmaßlich dem kranialen Bereich wie in den Retina-Flat-Mounts konnte auch in den Querschnittpräparaten nachvollzogen werden. In allen Querschnitten war außerdem ein mittiger Streifen mit intensivierter Leuchtstärke, d. h. mit einer verstärkten axonalen Transduktion auszumachen. 

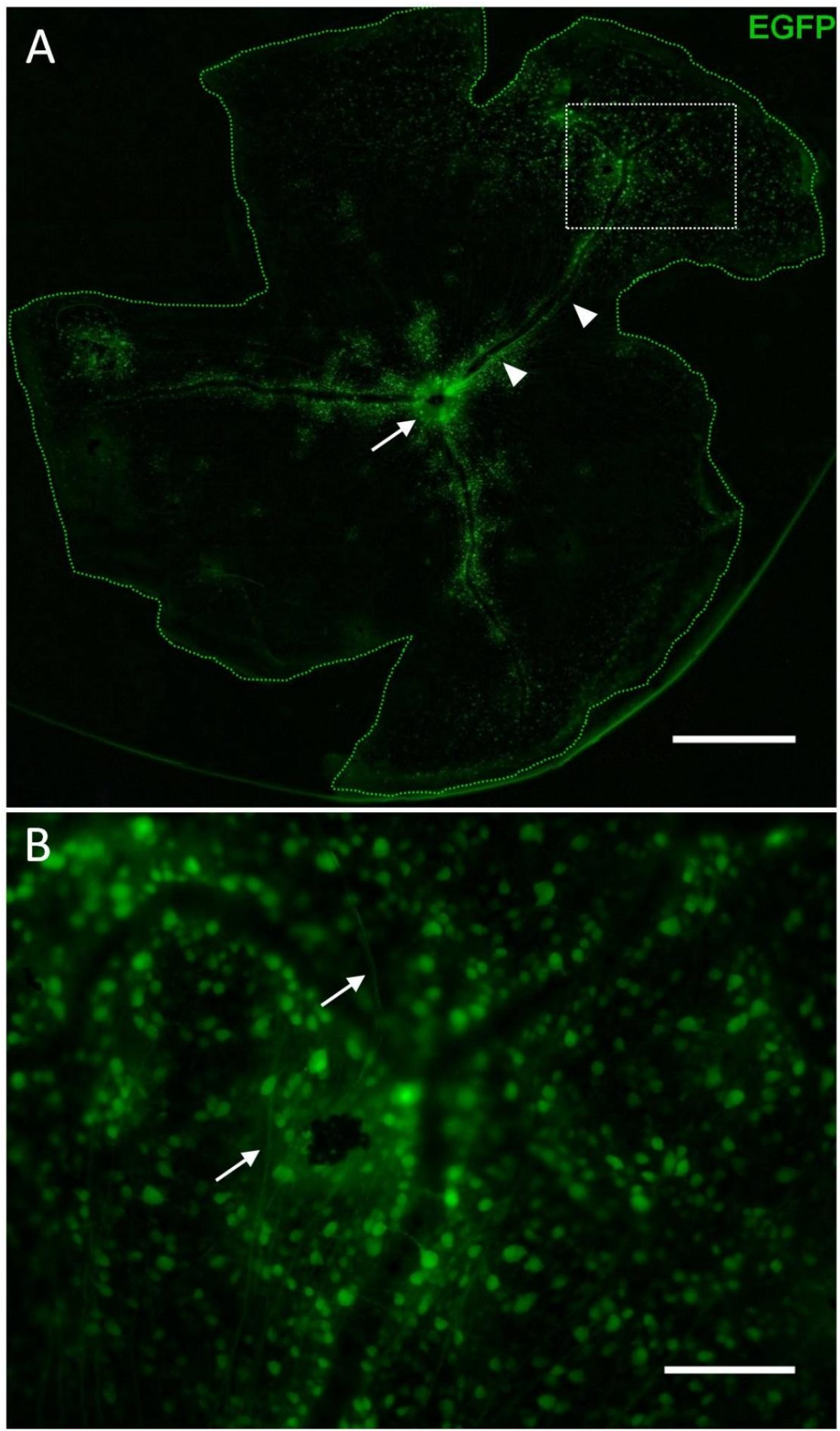

Abbildung 7: Fluoreszenzmikroskopische Aufnahme eines Retina-Flat-Mounts zwei Wochen nach Transduktion der RGZ mit AAV-EGFP. A: Übersicht. Transduzierte RGZ sind grün markiert. Die Transduktion zeigt sich verstärkt im mutmaßlich kranialen Abschnitt der Netzhautperipherie (oberer Bildabschnitt) und in Bereichen um die retinalen Blutgefäße (Pfeilspitzen). Pfeil: Papille. Maßstabsbalken: $500 \mu \mathrm{m}$. B: Detailansicht (Ausschnitt, siehe Rechteck in A). Neben den grün aufleuchtenden RGZ sind transduzierte Axone erkennbar (Pfeile), die aus der Netzhautperipherie Richtung Papille ziehen. Maßstabsbalken: $100 \mu \mathrm{m}$. 


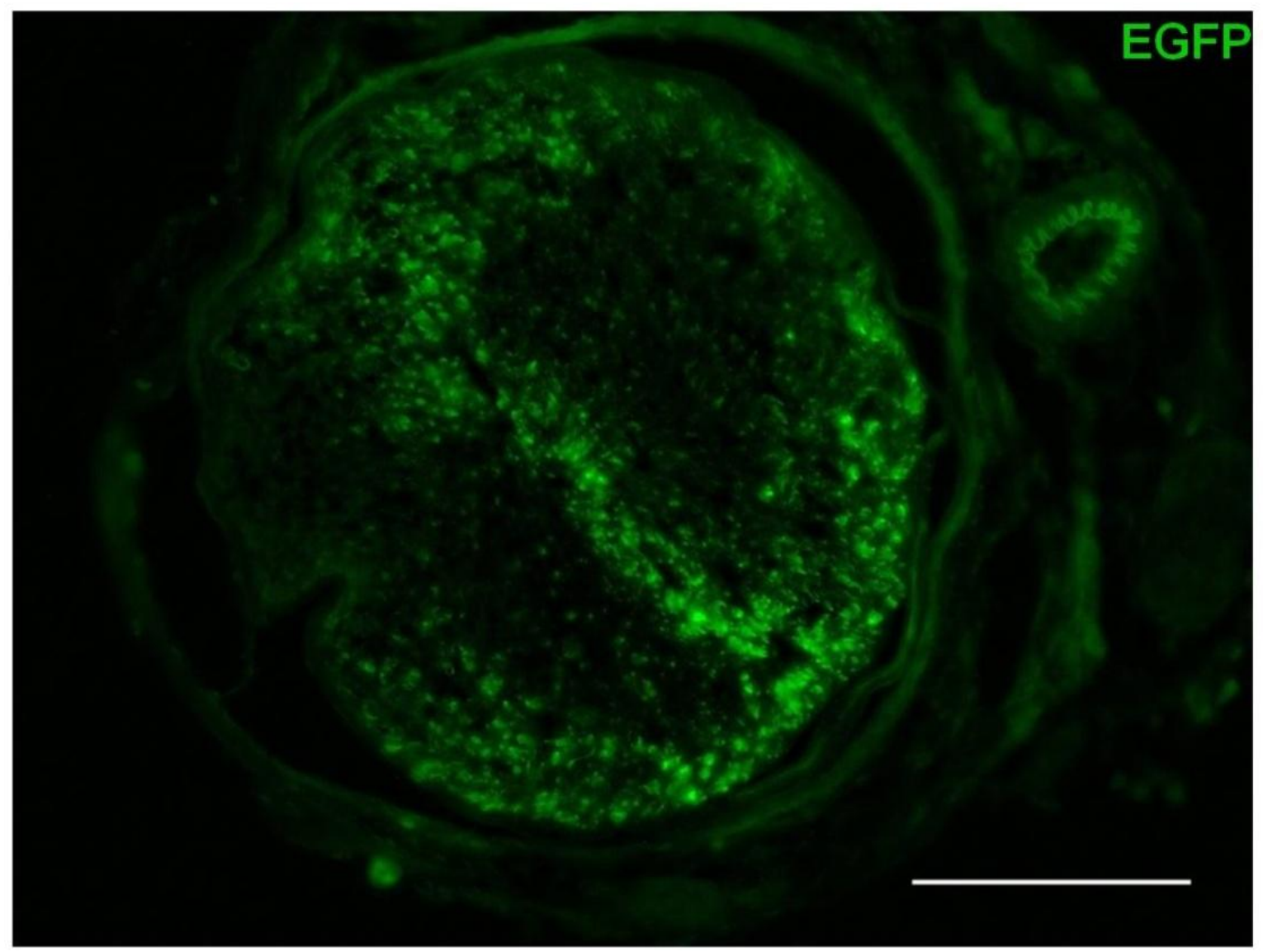

Abbildung 8: Fluoreszenzmikroskopische Aufnahme des ON einer Maus im Querschnitt zwei Wochen nach Transduktion der RGZ mit AAV-EGFP. Der Nerv ist in sein umgebendes Bindegewebe eingebettet. Transduzierte Axone sind als grün aufleuchtende Punkte zu erkennen. Es zeigt sich eine Verstärkung der Transduktion in einer halbmondförmigen Zone der Nervenperipherie (im Bild rechts unten) sowie auf der gegenüber liegenden Seite. Die Axone der inneren Bereiche des Nervs sind bis auf eine bandförmige Zone in der Mitte eher schwach transduziert. Maßstabsbalken: $100 \mu \mathrm{m}$. 


\subsection{Expression von $\alpha$-Synuclein im optischen Nerv transgener Versuchstiere}

Zunächst sollte untersucht werden, ob das mutierte humane $\alpha$ SYN im ON der transgenen Versuchstiere exprimiert wird. Hierzu wurden Western Blots durchgeführt mit einem $\alpha S Y N$-Antikörper ( $B D$ ), der sowohl endogenes Mäuse- als auch zusätzlich exprimiertes humanes $\alpha$ SYN nachweist, und Gewebeproben aus dem ON junger Versuchstiere. In den Proben der transgenen Tiere ([A53T] $\alpha$ SYN und $[A 30 \mathrm{P}] \alpha S Y N)$ ließ sich das endogen exprimierte humane $\alpha$ SYN mit einem Molekulargewicht von $19 \mathrm{kDa}$ nachweisen. Die WT-Tiere zeigten wesentlich schwächere Banden, die auf einen geringen Gehalt von murinem $\alpha \mathrm{SYN}$ hindeuteten.

Die dazugehörige Quantifizierung (siehe Abbildung 9B) belegte einen statistisch signifikant vermehrte Expression von $\alpha \mathrm{SYN}$ in den $\mathrm{ON}$ transgener Tiere gegenüber den Wildtypen im Alter von 3-5 Monaten. Hervorzuheben ist, dass sich auch zwischen den beiden untersuchten transgenen Gruppen ein unterschiedlicher $\alpha$ SYN-Gehalt im ON nachweisen ließ: So war der $\alpha$ SYN-Gehalt in den Proben der [A53T] $\alpha$ SYN-Tiere signifikant höher als in den Proben der [A30P] $\alpha$ SYN-Tiere.

Für die Western Blots wurden fast ausschließlich transgene Tiere verwendet, die homozygote Träger des mutierten SNCA-Gens waren. Nur Bande 6 (siehe Abbildung 9A) repräsentiert ein heterozygotes Tier aus der [A53T] $\alpha$ SYN-Gruppe. Dieses Tier wurde für die oben gezeigte Quantifizierung nicht mitberücksichtigt. Auch in den Live-Imaging-Experimenten wurden ausschließlich homozygote Tiere verwendet. Jedoch zeigte sich hier auch bei Heterozygotie ein deutlich erhöhtes ExpressionsLevel für $\alpha$ SYN im Vergleich zum WT. Zwischen den homozygoten Tieren und dem heterozygoten Tier ergab sich kein signifikanter Unterschied des $\alpha \mathrm{SYN}$-Gehalts im ON: Ordinary one-way ANOVA ( $p<0.0001)$; Tukey's multiple comparisons test: $p<0,01$

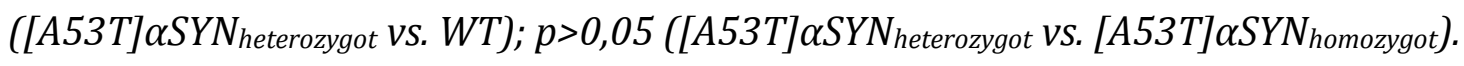


A
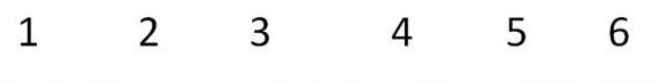

Tubulin (50 kDa)

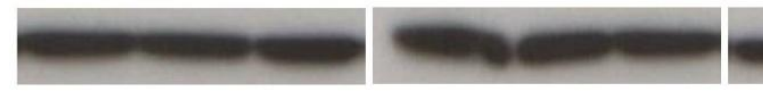

$$
\text { aSyn (19 kDa) }
$$

$[\mathrm{A} 30 \mathrm{P}] \alpha \mathrm{SYN} \quad[\mathrm{A} 53 \mathrm{~T}] \alpha \mathrm{SYN}$

WT

B

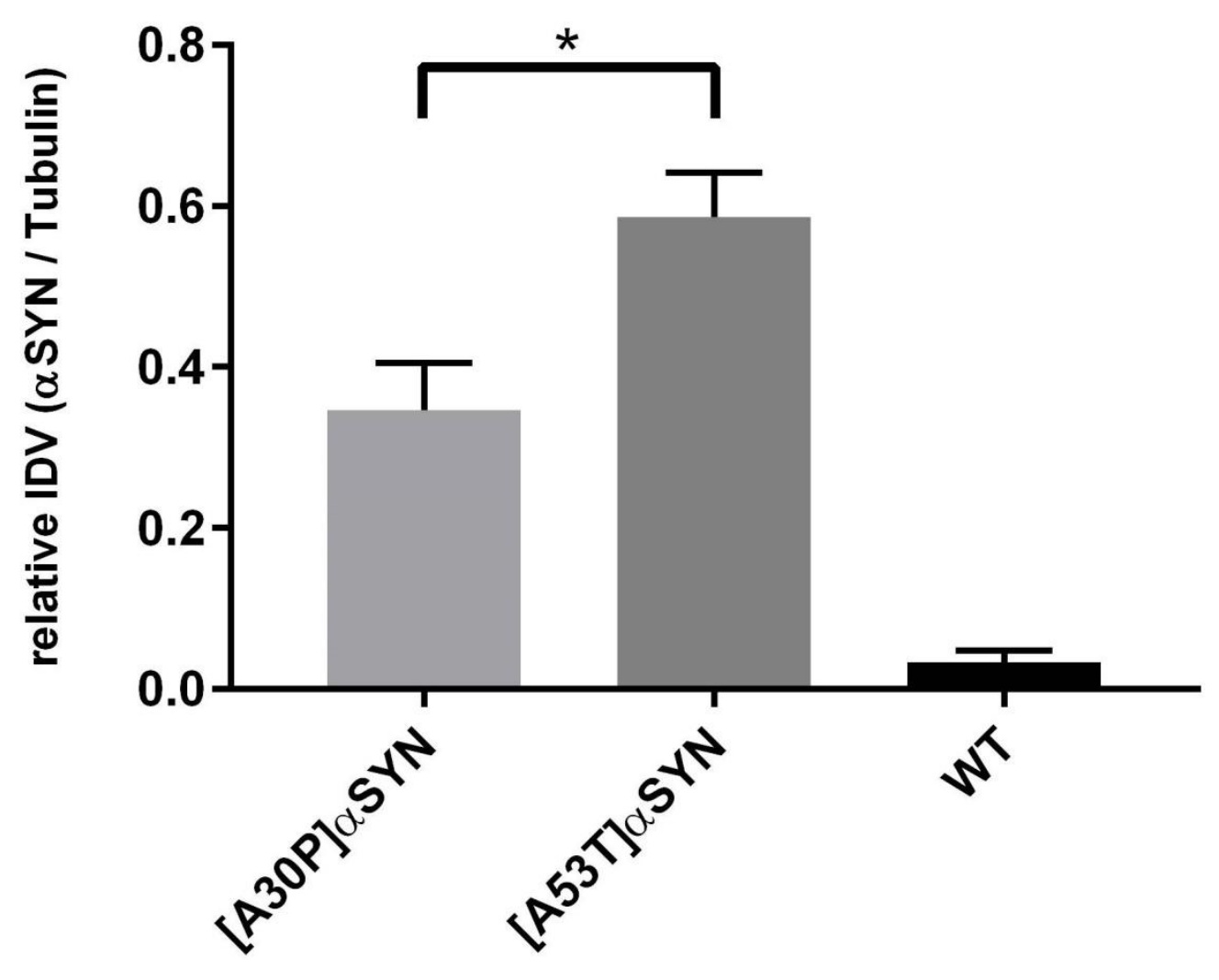

Abbildung 9: Nachweis der Expression von $\alpha S Y N$ im ON transgener Mäuse mittels Western Blot. A: Die oberen Banden zeigen Tubulin mit einem Molekulargewicht von $50 \mathrm{kDa}$, die unteren Banden $\alpha \mathrm{SYN}$ mit einem Molekulargewicht von $19 \mathrm{kDa}$. Gezeigt sind repräsentative Banden (Bd. 1-9) einzelner Tiere (keine Duplikate) im Alter von 3-5 Monaten für folgende Tierstämme: [A30P] $\alpha S Y N$ : $n=4$ (Bd. 1-3); [A53T] $\alpha$ SYN: $n=7$ (Bd. 4-6); WT: $n=5$ (Bd. 7-9). Bande 6 stammt von einem heterozygoten Träger des mutierten SNCA-Gens, alle anderen Banden stammen von homozygoten Tieren. B: Quantifizierung des $\alpha$ SYN-Gehalts gegenüber dem Tubulin-Gehalt. Die Abzisse zeigt die relative IDV von $\alpha$ SYN zu Tubulin bei den untersuchten Tierstämmen. Es zeigt sich neben einem signifikant höheren $\alpha \mathrm{SYN}-$ Gehalt bei transgenen Tieren gegenüber den Wildtypen (Statistik nicht gezeigt) ebenfalls ein signifikanter Unterschied der transgenen Stämme untereinander. Statistische Tests: Ordinary oneway ANOVA: $p<0,001$ (nicht gezeigt), Tukey's multiple comparisons test: [A53T] $\alpha S Y N$ vs. WT: $p<0,0001$ (nicht gezeigt); [A30P] $\alpha S Y N$ vs. WT: $p<0,01$ (nicht gezeigt); [A30P] $\alpha S Y N$ vs. [A53T] $\alpha S Y N$ : $p<0,05\left(^{*}\right)$. Fehlerbalken: Standardfehler des arithmetischen Mittelwerts. 
Zusätzlich wurden immunhistochemische Färbungen von Kryogewebeschnitten von ON mit $\alpha$ SYN-Antikörpern (Covance) angefertigt zur Untersuchung der Lokalisation von $\alpha$ SYN im optischen Nerven von transgenen Tieren. Abbildung 10 zeigt repräsentative immunhistochemisch gefärbte Schnitte des ON einer [A53T] $\alpha$ SYN-Maus (Alter: 3 Monate) in Übersichtsvergrößerung (13A) und als Detailausschnitt (13B). Die Nerven waren parallel zur Axonverlaufsrichtung geschnitten worden. Die Färbung der Zellkerne mit DAPI (blau) zeigt Reihen von Gliazellen, die vornehmlich den Oligodendrozyten um die Axone entsprechen. Zwischen den Reihen sind Bereiche ohne Zellkerne abgrenzbar, in denen die Axone verlaufen. In diesem Bereich ist eine relativ gleichmäßige Anfärbung von $\alpha S Y N$ zu beobachten. Einzelne Axone sind nur teilweise abgrenzbar. Auch in den Bereichen mit Zellkernen, d. h. in den Oligodendrozyten, kann eine deutliche perinukleäre Anfärbung von $\alpha \mathrm{SYN}$ beobachtet werden. 13C zeigt denselben Ausschnitt unter Ausblendung des DAPI-Signals. Hier ist erkennbar, dass $\alpha$ SYN im Bereich um die Zellkerne vorliegt, in den Zellkernen selbst ist kein $\alpha$ SYN nachweisbar.

13D zeigt einen mit demselben $\alpha \mathrm{SYN}$-Antikörper gefärbten Gewebeschnitt des ON einer Wildtyp-Maus (Alter: 3 Monate). Passend zum Befund der Western Blots, in denen auch bei Wildtyp-Mäusen nur ein sehr geringer $\alpha$ SYN-Gehalt nachgewiesen werden konnte, ließ sich hier kaum ein Signal nach Färbung mit dem $\alpha$ SYN-Antikörper nachweisen.

Zur Validierung der IHC-Färbungen führten wir eine Kontrollfärbung mit dem Sekundärantikörper durch, um zu garantieren, dass er selektiv an den $\alpha \mathrm{SYN}$ Primärantikörper bindet und keine unspezifischen Bindungen mit dem Gewebe eingeht. 13E und F zeigen diese Kontrollfärbungen, bei denen der Sekundärantikörper ohne den Primärantikörper zur Anwendung kam. Wie erwartet kam es nicht zur Anfärbung des Gewebes. 


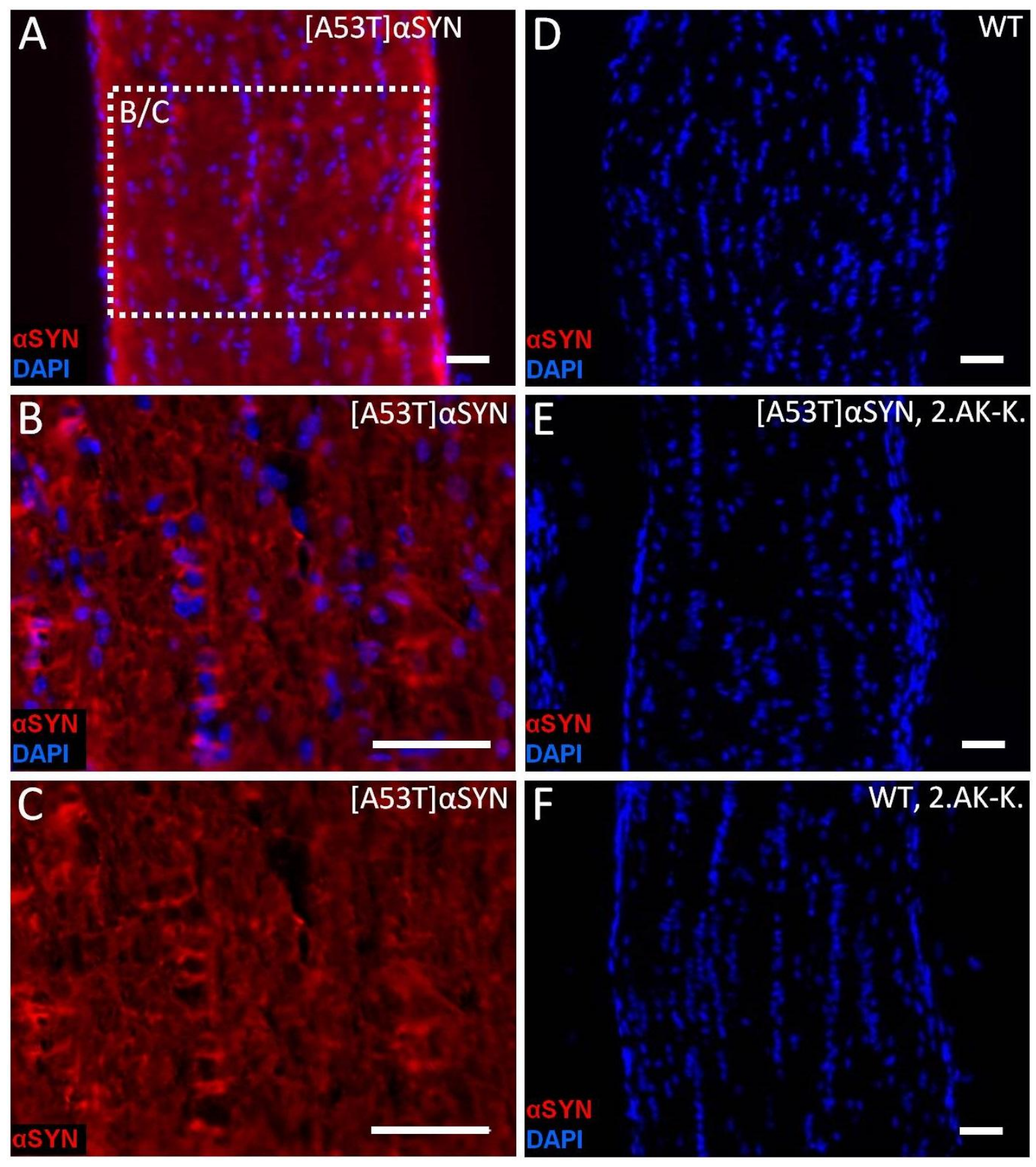

Abbildung 10: IHC-gefärbte Kryogewebeschnitte von ON transgener und Wildtypmäuse. Die Nerven sind in Längsrichtung angeschnitten. Jeweils unten links im Bild: gezeigte Fluoreszenzkanäle: $\alpha$ SYN (Primärantikörper der Firma Covance, rot), DAPI (blau). A zeigt den ON eines 3 Monate alten [A53T] $\alpha$ SYN-Tieres. B, E zeigen Detailansichten des in A markierten Bereichs. D: ON eines 3-5 Monate alten Wildtyptieres. E, F: Sekundärantikörperkontrollen. Maßstabsbalken: $50 \mu \mathrm{m}$. 


\subsection{Ergebnisse der Live-Imaging-Experimente}

\subsubsection{Weiterentwicklung des Live-Imaging-Verfahrens}

Die Live-Imaging-Technik, die im Zentrum dieser Arbeit steht, war ursprünglich für die Anwendung an Ratten etabliert worden. Da in diesem Projekt mit den bereits beschriebenen transgenen Mausmodellen gearbeitet werden sollte, musste das LiveImaging-Verfahren und insbesondere die Operationstechnik an die besonderen Herausforderungen angepasst werden, die diese deutlich kleineren Nagetiere mit sich brachten.

\subsubsection{Präoperative Herausforderungen und orbitachirurgischer Eingriff}

Für den Erhalt verwertbarer mikroskopischer Aufnahmen war eine gute Fixierung des Kopfes unerlässlich. Für die Verwendung an Ratten war ein Headholder (Eigenanfertigung) angefertigt worden, der mit dem Prinzip der Dreipunktfixation arbeitete: Die Fixierung des Kopfes erfolgte durch Metallstifte, die in den Gehörgang der Ratte eingeführt wurden und über eine Fixierung des Oberkiefers durch eine Schraubzwinge. Dieses Prinzip wurde auf die Maus übertragen. Ein Headholder in kleinerer Ausführung wurde angefertigt. Eine wesentliche Neuerung bestand in einer Veränderung der Form der Ohrstifte: die kegelförmige Spitze wurde abgeflacht, der Stift insgesamt dicker. So füllt der Stift den Gehörgang besser aus und fixiert den Kopf, ohne dass die Spitze Schaden anrichten kann. Die Fixation konnte über die Veränderung des Hakenzugs weiter verbessert werden. Schon bei Ratten hatte man den Hautschnitt über das Einführen von vier Haken gespreizt. Um die Fixation des Mäusekopfs zu verbessern, wurde der Zug auf die Haken, die rechts und links lateral des Hautschnitts eingeführt wurden, verstärkt. Dies führte zu fast optimalen Fixationsergebnissen.

Orbitachirurgische Eingriffe bei der Maus bergen im Unterschied zur Ratte eine deutlich größere Gefahr stärkerer Blutungen, da das intraorbitale Gewebe der Maus deutlich besser vaskularisiert ist. Daher muss noch gewebeschonender operiert werden. Bei der Durchtrennung des Unterhaut-Bindegewebes per Kauterisation zur Eröffnung der Orbita wurde daher sehr zurückhaltend vorgegangen. Die Tränendrüse wurde nicht - wie bei Ratten - durchtrennt, sondern vorsichtig beiseitegeschoben. Nach der Mobilisierung des M. rectus superior kam es oft zu einer mittelstarken Blutung, die konsequent durch Kompression mit Tupfern gestillt werden musste. Dafür wurde mitunter bis zu fünf Minuten gewartet, bevor die Tupfer wieder entfernt wurden. 
Wenn gespült werden musste, wurde vornehmlich kalte Ringer-Lösung verwendet. Um Blutungen im Bereich des ON zu vermeiden, wurde ausschließlich stumpf präpariert, sichtbare Blutgefäße wurden mobilisiert und zur Seite geschoben. Da es gerade am Ort des Eintritts des ON in den Bulbus häufig zu persistierenden Sickerblutungen kam, die für den Imaging-Prozess sehr störend waren, wurde manchmal in Kauf genommen, dass in diesem Bereich Bindegewebsreste bestehen blieben und stattdessen ein Imaging-Bereich weiter distal gewählt.

Damit das Objektiv des Mikroskops nicht auf der knöchernen Orbitakante aufsetzte, wurde diese bei Ratten regelhaft mittels einer Fräse teilweise entfernt. Es stellte sich heraus, dass dies bei Mäusen nicht zwingend notwendig war und der ON auch ohne Entfernung der Orbitakante gut im Fluoreszenzmikroskop eingestellt werden konnte. Wenn möglich, wurde deshalb auf diesen Operationsschritt verzichtet, zumal dabei stets die Gefahr bestand, die Schädelkalotte so weit auszudünnen, dass sie brach. Stattdessen wurde zur optimalen Einstellung des ON der Zug der Haken variiert und die Neigung des gesamten Head-Holders verändert.

\subsubsection{Entwicklung eines Auswertungsverfahrens für die Bilddaten}

Bei vorausgegangenen Live-Imaging-Studien an Ratten wurden die Bilddaten mit einer Methode zur Bestimmung der sogenannten axonalen Integrity-Ratio ausgewertet. Dafür wurden im Verlauf des Axons auftretende Unterbrechungen detektiert, wobei es wichtig, war den Verlauf des Axons über wenigstens etwa $100 \mu \mathrm{m}$ sicher nachzuvollziehen. Die gewonnenen Bilddaten von Axonen des ON von Mäusen unterschieden sich jedoch in einigen wichtigen Punkten von vergleichbaren Aufnahmen bei Ratten. Die Axone waren nicht nur wesentlich dünner, sondern ihr Verlauf von proximal nach distal stellte sich darüber hinaus wesentlich chaotischer dar. Die Axone verliefen weniger parallel zueinander und tauchten mitunter in die Tiefe des Nervs ab, sodass es nur selten möglich war, einzelne Axone über einen Verlauf von mindestens $100 \mu \mathrm{m} \mathrm{zu}$ verfolgen. Deshalb wurde für das vorliegende Projekt ein neues Auswertungsverfahren entwickelt (siehe dazu Kapitel 2.2.2.7. Auswertung), dass sich statt auf die axonale Integrität auf die numerische Erfassung der Bulb-Entstehung als Maß für axonale Degeneration konzentrierte. Dieses Verfahren ermittelte die Axonlänge, auf die die Anzahl der gemessenen Bulbs bezogen wurde, statistisch aus den sichtbaren Axonen eines flächigen Auswertungsbereichs und war somit unabhängig von einem geraden 
Axonverlauf. Ein weiterer Vorteil gegenüber der vorbekannten Methode bestand in der geringeren Anfälligkeit gegenüber dem Verblassen des fluoreszierenden Proteins, das durch den langen Imaging-Zeitraum und häufige Aufnahmen gerade zu späten Imaging-Zeitpunkten auftraten. Dünne Axone blichen relativ schnell aus und waren nicht mehr sicher abgrenzbar. Eine Aussage darüber, ob sie zerfallen oder nur ausgeblichen war, ließ sich kaum treffen. Die Bulbs waren dagegen wesentlich größer und leuchtstärker und damit bis zuletzt sicher abgrenzbar. Insgesamt war die Methode zur Bestimmung der Bulb-Verteilungsdichte damit wesentlich weniger störanfällig für methodische Einschränkungen, die sich aus dem Verfahren selbst ergaben.

\subsubsection{Dynamik der Bulb-Formierung im optischen Nerv nach Applikation von Kalzium-Ionophor}

\subsubsection{Initiation der Bulb-Formierung durch Applikation von Kalzium-Ionophor}

Grundlage einer Auswertung der Live-Imaging-Experimente war zunächst der Nachweis des Einflusses von Kalzium-Ionophor auf Entstehung von axonalen Bulbs im ON. Dazu wurden die freipräparierten ON von Wildtypmäusen im Alter von 3-9 Monaten mit Kalzium-Ionophor behandelt $(n=13)$ und das Ausmaß der BulbFormierung mit derjenigen unbehandelter ON von Wildtypmäusen desselben Alters $(n=4)$ verglichen. Die Abbildung 11 zeigt die Verläufe der axonalen Bulb-Entstehung für behandelte und unbehandelte Tiere. Als quantifizierbare Größe diente die Anzahl von axonalen Bulbs bezogen auf die Axonlänge (siehe auch Kapitel „2.2.2.7 Auswertung"). Während unbehandelte Nerven kaum Anzeichen der Bulb-Entstehung zeigten - erst nach 180 Minuten kam es zum Auftreten vereinzelter Bulbs mit geringer Verteilungsdichte - setzte bei behandelten Nerven eine deutliche BulbFormierung 90 Minuten nach dem Kontakt mit Kalzium-Ionophor ein, die nach 120 Minuten ein Plateau erreichte. Dieser Unterschied erwies sich in der Two-way Repeated Measures ANOVA als hochsignifikant: Source of variation: Interaction: $p<0,0001$. Der hier durchgeführte Post-hoc-Test Sidak's multiple comparisons test fokussierte auf die einzelnen Messzeitpunke und verglich $\mathrm{zu}$ den jeweiligen Zeitpunkten die Bulb-Verteilungsdichte der behandelten mit denen der unbehandelten Gruppe. Mit diesem Test wurde deutlich, dass sich ab dem Messzeitpunkt 90 Minuten ein signifikanter Unterschied in der Höhe der BulbVerteilungsdichte zeigte. Aufgrund dieses Ergebnisses ist also mit sehr hoher 
Wahrscheinlichkeit davon auszugehen, dass die Ausbildung von Bulbs direkt auf die Behandlung der Nerven mit Kalzium-Ionophor zurückzuführen ist.

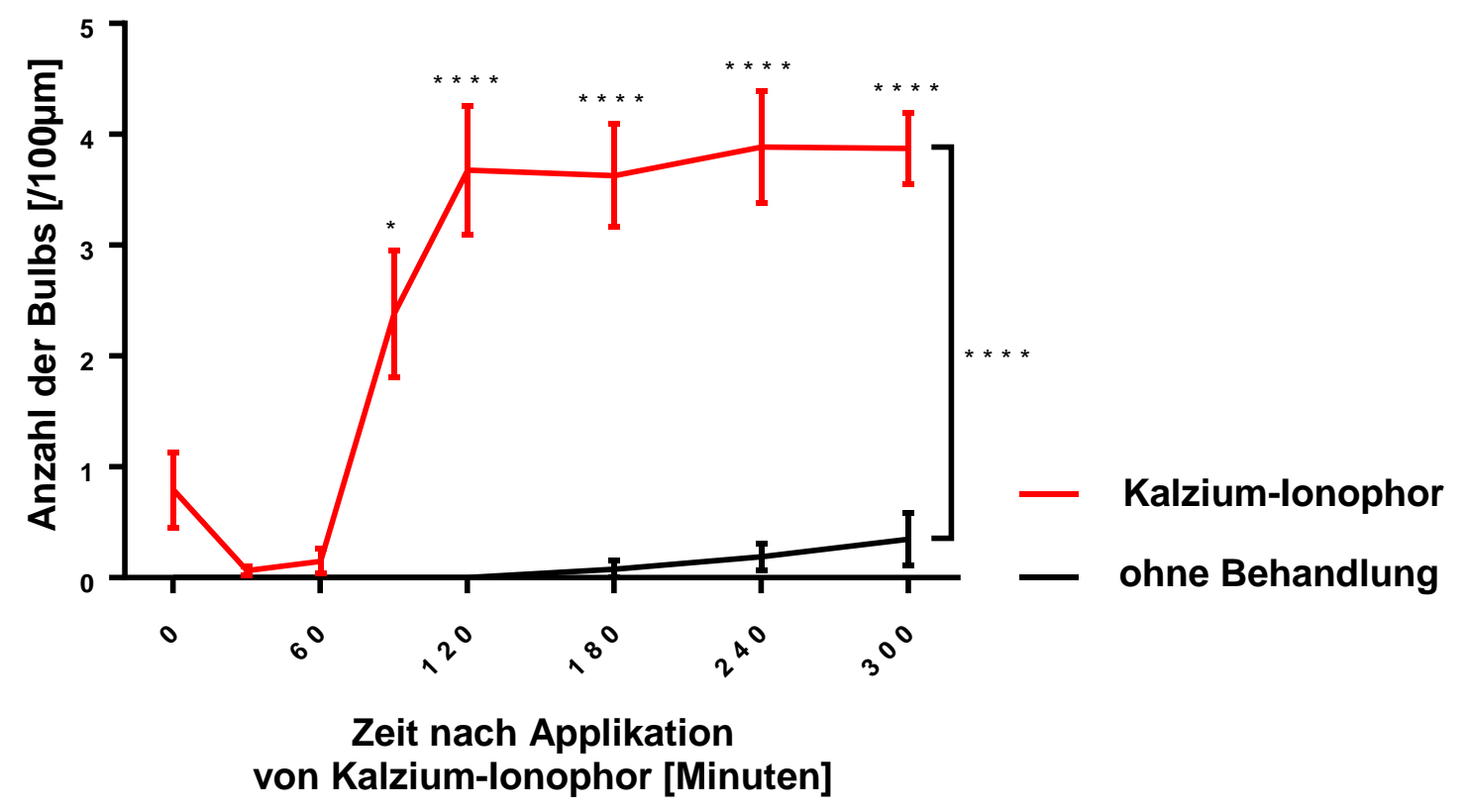

Abbildung 11: Die Applikation von Kalzium-Ionophor auf den freigelegten optischen Nerv führte zur Ausbildung axonaler Bulbs. Aufgetragen ist die BulbVerteilungsdichte als Anzahl der Bulbs pro $100 \mu \mathrm{m}$ Axonlänge (Ordinatenachse) in Abhängigkeit von der Zeit nach Applikation von Kalzium-Ionophor [Minuten] (Abszissenachse). Vergleichend gegenübergestellt werden hier der Verlauf der BulbVerteilungsdichte von Wildtypmäusen (Alter: 3-9 Monate) mit (rot, n=13) und ohne (schwarz, n=4) Applikation von Kalzium-Ionophor auf den ON zum Zeitpunkt 0 Minuten. Statistische Tests: Two-way Repeated Measures ANOVA (eckige Klammer): $p<0,0001$ ( $\left.^{* * *}\right) ;$ Sidak's multiple comparisons test: Vergleich der Messwerte beider Kohorten (rot und schwarz) zu unterschiedlichen Zeitpunkten: $p<0,0001$ (****); $p<0,05$ (*). Fehlerbalken: Standardfehler des arithmetischen Mittelwerts (SEM).

\subsubsection{Unterschiede der Bulb-Verteilungsdichte zwischen den untersuchten Genotypen}

Mittels des beschriebenen Live-Imaging-Verfahrens konnte ein fünfstündiger Verlauf der Bulb-Entstehung am ON transgener ([A53T] $\alpha$ SYN und [A30P] $\alpha$ SYN) und nicht transgener Mäuse (WT) dargestellt werden. Es wurde zwischen jungen Tieren im Alter von drei bis fünf Monaten und alten Tieren im Alter von 7 bis 9 Monaten unterschieden, insbesondere auch, weil das Alter der wichtigste Risikofaktor für die Entstehung einer Parkinsonerkrankung bei Menschen ist. Die Abbildungen 12-15 zeigen repräsentative Verläufe der untersuchten Genotypen und Altersgruppen. Bis 60 Minuten nach der Applikation von Kalzium-Ionophor zeigten sich die Axone im ON 
stabil und ohne Ausbildung von Bulbs. Die Axone waren in ihrem Verlauf von proximal (unterer Bildrand) nach distal (oberer Bildrand) als schmale helle Linien gut abgrenzbar. Nach 90 Minuten setzte bei allen Genotypen und Altersgruppen die Formierung von Bulbs ein, erkennbar als rundliche Aufhellungen, die häufig perlschnurartig aufgereiht waren. Zudem kam es zur Störung der axonalen Integrität: Die Axone zerfielen, ihr Verlauf war zunehmend schlechter nachzuvollziehen. Nach 120-180 Minuten war schließlich ein Plateau der Bulb-Verteilungsdichte erreicht. Zudem waren nun einzelne intakte Axone kaum noch auszumachen. Nur bei den WT-Tieren beider Altersgruppen waren bis zum letzten erfassten Zeitpunkt 300 Minuten nach der Applikation von Kalzium-Ionophor neben zerfallenen Axonen auch vollständig intakte Axone abgrenzbar.

Bildmorphologisch ergaben sich folgende Beobachtungen: Insgesamt fiel die Verteilungsdichte der Bulbs bei den [A53T] $\alpha$ SYN-Mäusen beider Altersgruppen erkennbar höher aus als bei den altersentsprechenden [A30P] $\alpha$ SYN- und WT-Tieren. Zwischen den beiden Tiergruppen [A30P] $\alpha$ SYN und WT ergab sich dagegen kein großer Unterschied in der Bulb-Verteilungsdichte, wenngleich auf den Abbildungen 12-15 ein leichter Trend in Richtung einer höheren Bulb-Verteilungsdichte bei [A30P] $\alpha$ SYNTieren auszumachen ist. Auffällig war der Unterschied im Kaliber der formierten Bulbs, die besonders bei jungen, in geringerem Maße auch bei alten [A53T] $\alpha$ SYNMäusen einen deutlich geringeren Durchmesser gegenüber den Bulbs von WT- und $[\mathrm{A} 30 \mathrm{P}] \alpha \mathrm{SYN}-$ Tieren aufwiesen. 


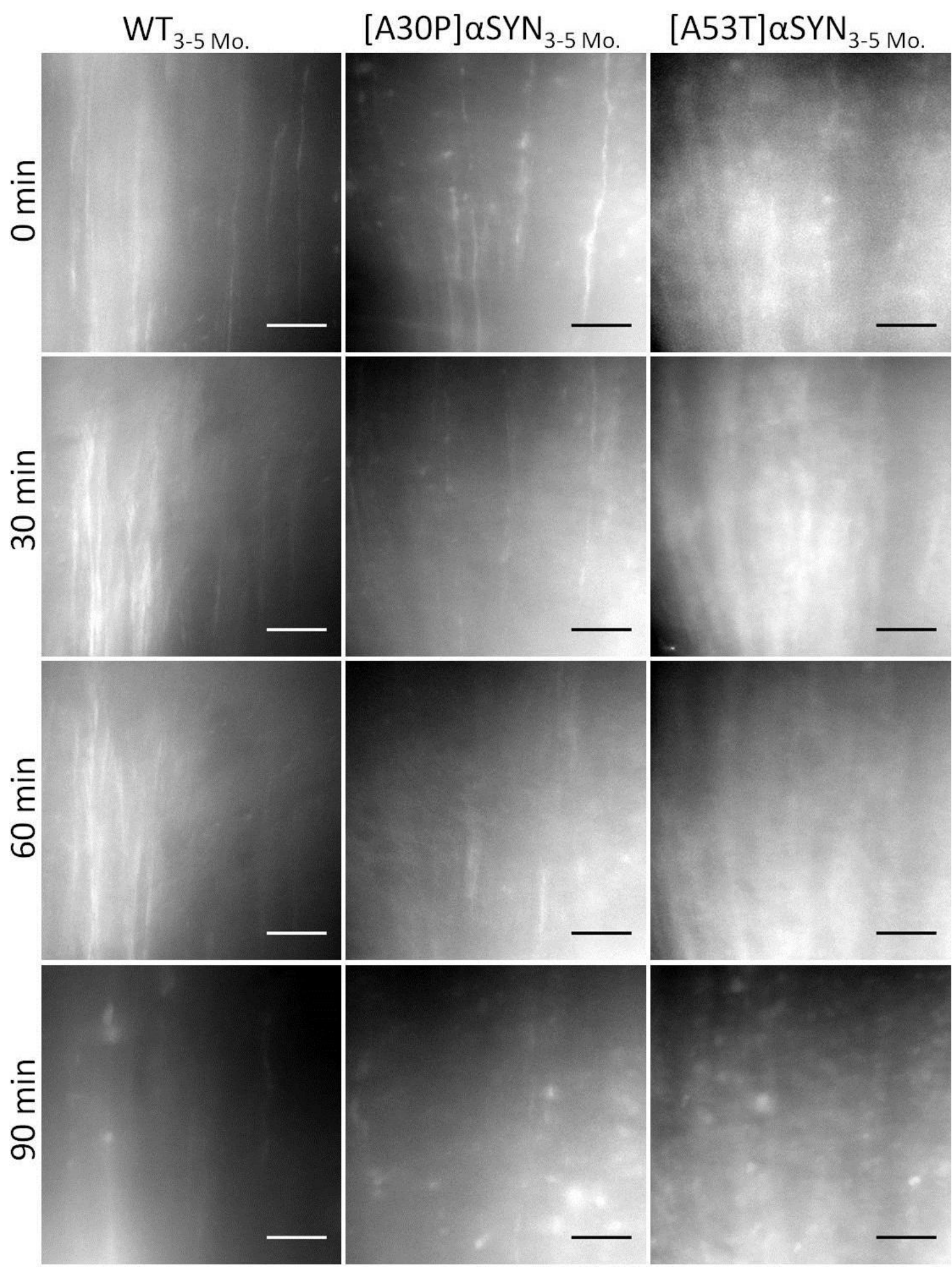

Abbildung 12: Exemplarische Additionsbilder aus Live-Imagings von WT- und transgenen Mäusen ([A30P] $\alpha S Y N$, [A53T] $\alpha S Y N)$ im Alter von 3-5 Monaten vom Zeitpunkt vor Applikation von Kalzium-Ionophor bis 90 Minuten danach. Von unten nach oben: proximal nach distal. Maßstabsbalken: $20 \mu \mathrm{m}$. 


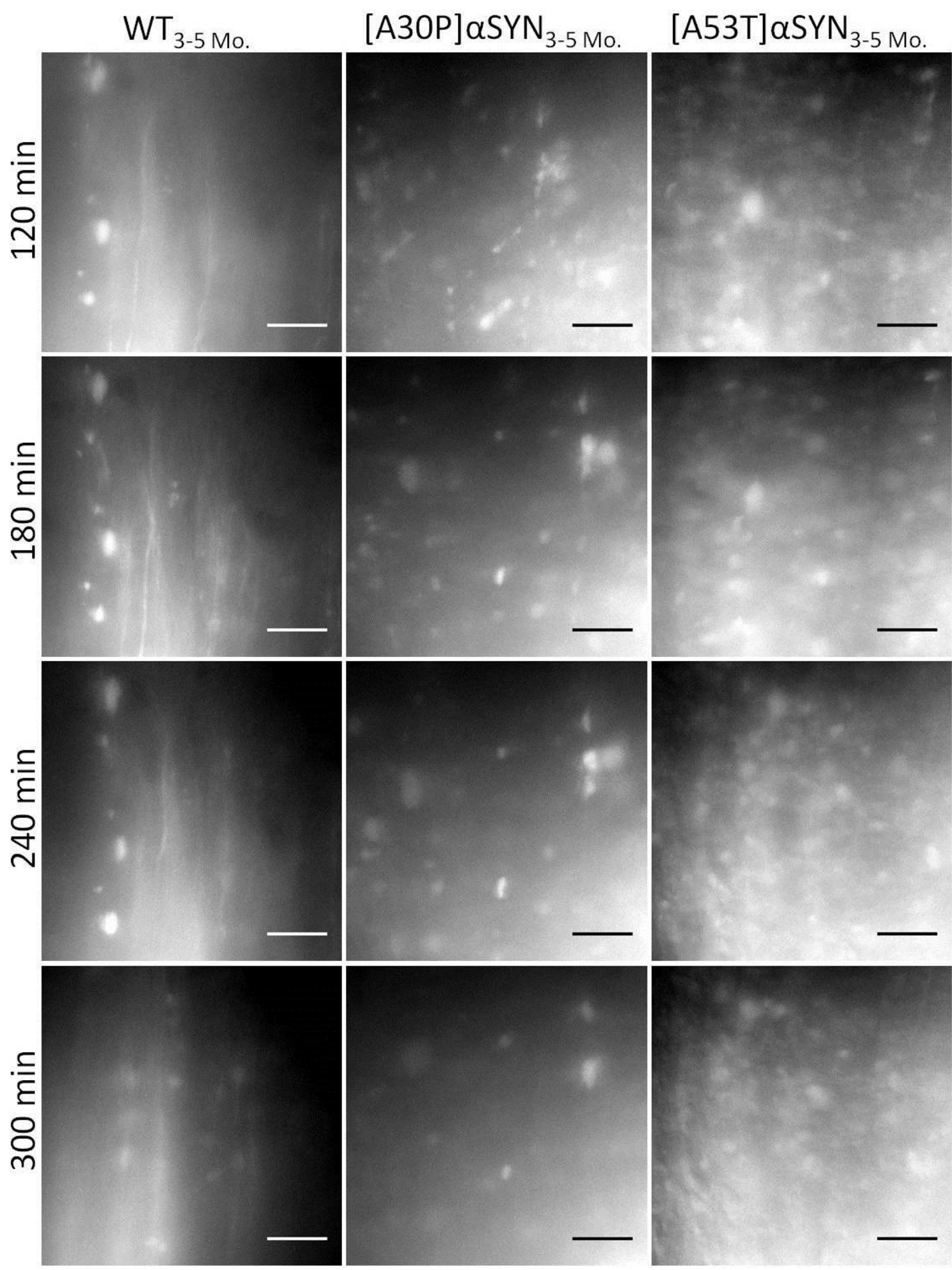

Abbildung 13: Exemplarische Additionsbilder aus Live-Imagings von WT- und transgenen Mäusen ([A30P] $\alpha S Y N,[A 53 T] \alpha S Y N)$ im Alter von 3-5 Monaten im Zeitraum 120-300 Minuten nach Applikation von Kalzium-Ionophor. Von unten nach oben: proximal nach distal. Maßstabsbalken: $20 \mu \mathrm{m}$. 


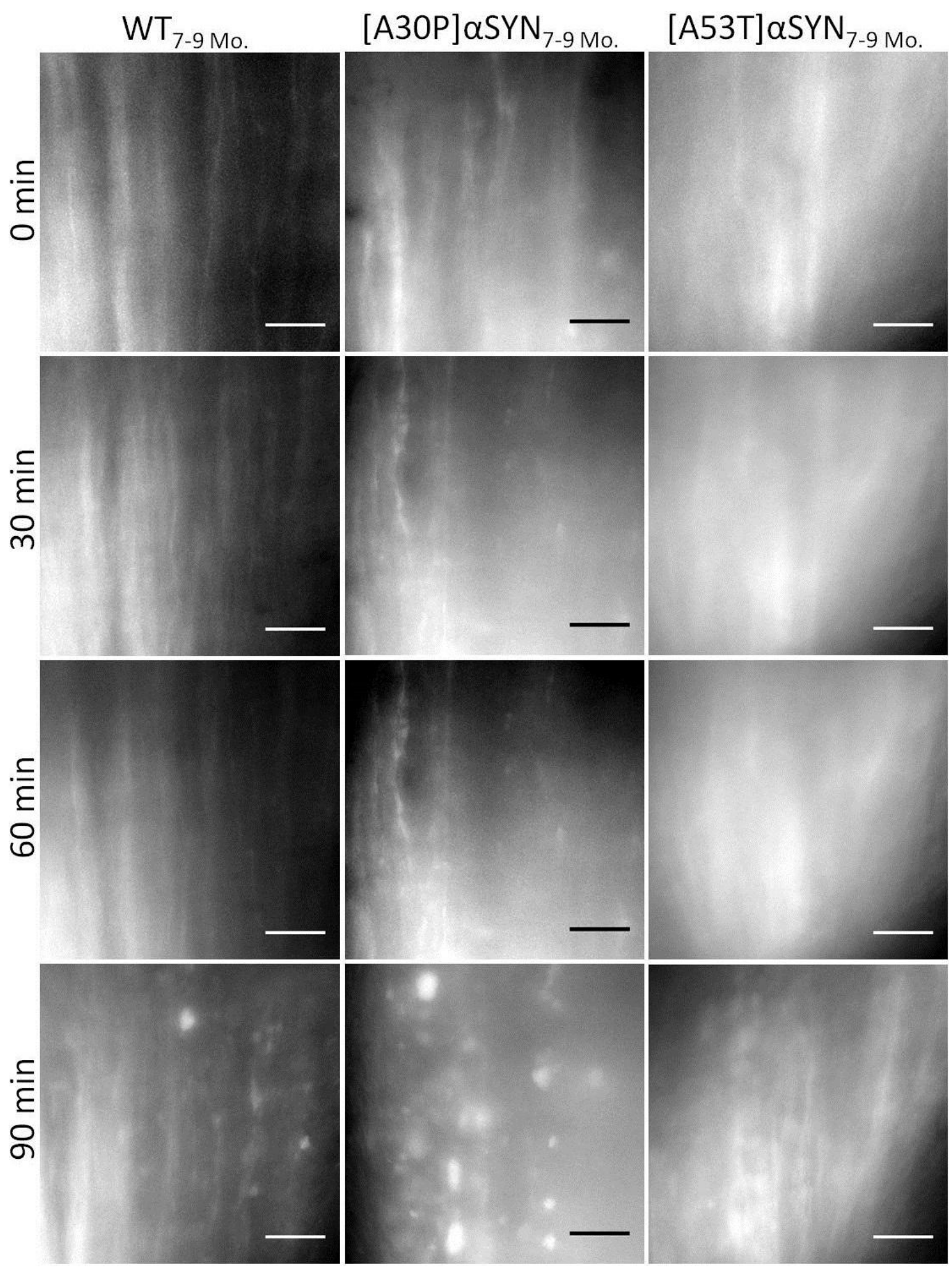

Abbildung 14: Exemplarische Additionsbilder aus Live-Imagings von WT- und transgenen Mäusen ([A30P] $\alpha S Y N$, [A53T] $\alpha S Y N)$ im Alter von 7-9 Monaten vom Zeitpunkt vor Applikation von Kalzium-Ionophor bis 90 Minuten danach. Von unten nach oben: proximal nach distal. Maßstabsbalken: $20 \mu \mathrm{m}$. 


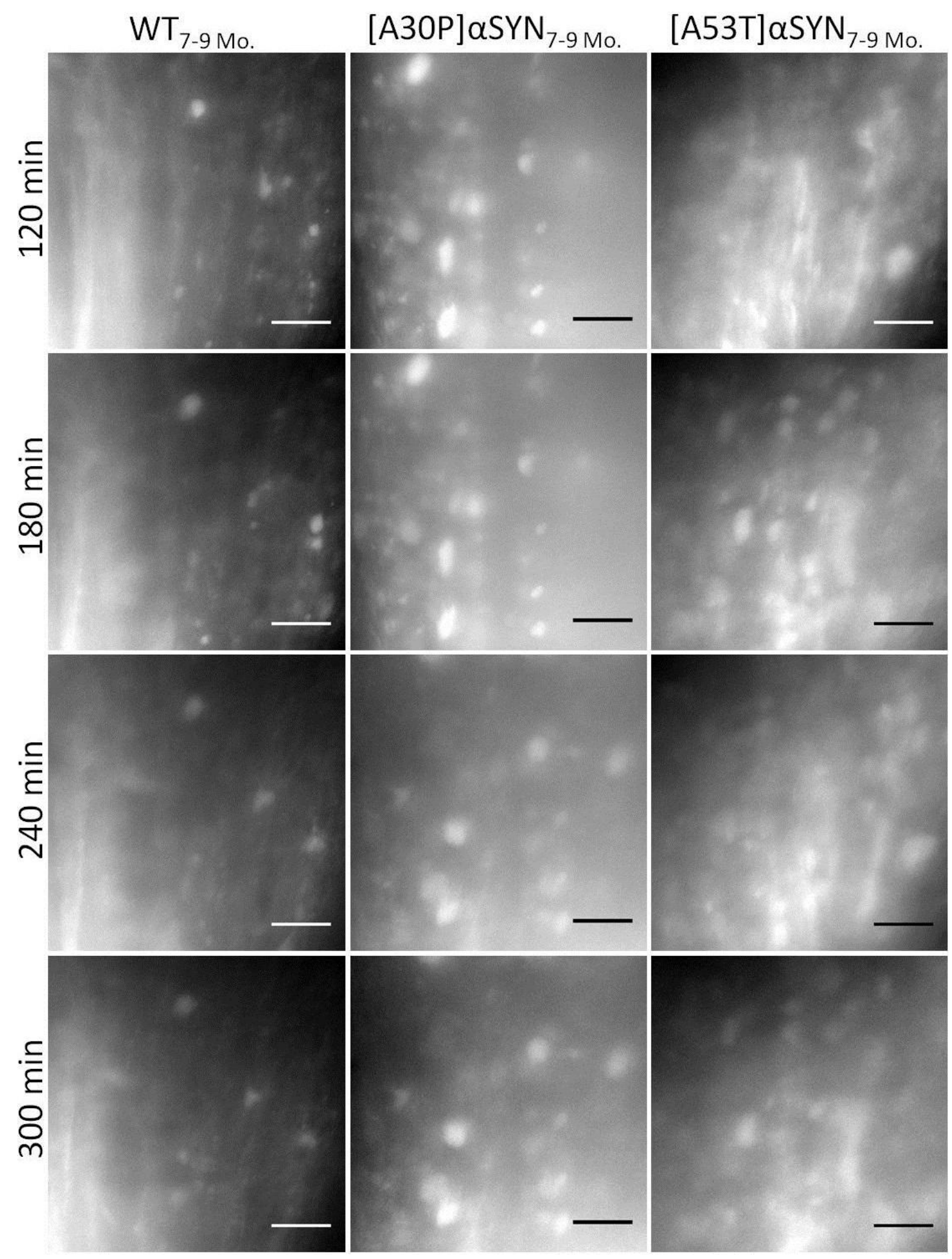

Abbildung 15: Exemplarische Additionsbilder aus Live-Imagings von WT- und

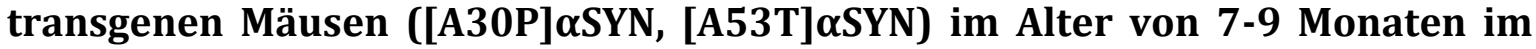
Zeitraum 120-300 Minuten nach Applikation von Kalzium-Ionophor. Von unten nach oben: proximal nach distal. Maßstabsbalken: $20 \mu \mathrm{m}$. 
Nun galt es, den bildmorphologisch sichtbaren Verlauf der Bulb-Formierung der transgenen MP-Mausmodelle [A30P] $\alpha$ SYN und [A53T] $\alpha$ SYN zu quantifizieren und mit den Verläufen der altersentsprechenden Wildtyp-Kontrollen zu vergleichen.

An dieser Stelle muss darauf hingewiesen werden, dass zur statistischen Auswertung nur kontinuierliche Messreihen verwendet wurden. Live-Imagings, deren Messwerte zu einem oder mehreren Zeitpunkten Lücken aufwiesen, wurden nicht berücksichtigt. Dies war Bedingung zur Durchführung des für diese Art von Daten bevorzugten statistischen Test: die Two-way Repeated Measures ANOVA. Bei der folgenden Statistik zu den transgenen Versuchstieren (Abbildungen 16-19) war aus diesem Grund der Messzeitpunkt 300 Minuten ausgespart, da sich gegen Ende der Live-ImagingExperimente vermehrt Lücken in den Messreihen zeigten und dieser Zeitpunkt für die zugrundeliegende Fragestellung weniger relevant war.

Abbildung 16 zeigt die Verläufe der Bulb-Entstehung junger (Alter: 3-5 Monate) [A53T] $\alpha$ SYN-Tiere $(n=5)$ mit der altersentsprechenden Wildtypkontrolle $(n=8) .30$ 60 Minuten nach der Applikation von Kalzium-Ionophor begann in der transgenen Kohorte die Bulb-Formierung (Anstieg der Bulb-Verteilungsdichte) und erreichte ihr Plateau 120 Minuten nach Ionophor-Kontakt. Bei der Wildtypkontrolle begann die Bulb-Formierung etwas später zwischen den Zeitpunkten 60 und 90 Minuten. Die Two-way Repeated Measures ANOVA wies der transgenen Kohorte [A53T] $\alpha \mathrm{SYN}$ in Betrachtung des gesamten Verlaufs der Bulb-Entstehung eine signifikant höhere BulbVerteilungsdichte nach (Source of variation: Interaction: $p<0,01$ ). Der Post-hoc-Test Sidak's multiple comparisons test betrachtete den Unterschied der BulbVerteilungsdichte zu den einzelnen Messzeitpunkten. Hier zeigte sich ein statistisch signifikanter Unterschied $(\mathrm{p}<0,05)$ zu den Zeitpunkten 120 und 180 Minuten. 


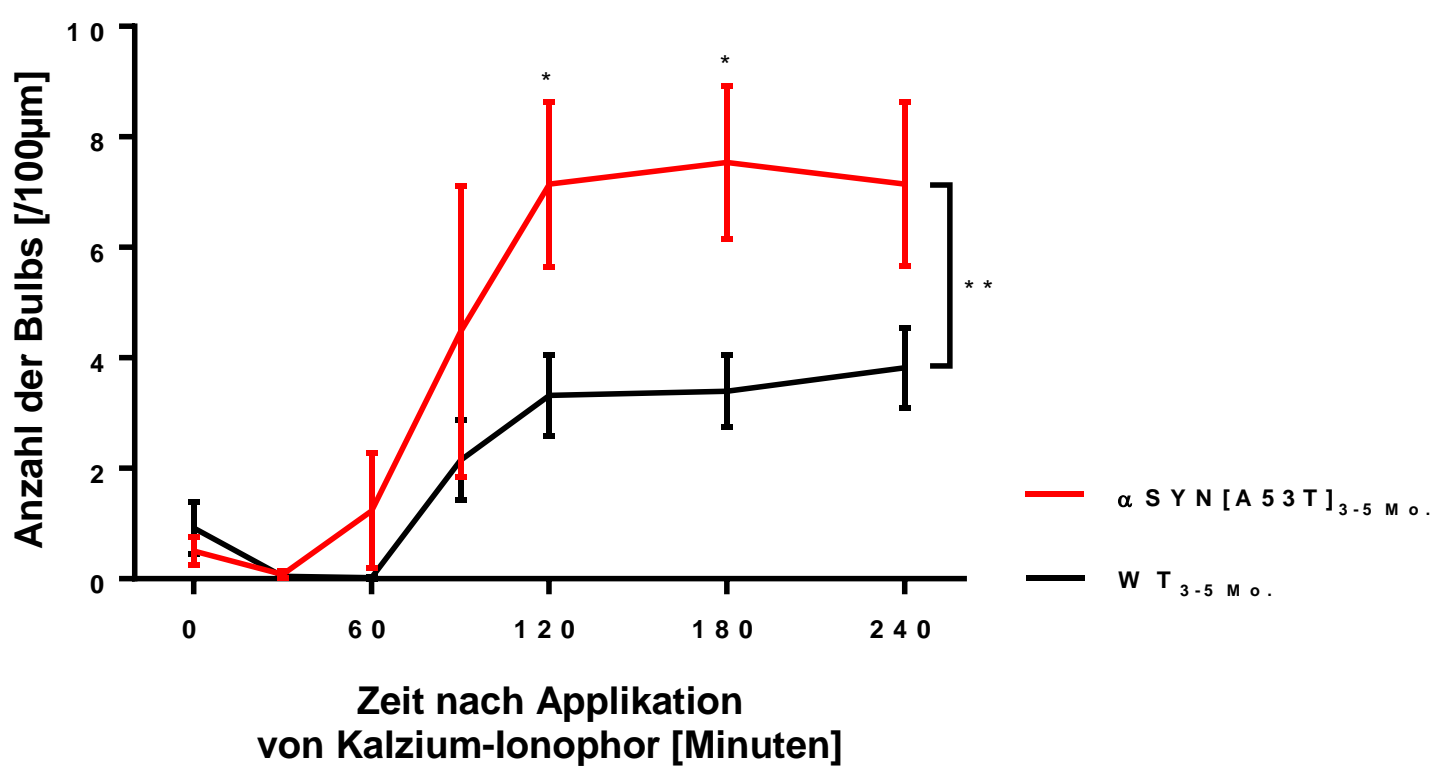

Abbildung 16: [A53T] $\alpha$ SYN-Mäuse im Alter von 3-5 Monaten zeigten eine signifikant stärkere Erhöhung der Bulb-Verteilungsdichte als Wildtypmäuse desselben Alters. Aufgetragen ist die Bulb-Verteilungsdichte als Anzahl der Bulbs pro $100 \mu \mathrm{m}$ Axonlänge (Ordinatenachse) in Abhängigkeit von der Zeit nach Applikation von Kalzium-Ionophor [Minuten] (Abszissenachse). Vergleichend gegenübergestellt werden hier Verläufe der Bulb-Verteilungsdichte von [A53T] $\alpha$ SYN-Mäusen (rot, n=5) und Wildtypmäusen (schwarz, $\mathrm{n}=8$ ) im Alter von 3-5 Monaten. Statistische Tests: Two-way Repeated Measures ANOVA (eckige Klammer): $p<0,01$ (**); Sidak's multiple comparisons test: Vergleich der Messwerte beider Kohorten (rot und schwarz) zu unterschiedlichen Zeitpunkten (Sternchen über den Fehlerbalken der roten Kurve): $p<0,05$ (*); Fehlerbalken: Standardfehler des arithmetischen Mittelwerts (SEM).

Die älteren [A53T] $\alpha$ SYN-Tiere zeigten ähnliche Verläufe der Bulb-Verteilungsdichte..

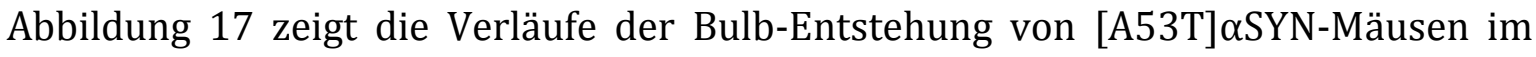
Alter von 7-9 Monaten $(n=5)$ und der altersentsprechenden Wildtypkontrolle $(n=5)$. Die Kurven von transgenen und Wildtyptieren verliefen zunächst nahezu parallel. Ab dem Zeitpunkt 60 Minuten begann bei beiden Kohorten die Bulb-Formierung, wobei die [A53T] $\alpha$ SYN-Tiere einen schnelleren Anstieg der Bulb-Verteilungsdichte zeigten als die Wildtypkontrolle. Schließlich erreichten beide Gruppen 120 Minuten nach Ionophor-Kontakt ein Plateau der Bulb-Verteilungsdichte. Wie bei den jungen [A53T] $\alpha$ SYN-Tieren zeigte sich in der Two-way Repeated Measures ANOVA für den gesamten Verlauf eine signifikant höhere Bulb-Verteilungsdichte bei den [A53T] $\alpha$ SYN-Tieren gegenüber der Wildtypkontrolle (Source of variation: Interaction: $p<0,05$ ). In der spezifischen Betrachtung der Zeitpunkte (Sidak's multiple comparisons 
test) bestätigte sich diese Beobachtung für die Zeitpunkte $120(p<0,01) ; 180(p<0,01)$ und 240 Minuten $(p<0,05)$.

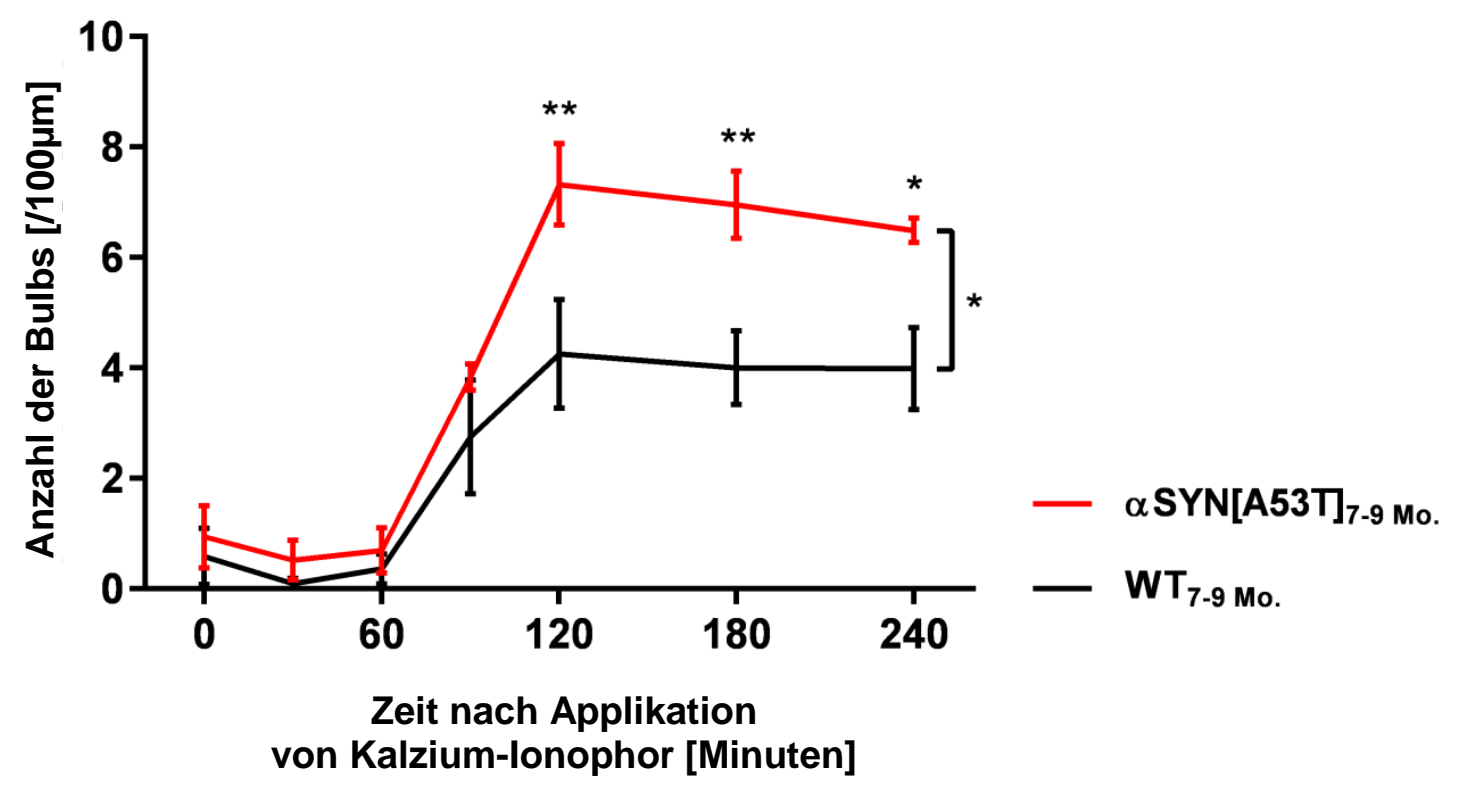

Abbildung 17: [A53T] $\alpha$ SYN-Mäuse im Alter von 7-9 Monaten zeigten eine signifikant stärkere Erhöhung der Bulb-Verteilungsdichte als Wildtypmäuse desselben Alters. Aufgetragen ist die Bulb-Verteilungsdichte als Anzahl der Bulbs pro $100 \mu \mathrm{m}$ Axonlänge (Ordinatenachse) in Abhängigkeit von der Zeit nach Applikation von Kalzium-Ionophor [Minuten] (Abszissenachse). Vergleichend gegenübergestellt werden hier die Verläufe von [A53T] $\alpha$ SYN-Mäusen (rot, $n=5$ ) und Wildtypmäusen (schwarz, $\mathrm{n}=5$ ) im Alter von 7-9 Monaten. Statistische Tests: Two-way Repeated Measures ANOVA (eckige Klammer): $p<0,05\left(^{*}\right)$; Sidak's multiple comparisons test: Vergleich der Messwerte beider Kohorten (rot und schwarz) zu unterschiedlichen Zeitpunkten (Sternchen über den Fehlerbalken der roten Kurve): $p<0,01\left(^{* *}\right) ; p<0,05\left(^{*}\right)$; Fehlerbalken: Standardfehler des arithmetischen Mittelwerts (SEM).

Neben den [A53T] $\alpha$ SYN-Mäusen standen als zweites transgenes MP-Tiermodell Mäuse mit der [A30P] $\alpha$ SYN-Mutation im Fokus dieser Arbeit. Auch hier wurden junge (Alter: 3-5 Monate, $n=8$ ) und alte (Alter: 7-9 Monate, $n=10$ ) Versuchstiere mit ihren jeweiligen altersentsprechenden Wildtypkontrollen (Alter: 3-5 Monate, n=8; Alter: 79 Monate, n=5) verglichen. Abbildung 18 zeigt den Verlauf der Bulb-Verteilungsdichte junger $[\mathrm{A} 30 \mathrm{P}] \alpha \mathrm{SYN}-M a ̈ u s e$ und der Wildtypkontrolle desselben Alters. Eine erste Zunahme der Bulb-Verteilungsdichte erfolgte bei transgenen und Wildtyptieren $60 \mathrm{Mi}$ nuten nach Exposition der ON mit Kalzium-Ionophor. Zum Zeitpunkt 120 Minuten erreichten die Verläufe ein Plateau. Die durchschnittlichen Werte der BulbVerteilungsdichte lagen bei der [A30P] $\alpha$ SYN-Kohorte leicht höher als bei der Wildtypkontrolle. Insgesamt fiel das Ausmaß der Bulb-Formierung deutlich geringer aus 
als bei der [A53T] $\alpha$ SYN-Kohorte desselben Alters und unterschied sich nicht signifikant vom Verlauf der Bulb-Verteilungsdichte der altersentsprechenden Wildtypkontrolle (Two-way Repeated Measures ANOVA: Source of variation: Interaction: $p>0,05$; Sidak's multiple comparisons test: $p>0,05$ für alle Zeitpunkte).

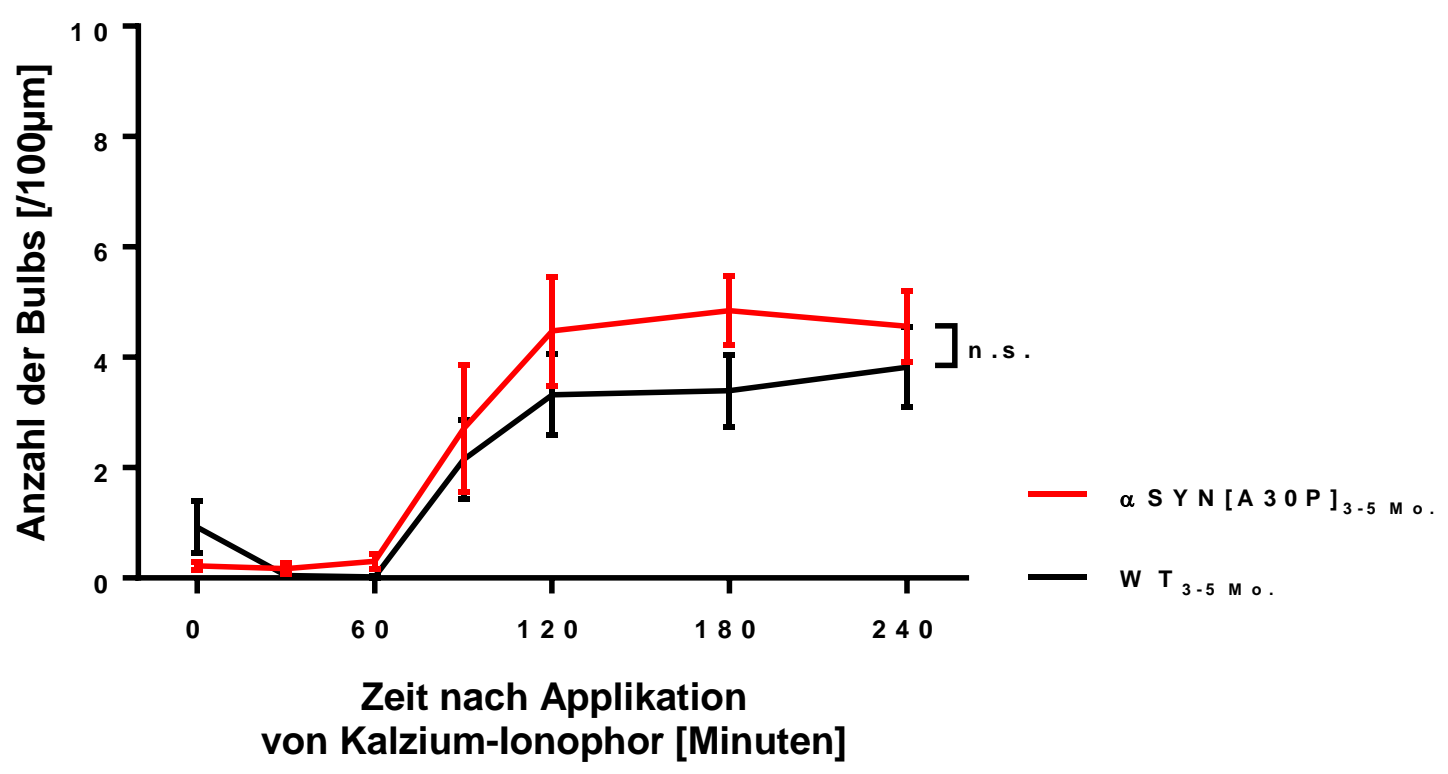

Abbildung 18: Das Ausmaß der Bulb-Formierung von [A30P] $\alpha$ SYN-Mäusen im Alter von 3-5 Monaten unterschied sich nicht signifikant von demjenigen der Wildtypmäuse desselben Alters. Aufgetragen ist die Bulb-Verteilungsdichte als Anzahl der Bulbs pro $100 \mu \mathrm{m}$ Axonlänge (Ordinatenachse) in Abhängigkeit von der Zeit nach Applikation von Kalzium-Ionophor [Minuten] (Abszissenachse). Vergleichend gegenübergestellt werden hier Verläufe der Bulb-Formierung von [A30P] $\alpha$ SYNMäusen (rot, $\mathrm{n}=8$ ) und Wildtypmäusen (schwarz, $\mathrm{n}=8$ ) im Alter von 3-5 Monaten. Statistische Tests: Two-way Repeated Measures ANOVA (eckige Klammer): p>0,05 (nicht signifikant: n.s.); Sidak's multiple comparisons test: Vergleich der Messwerte beider Kohorten (rot und schwarz) zu unterschiedlichen Zeitpunkten (nicht gezeigt): p>0,05 für alle Zeitpunkte (nicht signifikant); Fehlerbalken: Standardfehler des arithmetischen Mittelwerts (SEM).

Die Versuchsreihe mit alten [A30P] $\alpha$ SYN-Tieren brachte ähnlicher Ergebnisse hervor. Abbildung 19 zeigt die Verläufe der Bulb-Verteilungsdichte der [A30P] $\alpha$ SYN-Kohorte und ihrer Wildtypkontrolle im Alter von 7-9 Monaten. Beide Kohorten zeigten erstmals zum Zeitpunkt 60 Minuten einen Anstieg der Bulb-Verteilungsdichte. Die Kurve der Wildtypkontrolle erreichte ihr Plateau zum Zeitpunkt 120 Minuten. Bis zu diesem Zeitpunkt liefen die Kurven nahezu deckungsgleich. Bis zum Zeitpunkt 180 Minuten stiegen die Werte der Bulb-Verteilungsdichte bei der transgenen Kohorte noch an und erreichten ein Plateau zum Zeitpunkt 180 Minuten. Die beobachteten leichten 
Unterschiede erwiesen sich in der statistischen Analyse jedoch als nicht signifikant (Two-way Repeated Measures ANOVA: Source of variation: Interaction: p>0,05; Sidak's multiple comparisons test: $p>0,05$ für alle Zeitpunkte).

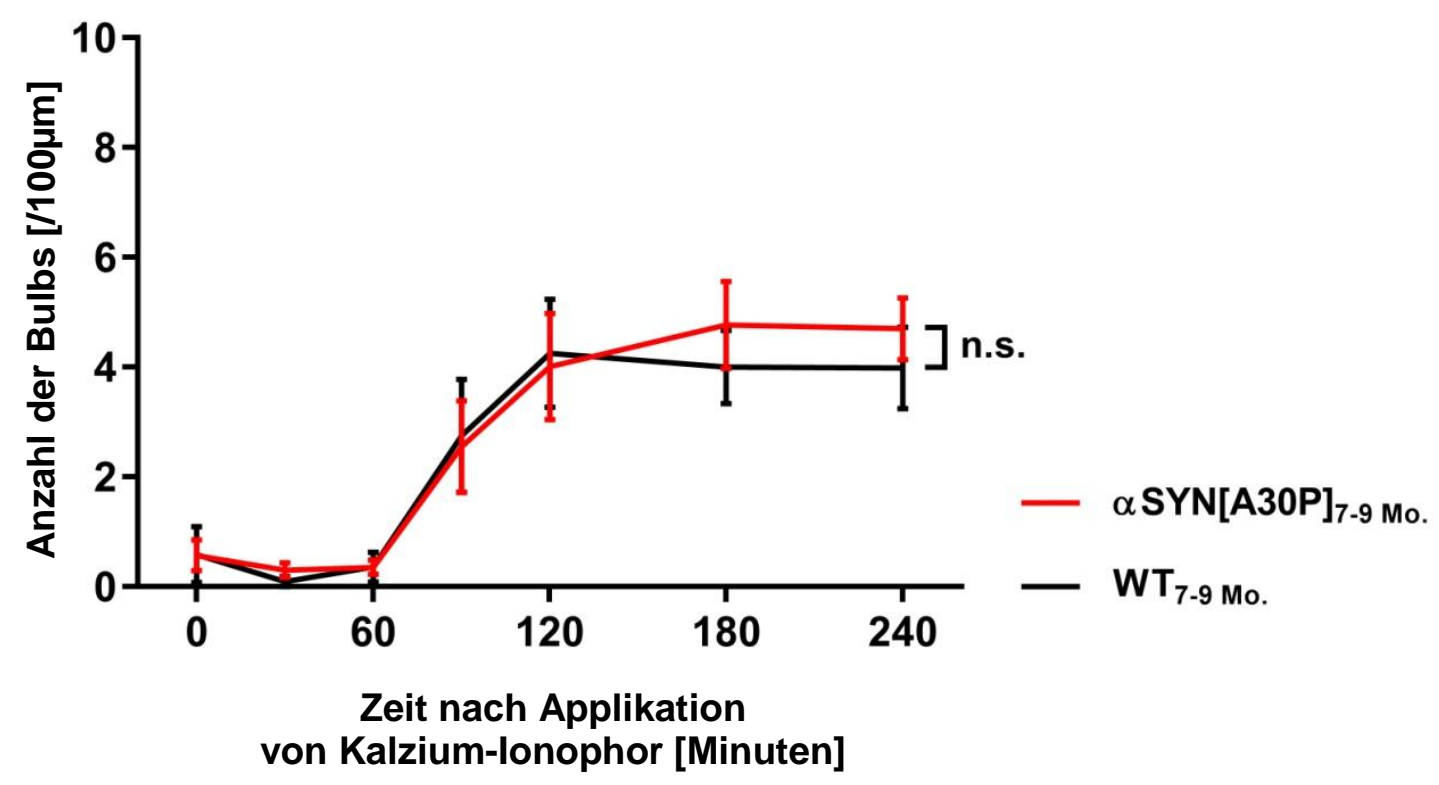

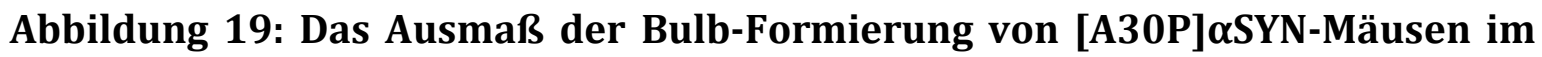
Alter von 7-9 Monaten unterschied sich nicht signifikant von demjenigen der Wildtypmäuse desselben Alters. Aufgetragen ist die Bulb-Verteilungsdichte als Anzahl der Bulbs pro $100 \mu \mathrm{m}$ Axonlänge (Ordinatenachse) in Abhängigkeit von der Zeit nach Applikation von Kalzium-Ionophor [Minuten] (Abszissenachse). Vergleichend gegenübergestellt werden hier axonale Degenerationsverläufe von [A30P] $\alpha \mathrm{SYN}$ Mäusen (rot, $n=10$ ) und Wildtypmäusen (schwarz, n=5) im Alter von 7-9 Monaten. Statistische Tests: Two-way Repeated Measures ANOVA (eckige Klammer): $p>0,05$ (nicht signifikant: n.s.); Sidak's multiple comparisons test: Vergleich der Messwerte beider Kohorten (rot und schwarz) zu unterschiedlichen Zeitpunkten (nicht gezeigt): p>0,05 für alle Zeitpunkte (nicht signifikant); Fehlerbalken: Standardfehler des arithmetischen Mittelwerts (SEM). 
Innerhalb jedes untersuchten Genotyps wurden zwei Kohorten gebildet mit unterschiedlichem Alter der Versuchstiere. Es ergab sich deshalb die Frage, ob nicht nur der Genotyp, sondern - innerhalb der untersuchten Genotypen - auch das Alter der Versuchstiere Einfluss auf die Dynamik der Bulb-Formierung hatte. Abbildung 20 zeigt die Gegenüberstellung der Verläufe der Bulb-Verteilungsdichte junger (Alter: 35 Monate) und alter (Alter: 7-9 Monate) Tiere für die Genotypen [A53T] $\alpha$ SYN (jung/alt jeweils $n=5$ ), [A30P] $\alpha$ SYN (jung: $n=8$; alt: $n=10$ ) und Wildtyp (jung/alt jeweils $n=5)$. Es fiel bei allen Genotypen auf, dass die Kurven der BulbVerteilungsdichte sich nur wenig unterschieden. Die Verläufe der Bulb-Formierung junger und alter Tiere präsentierten sich sowohl in Ausmaß als auch Dynamik sehr ähnlich. Die Two-way Repeated Measures ANOVA ergab so auch keinen statistisch signifikanten Unterschied zwischen jungen und alten Versuchstieren innerhalb eines Genotyps (Source of variation: Interaction: $p>0,05$ ). 
A

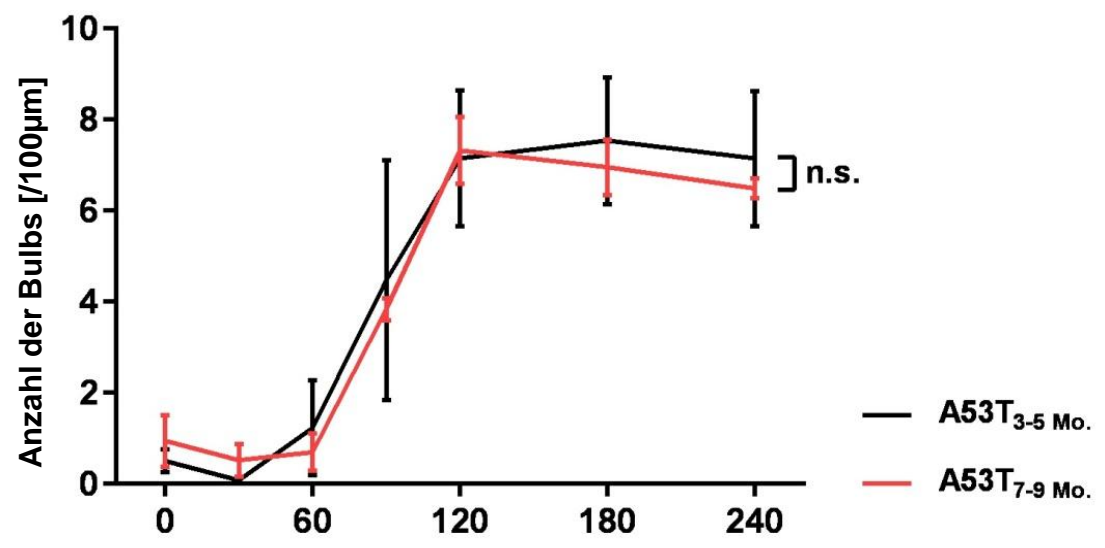

B

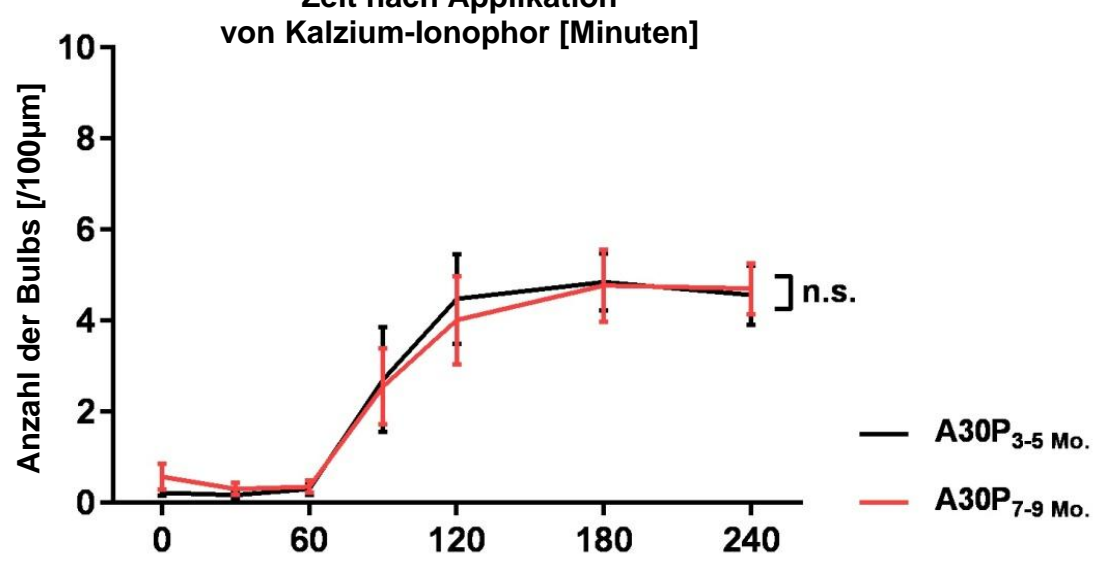

C

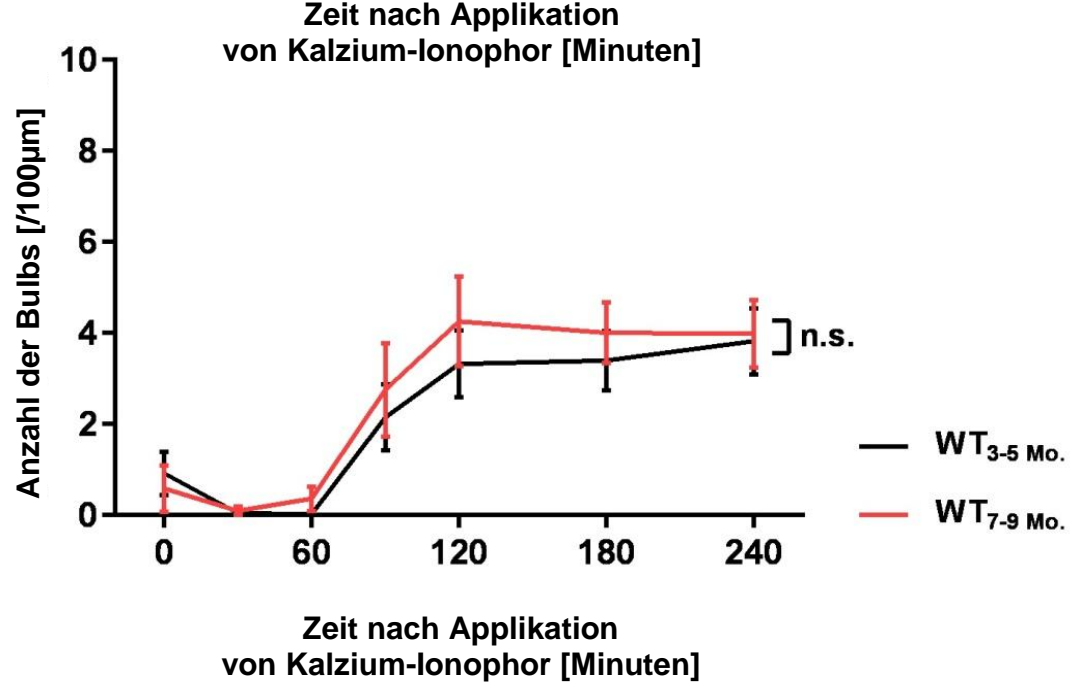

Abbildung 20: Das Alter der Versuchstiere beeinflusste nicht den Verlauf der Bulb-Formierung bei den Genotypen [A53T] $\alpha$ SYN, [A30P] $\alpha$ SYN und WT. Aufgetragen ist die Bulb-Verteilungsdichte als Anzahl der Bulbs pro $100 \mu \mathrm{m}$ Axonlänge (Ordinatenachse) in Abhängigkeit von der Zeit nach Applikation von Kalzium-Ionophor [Minuten] (Abszissenachse). Vergleichend gegenübergestellt werden hier axonale Degenerations-verläufe junger (Alter: 3-5 Monate, schwarz) und alter (Alter: 7-9 Monate, rot) Mäuse, die jeweils demselben Genotyp angehören. A: [A53T] $\alpha$ SYN (jung/alt jeweils $n=5$ ), B: $[A 30 P] \alpha S Y N$ (jung: $n=8$; alt: $n=10$ ), C: WT (jung/alt jeweils $n=5$ ). Statistischer Test: Two-way Repeated Measures ANOVA (eckige Klammer): p>0,05; nicht signifikant (n.s.); Fehlerbalken: Standardfehler der arithmetischen Mittelwerts (SEM). 
Neben der Bulb-Verteilungsdichte wurde ebenfalls der Bulb-Durchmesser zu verschiedenen Zeitpunkten bestimmt. Die Größe der Stichproben unterschied sich - anders als bei den Experimenten zur Bulb-Verteilungsdichte - nicht nur zwischen den Genotypen bzw. Altersgruppen, sondern auch zwischen den Zeitpunkten, da die Anzahl der gemessenen Bulbs sowohl zwischen den genannten Versuchstierkohorten als auch zwischen den Zeitpunkten stark variierte, jeder einzelne Bulb jedoch in der Analyse des Bulb-Diameters einen eigenen, unabhängigen Datenpunkt darstellte. Tabelle 2 bietet eine Übersicht über die Stichprobengrößen zu allen gemessenen Zeitpunkten zwischen 90 und 300 Minuten.

Tabelle 2: Stichprobengrößen zur Analyse des Bulb-Durchmessers.

\begin{tabular}{|c|c|c|c|}
\hline & $\mathrm{WT}_{\text {3-5 Mo. }}$ & {$[\mathrm{A} 30 \mathrm{P}] \mathrm{aSYN} \mathrm{N}_{3-5 \mathrm{Mo}}$} & [A53T]aSYN ${ }_{3-5}$ Mo. \\
\hline 90 Min. & 438 & 460 & 341 \\
\hline $120 \mathrm{Min}$. & 738 & 690 & 601 \\
\hline $180 \mathrm{Min}$. & 761 & 829 & 693 \\
\hline 240 Min. & 752 & 810 & 637 \\
\hline \multirow[t]{2}{*}{300 Min. } & 796 & 760 & 674 \\
\hline & $\mathrm{WT}_{\text {7-9 Mo. }}$ & [A30P] $]$ SYYN & {$[\mathrm{A53T}] \mathrm{aSYN}$ 7-9 Mo. } \\
\hline 90 Min. & 294 & 466 & 376 \\
\hline 120 Min. & 487 & 641 & 700 \\
\hline 180 Min. & 475 & 668 & 670 \\
\hline 240 Min. & 449 & 479 & 610 \\
\hline 300 Min. & 456 & 393 & 404 \\
\hline
\end{tabular}

Abbildung 21 zeigt für alle gemessenen Zeitpunkte zwischen 90 und 300 Minuten nach Applikation von Kalzium-Ionophor die durchschnittlichen Bulb-Durchmesser der Genotypen [A53T] $\alpha$ SYN, [A30P] $\alpha$ SYN und Wildtyp. Unterschieden wurde wieder in Tiere im Alter von 3-5 Monaten (Abbildung 21A) und Tiere im Alter von 7-9 Monaten (Abbildung 21B). Über den Zeitpunkt des Beginns der Bulb-Formierung (90 Minuten) bis zum Ende der Messungen zum Zeitpunkt 300 Minuten zeigte sich bei den jungen Tieren ein leichter Anstieg des Bulb-Durchmessers über die Zeit. Insgesamt waren die Bulbs bei jungen [A53T] $\alpha$ SYN-Tieren zu allen Zeitpunkten deutlich kleiner als bei $[\mathrm{A} 30 \mathrm{P}] \alpha \mathrm{SYN}$ - und Wildtyp-Tieren, die sich kaum voneinander unterschieden. Bei 
der Versuchsreihe mit den älteren Tieren bestätigte sich diese Beobachtung nicht. Der Bulb-Durchmesser zeigte bei keiner der Versuchstierkohorten über die gemessenen Zeitpunkte hinweg einen Trend zu größeren oder kleineren Bulbs, innerhalb eines Zeitpunkts ergaben sich dennoch teilweise große Unterschiede zwischen den Gruppen. In der Ordinary One-way ANOVA zeigten sich so statistisch signifikante Unterschiede zwischen den Genotypen beider Altersgruppen zu jedem gemessenen Zeitpunkt zwischen 90 und 300 Minuten (siehe Abbildung 21). Die Ergebnisse der entsprechenden Post-hoc-Tests sind in den nachfolgenden Abbildungen 22-24 dargestellt. Diese Streudiagramme zeigen jeden gemessenen Bulb-Durchmesser als eigenen Datenpunkt und ermöglichen einen detaillierten Blick auf das erhobene Datenmaterial. Der in diesen Abbildungen ebenfalls dargestellte Tukey's multiple comparisons test wies nach, dass junge [A53T] $\alpha$ SYN-Tiere hochsignifikant $(p<0,0001)$ kleinere Bulbs ausbildeten als [A30P] $\alpha$ SYN- und Wildtyp-Tiere desselben Alters, die sich - außer zum Zeitpunkt 180 Minuten: p<0,05 - nicht signifikant voneinander unterschieden. Bei alten Tieren ergaben sich im Tukey's multiple comparisons test teilweise ebenso hochsignifikante Unterschiede zwischen den Genotypen, allerdings variierten die Ergebnisse stark zwischen den Zeitpunkten. 
A

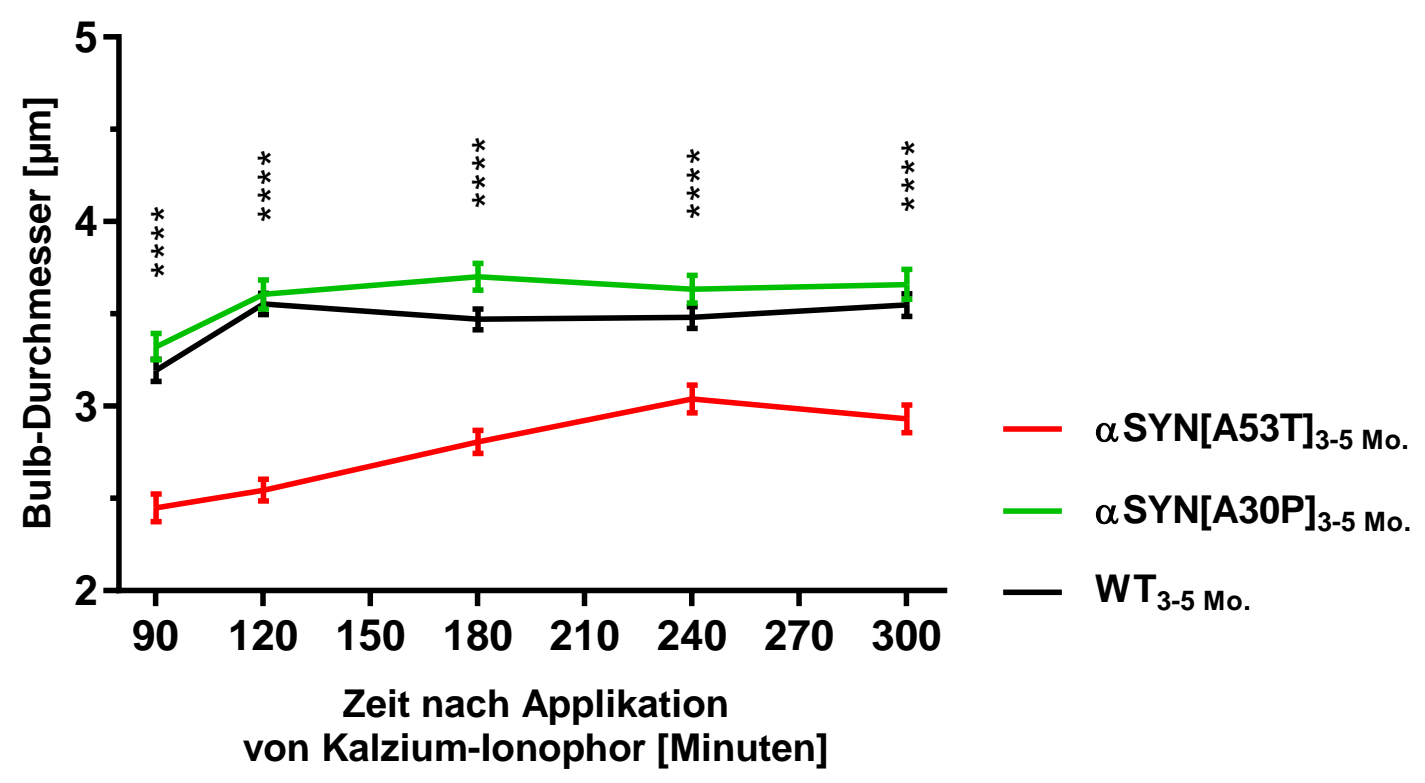

B

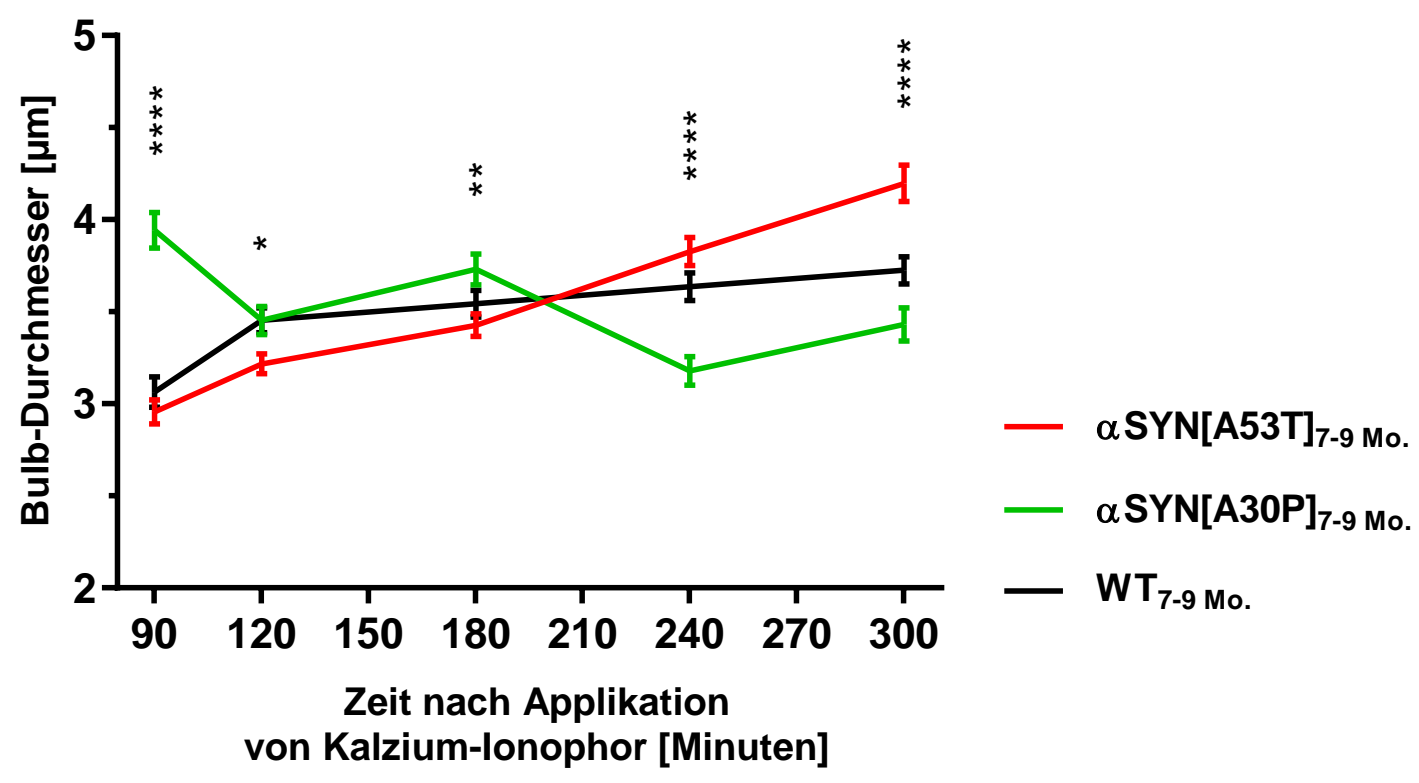

Abbildung 11: In Betrachtung des Bulb-Durchmessers ergaben sich bei jungen und alten Versuchstieren signifikante Unterschiede zwischen den Genotypen [A53T] $\alpha$ SYN, [A30P] $\alpha$ SYN und WT. Gezeigt werden die durchschnittlichen BulbDurchmesser $[\mu \mathrm{m}]$ (Ordinatenachse) aller gemessenen Bulbs zwischen 90 und 300 Minuten nach Applikation von Kalzium-Ionophor (Abszissenachse) bei jungen (Alter: 3-5 Monate, A) und alten (Alter: 7-9 Monate, B) Versuchstieren. Rot: [A53T] $\alpha \mathrm{SYN}$, grün: $[\mathrm{A} 30 \mathrm{P}] \alpha \mathrm{SYN}$, schwarz: WT. Statistischer Test: Ordinary One-way ANOVA, $p<0,05$ $\left({ }^{*}\right) ; p<0,01\left(^{* *}\right) ; p<0,0001\left(^{* * *}\right) ;$ Fehlerbalken: Standardabweichung des arithmetischen Mittelwerts. 
A

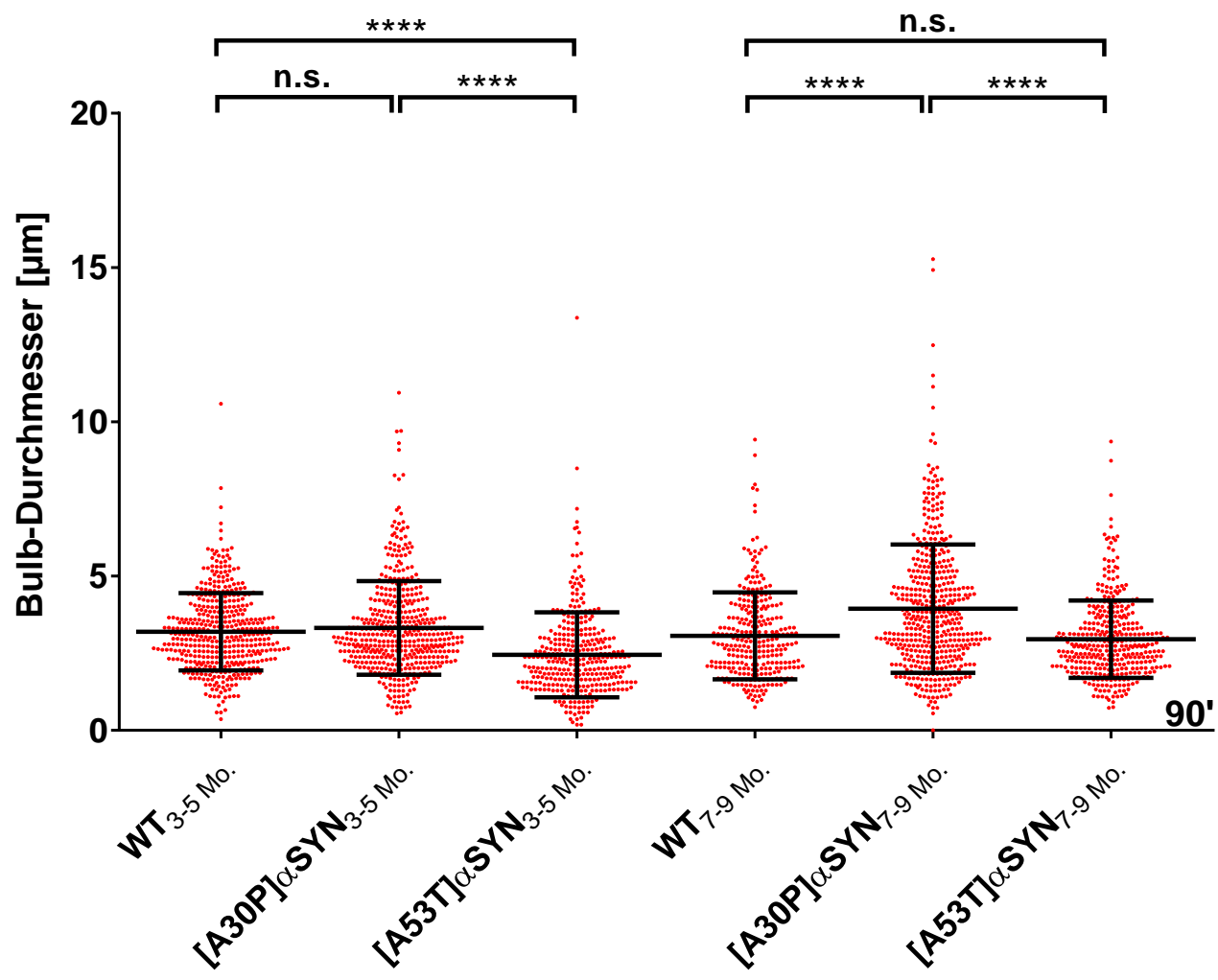

B

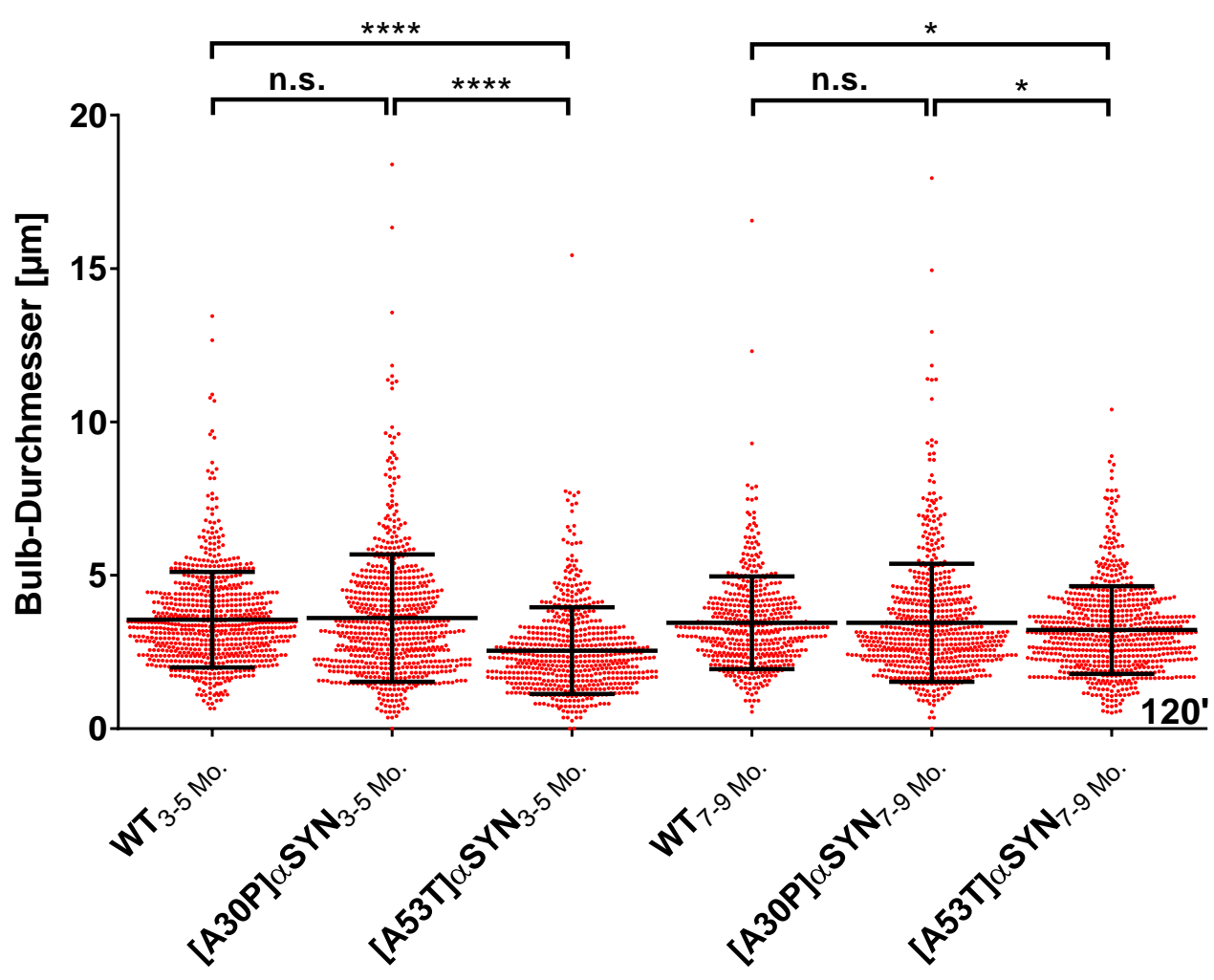

Abbildung 22: Verteilung der Bulb-Durchmesser 90 und 120 Minuten nach der Applikation von Kalzium-Ionophor. A: 90 Minuten, B: 120 Minuten. Jeder rote Punkt repräsentiert den Durchmesser eines Bulbs. Abzissenachse: Genotypen. Ordinatenachse: Bulb-Durchmesser $[\mu \mathrm{m}]$. Statistischer Test (eckige Klammern): Tukey's multiple comparisons test: $p>0,05$ (n.s.); $p<0,05$ ( $^{*}$ ); $p<0,0001$ (***). Fehlerbalken: Standardabweichung des arithmetischen Mittelwerts. 
A

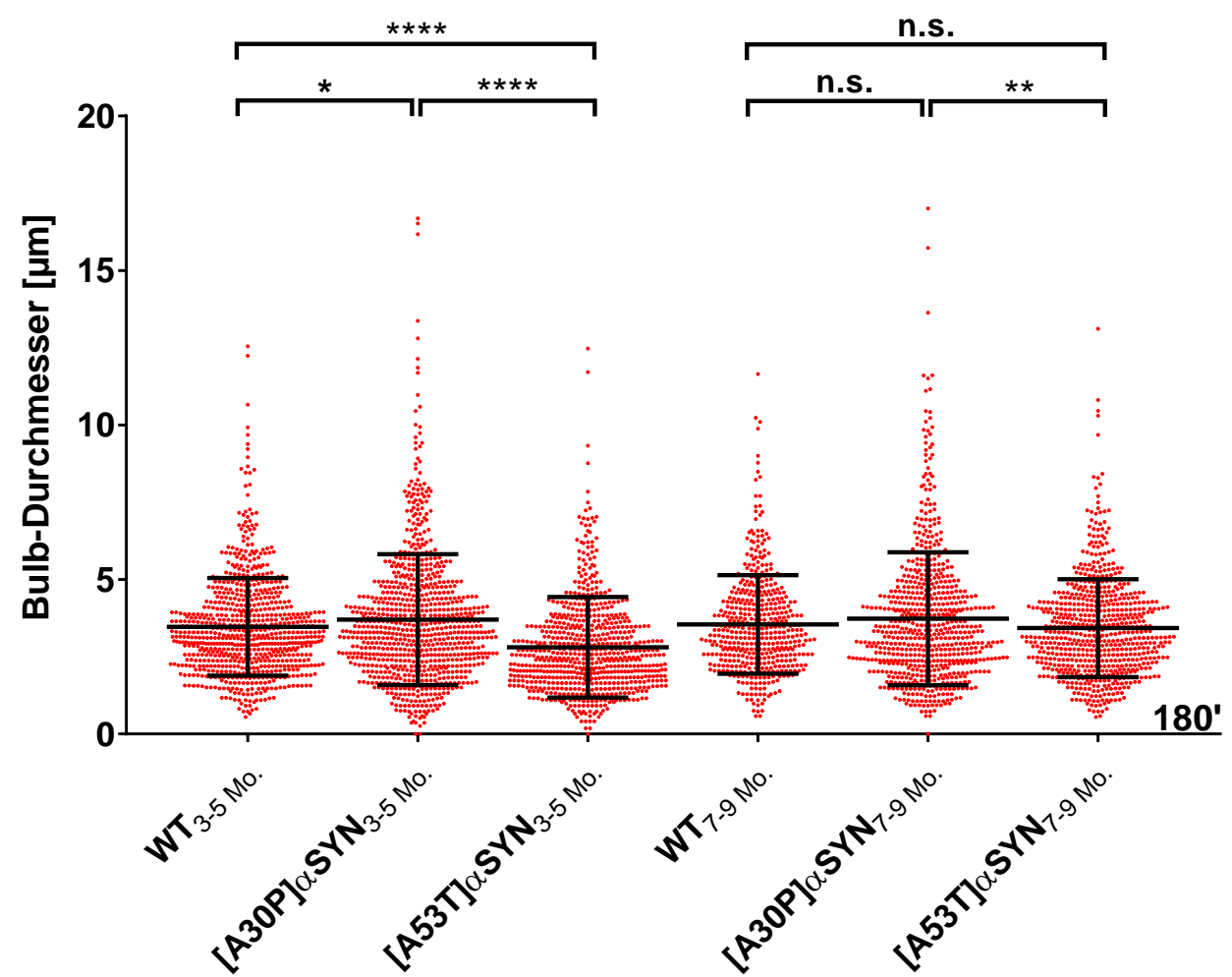

B

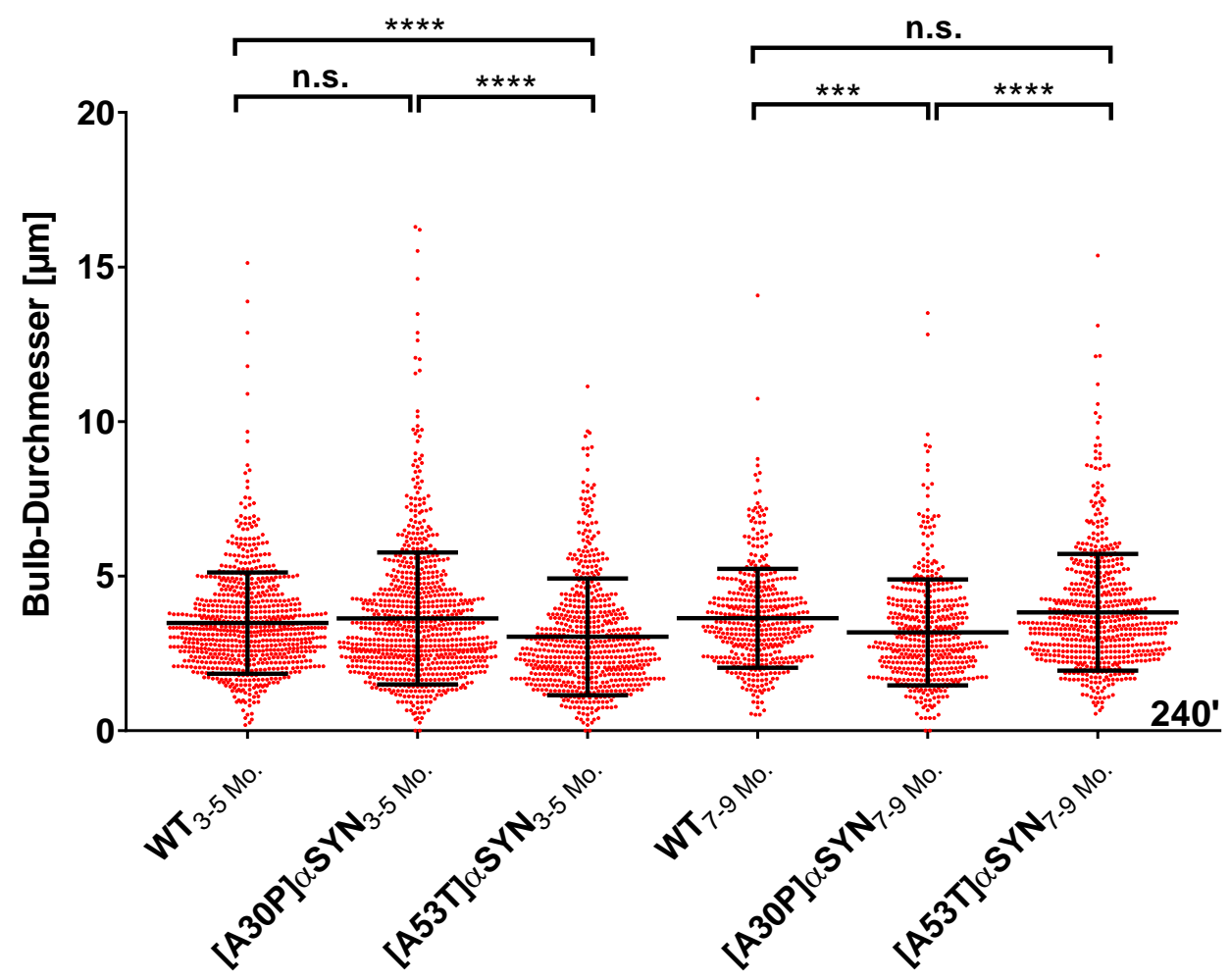

Abbildung 23: Verteilung der Bulb-Durchmesser 180 und 240 Minuten nach der Applikation von Kalzium-Ionophor. A: 180 Minuten, B: 240 Minuten. Jeder rote Punkt repräsentiert den Durchmesser eines Bulbs. Abzissenachse: Genotypen. Ordinatenachse: Bulb-Durchmesser $[\mu \mathrm{m}]$. Statistischer Test (eckige Klammern): Tukey's multiple comparisons test: $p>0,05$ (n.s.); $p<0,05\left(^{*}\right) ; p<0,01\left(^{* *}\right) ; p<0,001\left(^{* * *}\right.$ ); $p<0,0001$ ${ }^{* * * *}$. Fehlerbalken: Standardabweichung des arithmetischen Mittelwerts. 


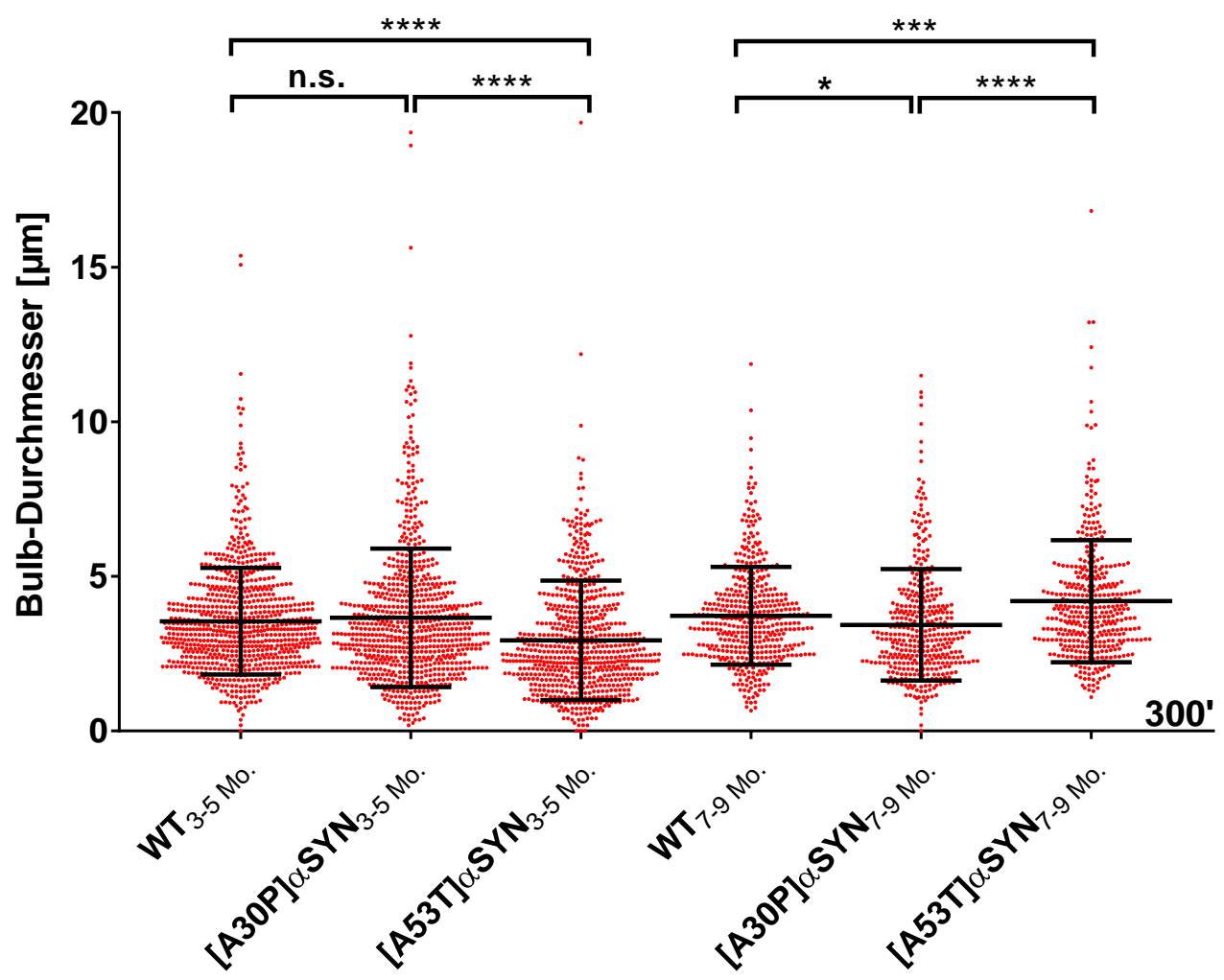

Abbildung 24: Verteilung der Bulb-Durchmesser 300 Minuten nach der Applikation von Kalzium-Ionophor. Jeder rote Punkt repräsentiert den Durchmesser eines Bulbs. Abzissenachse: Genotypen. Ordinatenachse: Bulb-Durchmesser [ $\mu \mathrm{m}]$. Statistischer Test (eckige Klammern): Tukey's multiple comparisons test: $p>0,05$ (n.s.); $p<0,05\left(^{*}\right) ; p<0,001\left(^{* * *}\right) ; p<0,0001\left(^{* * *}\right)$. Fehlerbalken: Standardabweichung des arithmetischen Mittelwerts.

Zusätzlich wurden die Daten zum Bulb-Durchmesser unabhängig von den einzelnen Zeitpunkten ausgewertet, indem die Zeitpunkt-bezogenen Teildatensätze zu einem Gesamtdatensatz der jeweiligen Versuchstiergruppen zusammengefasst wurden. In Anbetracht des heterogenen Bildes des Bulb-Durchmessers bei alten Versuchstieren ermöglichte dies eine bessere Gesamtbetrachtung des Bulb-Durchmessers der einzelnen Genotypen und Altersgruppen. Abbildung 25 zeigt diese zusammengefassten durchschnittlichen Bulb-Durchmesser von jungen und alten Tieren der untersuchten Genotypen mit den dazu gehörigen 95\%-Konfidenzintervallen; das Streuungsverhalten des Datensatzes wurde bereits gezeigt, hier stand die statistische Analyse im Vordergrund. Bei den jungen Tieren bestätigte sich das Bild aus den vorherigen Abbildungen. Die Bulbs der jungen [A53T] $\alpha$ SYN-Tiere waren hochsignifikant (Ordinary One-way ANOVA: $p<0,0001 ;$ Tukey's multiple comparisons test: $p<0,0001 \mathrm{zu}$ [A30P] $\alpha S Y N$ und WT) kleiner als bei den anderen Genotypen desselben Alters. Diese unterschieden sich ebenfalls signifikant voneinander, allerdings weniger deutlich 
(Tukey's multiple comparisons test: $p<0,01)$. Bei alten Versuchstieren ergaben sich keine signifikanten Unterschiede in der Bulb-Größe (Ordinary One-way ANOVA: $p>0,05)$.

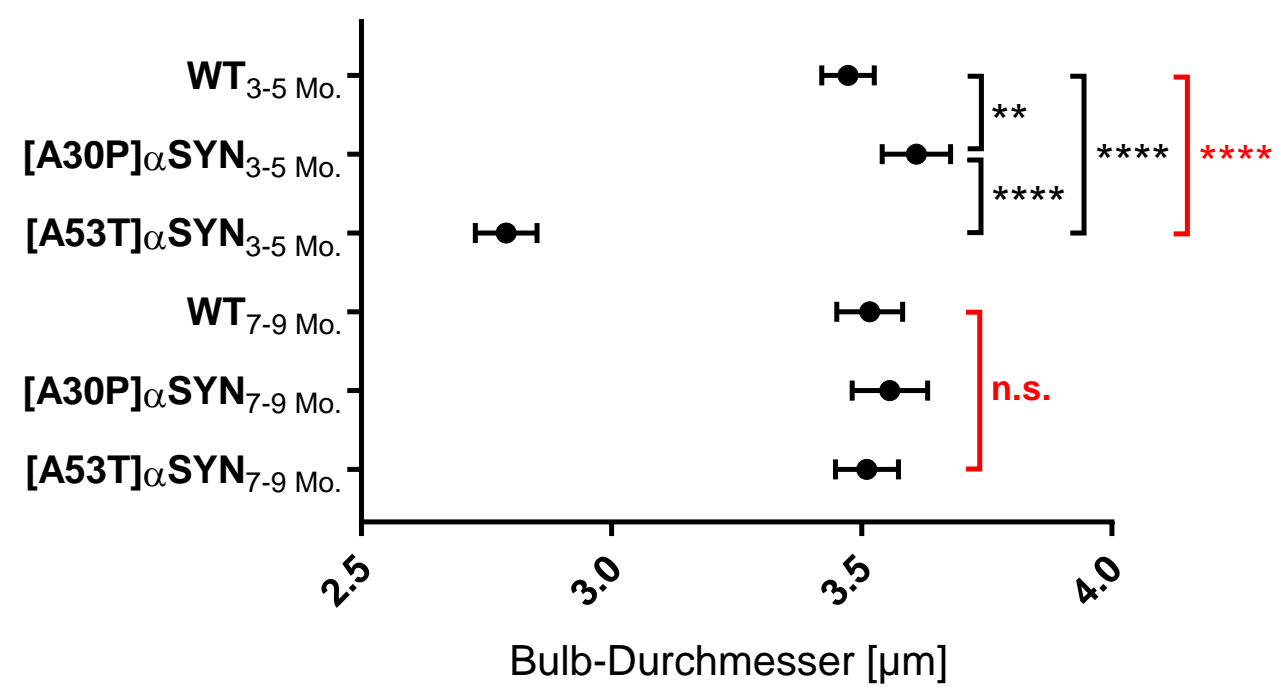

Abbildung 25: Zusammengefasste Verteilung der Bulb-Durchmesser aller Zeitpunkte. Die schwarzen Punkte repräsentieren die durchschnittlichen BulbDurchmesser (arithmetischer Mittelwert), berechnet aus den Daten aller Zeitpunkte. Abzissenachse: Bulb-Durchmesser $[\mu \mathrm{m}]$. Ordinatenachse: Genotypen. Statistische Tests: Ordinary One-way ANOVA (rote, eckige Klammer): $p>0,05$ (n.s.); $p<0,0001$ ( ${ }^{* * * *}$ ); Tukey's multiple comparisons test (schwarze, eckige Klammer): $p<0,01{ }^{* *}$ ); $p<0,0001$ (***). Fehlerbalken: arithmetischer Mittelwert mit 95\%-Konfidenzintervall. 


\section{$4 \quad$ Diskussion}

\subsection{Zusammenfassung der Ergebnisse}

Das Protein $\alpha$ SYN und seine mutierten Formen [A53T] $\alpha$ SYN und [A30P] $\alpha$ SYN werden seit ihrer Entdeckung mit neurodegenerativen Erkrankungen wie dem MP in Verbindung gebracht. Die Neurotoxizität seiner verschiedenen Erscheinungsformen (Oligomere, Fibrillen, etc.) ist in zahlreichen in-vitro-Experimenten und tierexperimentellen Studien gezeigt worden. Allerdings konnte der Effekt von $\alpha$ SYN auf neuronale Degenerationsprozesse bis jetzt noch nicht in Echtzeit und am lebenden Versuchstier visualisiert und nachvollzogen werden.

Das Ziel der vorliegenden Arbeit bestand daher in der Untersuchung des Effekts der neuronalen Überexpression von $\alpha \mathrm{SYN}$ auf das Ausmaß und den Verlauf der akuten axonalen Degeneration. Methodische Grundlage war dabei ein in vivo Live-Imaging Verfahren, das den zeitlichen Verlauf der axonalen Degeneration nach der Induktion eines axonalen Kalzium-Einstroms visualisierte. Mit dieser Technik verglichen wir zwei transgene Parkinson-Mausmodelle mit den $\alpha$ SYN-Mutationen [A53T] und [A30P] mit altersentsprechenden Wildtypmäusen, jeweils im Alter von 3-5 und von 79 Monaten.

Zur Validierung der Live-Imaging-Experimente untersuchten wir mittels Retina-FlatMounts und Querschnitten des ON zunächst, ob eine suffiziente Transduktion der RGZ mit AAV-EGFP erfolgt war. Wie angestrebt zeigte sich eine suffiziente Transduktion vornehmlich eines peripheren Bereichs von Retina und ON. Im zweiten Schritt erfolgte der Nachweis der Expression von $\alpha$ SYN im ON der Versuchstiere. Mittels WB konnte gezeigt werden, dass es bereits nach 3-5 Monaten in den transgenen, homozygoten Tieren zu einer starken Expression von $\alpha$ SYN kam, während die ON der Wildtypen einen weitaus geringeren $\alpha \mathrm{SYN}-\mathrm{Gehalt}$ aufwiesen. Zudem wiesen die ON der $[\mathrm{A} 30 \mathrm{P}] \alpha \mathrm{SYN}$-Tiere einen signifikant geringeren $\alpha \mathrm{SYN}$-Gehalt als die $\mathrm{ON}$ der [A53T] $\alpha$ SYN-Tiere. 
Eine Herausforderung lag in der Optimierung des Live-Imaging-Verfahrens, das für die Anwendung an Mäusen angepasst werden musste. Die Modifikation der Operationstechnik erreichte einen wesentlich blutungsärmeren und schonenderen Zugang zum ON, was Live-Imaging Untersuchungen über einen Zeitraum von 5 h ermöglichte. Durch die Applikation eines Kalzium-Ionophors konnte reproduzierbar axonale Degeneration ausgelöst werden.

Nach Applikation des Kalzium-Ionophors formierten sich bei allen untersuchten Tiergruppen nach 30 Minuten erste axonale Bulbs, deren Verteilungsdichte 120 Minuten nach Ionophor-Kontakt ihren Höhepunkt erreichte. [A53T] $\alpha$ SYN-Tiere eine signifikant höhere Anzahl axonaler Bulbs als [A30P] $\alpha$ SYN- und WT-Mäuse. Sowohl im Alter von 3-5 Monaten als auch im Alter von 7-9 Monaten war bei [A53T] $\alpha$ SYN-Mäusen im Vergleich zu den beiden anderen Gruppen eine signifikant höhere BulbVerteilungsdichte zu beobachten. Die Anzahl der Bulbs von [A30P] $\alpha$ SYN-Mäusen unterschied sich weder im Alter von 3-5 Monaten noch im Alter von 7-9 Monaten von Tieren der WT-Gruppe. In keiner der Versuchstiergruppen ergab sich ein signifikanter Unterschied zwischen der Anzahl an Bulbs im Alter von 3-5 und 7-9 Monaten.

In der Auswertung der Bulb-Durchmesser zeigte sich in der jungen Kohorte die Formierung signifikant kleinerer Bulbs bei [A53T] $\alpha$ SYN-Tieren bei einer insgesamt größerer Anzahl formierter Bulbs im Vergleich zu [A30P] $\alpha$ SYN- und WT-Tieren. Bei Versuchstieren der alten Kohorte war dieser Unterschied nicht nachweisbar.

\subsection{Diskussion der Ergebnisse}

\subsubsection{Die Transduktion retinaler Ganglienzellen mit AAV-EGFP führte zu einer verlässlichen fluoreszenzmikroskopischen Darstellung von Axonen im optischen Nerv}

AAV-basierte Vektoren stehen schon seit vielen Jahren im Fokus der ophthalmologischen Forschung zur Gen-Therapie retinaler Erkrankungen. Für den Subtyp AAV2 ist eine hochspezifische Transduktion von RGZ bekannt (Hellström et al. 2009). Auch der verwendete humanes-Synapsin-1-Promotor $h S Y N$ ist für seine spezifische Steuerung der Genexpression in neuronalen Geweben bekannt (Kügler et al. 2003; Shevtsova et al. 2005). Zudem wurde nachgewiesen, dass durch eine Kombination der Serotypen AAV1 und AAV2 eine wesentlich effizientere Transduktion erreicht werden kann 
(Rabinowitz et al. 2004). Es ist also davon auszugehen, dass der in dieser Arbeit verwendete Virus-Subtyp zu einer effizienten und spezifischen Transduktion der RGZ geführt hat. Zur weiteren Optimierung der AAV2-basierten Transduktion kann ein Ersatz des hSYN-Promotors durch die Promotoren Nefh oder Thy1 erwogen werden, da diese bei gleicher (Thy1) bzw. leicht erhöhter Expressionsrate (Nefh) eine höhere Spezifität für RGZ aufweisen (Ratican et al. 2018). Das für den $h S Y N$-Promotor nachgewiesene „off-target-Labelling“ von amakrinen Zellen (Ratican et al. 2018), das für die leicht unterlegene Spezifität des $h S Y N$-Promotors verantwortlich sein dürfte, spielt allerdings für die Frage, ob ein spezifisches axonales Labelling im ON zu erwarten ist, keine Rolle, da diese Zellen keine Fortleitung in den ON besitzen. Das teilweise leichte Hintergrundleuchten auf den Live-Imaging-Aufnahmen ist also wahrscheinlich nicht auf ein unspezifisches Labelling zurückzuführen, sondern vielmehr auf eine zu großflächige Transduktion abseits kranialer Retinaabschnitte. Schließlich ist sowohl in den Retina-Flat-Mounts als auch in den Querschnitten des ON zwar eine periphere, mutmaßlich kraniale Konzentration des Labellings der RGZ bzw. der Axone sichtbar, aber auch andernorts eine deutliche Transduktion erkennbar. In den Retina-FlatMounts fällt eine vermehrte Konzentration der Transduktion in direkter Nachbarschaft zu den retinalen Gefäßen auf, ein Phänomen, das in der Fachliteratur nicht vorbeschrieben ist. Unter der Prämisse, dass der virale Vektor über die venöse Drainage aus dem Glaskörperraum entfernt wird, ist eine höhere Virion-Konzentration perivaskulär denkbar, die zu einer vermehrten Transduktion der dortigen RGZ führt. Die verstärkte Transduktion perivaskulärer Bereiche entlang der Gefäßbögen liefert auch eine mögliche Erklärung zu der bei den Querschnitten des ON beobachteten bandförmigen Intensivierung der Transduktion, eine Erklärung, die zwar plausibel ist, für die sich jedoch keine direkten Nachweis in der aktuellen Literatur findet: Es ist bekannt dass die Axone des ON retinotopisch organisiert sind (Wirtschafter 1983), das heisst die projizierenden Axone peripherer, temporaler RGZ liegen im ON peripher und temporal usw. Zudem verlaufen die Axone intraretinal nicht radiär auf die Papille zu sondern bogenförmig und parallel zu den Gefäßbögen (Wirtschafter 1983). Eine Intensivierung der Transduktion perivaskulärer RGZ entlang des superioren und inferioren Gefäßbogens könnte somit bandförmig in den ON projizieren.

Eine interessante Frage ergibt sich aus der Rolle des Glaskörpers als mögliche Diffusionsbarriere für den viralen Vektor. So wurde an größeren Säugetieren gezeigt, dass 
nach einer Vitrektomie, also einer chirurgischen Entfernung des Glaskörpers, eine effektivere uns gleichmäßigerer Transduktion retinaler Ganglienzellen mit dem viralen Vektor AAV1/2 erreicht werden kann, da der Glaskörper offenbar eine Diffusionsbarriere für intraokular applizierte Substanzen darstellt (Tshilenge et al. 2016). Für das Ziel einer lokal begrenzten Transduktion ist eine solche Diffusionsbarriere vermutlich aber förderlich. Deshalb wäre eine Entfernung des Glaskörpers vor der intravitrealen Injektion des viralen Vektors nicht empfehlenswert.

Insgesamt erwies sich die in dieser Arbeit angewendete Methode des axonalen Labellings als zuverlässig und effizient. Die Methode der AAV-basierten Transduktion von RGZ birgt darüber hinaus das Potential der Weiterentwicklung der transgenen Parkinson-Tiermodelle, indem durch die Transduktion mit anderen Proteinen ähnlich wie in der Glaukom-Forschung gentherapeutische Ansätze erprobt werden können.

\subsection{2 [A53T] $\alpha S Y N-$ und [A30P] $\alpha S Y N-M a ̈ u s e$ exprimierten humanes $\alpha S Y N$ im optischen Nerv}

Der Nachweis der Expression von humanem $\alpha$ SYN in den ON der verwendeten transgenen Mäuse war essentiell für die Aussagekraft der Ergebnisse aus den LiveImaging-Experimenten. Zwar ist bei den verwendeten transgenen Krankheitsmodellen eine Überexpression von $\alpha S Y N$ in verschiedenen neuronalen Geweben vorbeschrieben - sowohl bei [A53T] $\alpha$ SYN- als auch bei [A30P] $\alpha$ SYN-Tieren wurde eine Überexpression von humanem $\alpha \mathrm{SYN}$ in Bereichen des Cerebrums, des Cerebellums, des Hirnstamms und des Rückenmarks nachgewiesen (Kahle et al. 2000; Giasson et al. 2002) - eine Überexpression von $\alpha$ SYN im ON der verwendeten Tiermodelle wurde jedoch erst durch die vorliegende Arbeit gezeigt.

$\alpha S Y N$ wurde in beiden untersuchten transgenen Gruppen überexprimiert, allerdings nicht im gleichen Maße: So waren die gemessen $\alpha$ SYN-Level bei [A53T] $\alpha$ SYN-Tieren signifikant höher als bei [A30P] $\alpha$ SYN-Tieren. Dies könnte eine mögliche Erklärung für die unterschiedliche Stärke der axonalen Degeneration sein, die wir in den durchgeführten Live-Imaging-Experimenten beobachteten.

Ein Grund für den Niveauunterschied in der Expression des SNCA-Gens zwischen den verwendeten Tiergruppen kann ein unterschiedliches Maß an genetischer Multiplikation des Gens sein, dass in der Folge zu einer vermehrten Expression des [A53T] $\alpha$ SYN 
führte. Es ist bekannt, dass nicht nur genetische Mutationen des SNCA-Gens, sondern auch Multiplikationen des WT-SNCA-Gens im Erbgut Ursache für einen familiären MP sein kann (Konno et al. 2016).

In der vorliegenden Arbeit konnte histologisch gezeigt werden, dass $\alpha$ SYN nicht nur intraneuronal bzw intraaxonal vorliegt, sondern ebenfalls in Oligodendrozyten des ON und dort vornehmlich perinukleär lokalisiert ist. Zwar deuten die histologischen Studien zu den verwendeten Tiermodellen ein vornehmlich intraneuronales Vorkommen von $\alpha$ SYN an (Kahle et al. 2000; Giasson et al. 2002), die dort verwendeten Antikörper waren jedoch vornehmlich spezifisch auf $\alpha \mathrm{SYN}$-Aggregate bzw. oxidiertes $\alpha S Y N$, während die in der vorliegenden Arbeit verwendeten Antikörper spezifisch auf $\alpha \mathrm{SYN}$ jeglicher Konformation waren, also neben Oligomeren und Fibrillen auch monomeres $\alpha \mathrm{SYN}$ markierten. Darüber hinaus ist bekannt, dass Oligodendrozyten nicht nur extrazelluläres $\alpha$ SYN aufnehmen können, um es nachfolgend zu degradieren (Lindström et al. 2017), sondern es ebenfalls selbst exprimieren (Djelloul et al. 2015). Die Wechselwirkung der Oligodendrozyten mit $\alpha$ SYN und der dazu gehörigen Synucleinopathie, der Multisystematrophie, stellt einen großen Themenkomplex der aktuellen wissenschaftlichen Literatur dar (Laurens et al. 2017). Die womöglich eingeschränkte Funktion der Oligodendrozyten könnte daher auch in der vorliegenden Arbeit Einfluss auf die Vulnerabilität der Axone gehabt haben.

\subsubsection{Die Applikation von Kalzium-Ionophor führte zur axonalen Degeneration}

\subsubsection{Die Entstehung axonaler Bulbs als Maß für akute axonale Degeneration}

Wie bereits in Kapitel 1.2.1 erläutert, folgt die akute axonale Degeneration einem bestimmten Ablauf mit spezifischen morphologischen Veränderungen. So kommt es nach axonaler Schädigung neben der Fragmentierung des Axons auch zur Ausbildung axonaler Schwellungen oder Bulbs. Im Live-Imaging-Tiermodell mit traumatischer Schädigung des ON traten diese bereits 30 Minuten nach axonaler Schädigung auf und enthielten u. a. geschwollene Mitochondrien und andere Zellorganellen sowie vakuolisiertes Axoplasma (Ribas et al. 2016). Daher eignet sich die Erfassung von axonalen Bulbs als Maß für axonale Degeneration. Vermutlich sind sie Folge einer axonalen Transportstörung, die zur Anhäufung von intrazellulärem Material führt. 


\subsubsection{Kalzium als Initiator der akuten axonalen Degeneration}

Der Kalzium-Einstrom steht am Anfang der Degenerationskaskade. Der Anstieg der Kalzium-Konzentration aktiviert intrazelluläre Proteasen wie Calpain (Ma 2013) und trägt damit zur Degradierung einer Vielzahl zytoplasmatischer Proteine bei (Vosler et al. 2008). Darunter fällt auch das Collapsin-response-mediator-protein-2 (CRMP-2), ein Protein, dass durch seine Interaktion mit Kinesin-1 am axonalen Transport beteiligt ist und dessen Spaltung die Akkumulation von Zellorganellen beim Degenerationsprozess erklärt (Touma et al. 2007; Zhang et al. 2016). Des Weiteren konnte gezeigt werden, dass die Applikation von Kalzium-Blockern zu einer geringeren Akkumulation von Autophagosomen in Nervenzellen des ON und des Rückenmarks führt (Koch et al. 2010; Ribas et al. 2015). Die Inhibierung des Kalziumeinstroms nach einer Nervenläsion im $\mathrm{ON}$ bei Ratten schwächte die AAD ab und verbesserte die Überlebensrate retinaler Ganglienzellen (RGZ). Dies konnte auf folgende Effekte zurück geführt werden: Neben einer verminderten Calpain-Aktivität bestand auch eine verminderte Aktivierung von c-Jun n-terminale Kinasen (JNK). JNKs sind Kinasen, die durch verschiedene zelluläre Stresssignale aktiviert werden und proapoptotisch wirken. Zudem beeinträchtigen sie den axonalen Transport, indem sie zur Dissoziation von Kinesin und Tubulin führen (Stagi et al. 2006). Zuletzt konnte eine vermehrte Aktivierung der pro-survival-Kinase Akt festgestellt werden. (Ribas et al. 2016).

Auch das an der Pathogenese des MP beteiligte $\alpha$ SYN wird durch unterschiedliche Kalzium-Konzentrationen beeinflusst. So fördert eine erhöhte Kalzium-Konzentration die Aggregation von $\alpha$ SYN (Tamamizu-Kato et al. 2006; Nath et al. 2011). Umgekehrt bewirken $\alpha S Y N$ und seine Oligomere selbst einen Kanal-vermittelten KalziumEinstrom (Adamczyk und Strosznajder 2006; Danzer et al. 2007).

\subsection{4 [A53T] $\alpha S Y N-T i e r e$ zeigten ein höheres Ausmaß an axonaler Degene- ration als $[\mathrm{A30P}] \alpha \mathrm{SYN}$-Tiere und Wildtyp-Tiere}

Die Rolle von $\alpha$ SYN und bei der Pathophysiologie des MP und die dazugehörigen molekularen Mechanismes wurde bereits in Kapitel 1.2.2 dargelegt. Der folgende Abschnitt behandelt die Unterschiede zwischen den $\alpha$ SYN-Varianten [A53T] $\alpha$ SYN und $[\mathrm{A} 30 \mathrm{P}] \alpha \mathrm{SYN}$.

Bei [A53T] $\alpha$ SYN-Mäusen sahen wir im Vergleich zu [WT] $\alpha$ SYN- und [A30P] $\alpha$ SYNMäusen ein stärkeres Ausmaß an axonaler Degeneration. Dies passt zu den Beobach- 
tungen Giassons, der bei diesen Tieren eine schwere Synucleinopathie mit Neurodegeneration und LB-Pathologie beschreibt (Giasson et al. 2002). Allerdings beschreibt er das Auftreten erster Symptome erst ab einem Alter der Versuchtiere von 8 Monaten und die Formierung erster $\alpha \mathrm{SYN}$-Aggregate im Alter von 7 Monaten. Wir sahen jedoch nicht nur bei älteren (7-9 Monate), sondern auch bei jüngeren Tieren (3-5 Monate) eine stärker ausgeprägte axonale Degeneration nach Kalzium-Einstrom. Offenbar sind schon vor dem Auftreten erster klinischer Symptome weitreichende zellbiologische Veränderungen bei diesen Tieren eingetreten, die die Axone vulnerabler gegenüber einer Kalzium-Influx-induzierten Degeneration machen.

Innerhalb des untersuchten Alters der Mäuse (3-5 bzw. 7-9 Monate) konnten wir keinen signifikanten Unterschied in Ablauf und Ausmaß der axonalen Degeneration von [A30P] $\alpha$ SYN- zu WT-Mäusen feststellen. Bezogen auf die von uns verwendeten (Thy1)-h[A30P] $\alpha$ SYN-Mäuse beschreiben IHC-Studien das Auftreten von $\alpha$ SYNAggregaten nach 6 Monaten, behaviorale Beobachtungen erste Symptome motorischer Beeinträchtigungen nach 12 Monaten (Kahle et al. 2000). Eine andere Studie zeigt dagegen eine klare Korrelation zwischen dem Auftreten von motorischen Symptomen und $\alpha$ SYN-Aggregatbildung (Lindström et al. 2014). Eine Verhaltensstudie zeigt, dass den motorischen Beeinträchtigungen kognitive Defizite vorausgehen. So waren (Thy-1)-h[A30P] $\alpha$ SYN-Mäuse im Alter von 12 Monaten signifikant eingeschränkt in den Bereichen Lernfähigkeit, Gedächtnis, Angst- sowie Vermeidungsverhalten und zeigten ein hyperaktives Bewegungsprofil. Erst nach 12 Monaten entwickelten die Tiere einen motorisch beeinträchtigten Phänotyp (Freichel et al. 2007). Die oben beschriebene aktuelle Studienlage legt den Schluss nahe, dass junge Exemplare (Alter: 3-5 Monate) dieses Tiermodells noch wenige bis keine $\alpha$ SYN-Aggregate aufweisen. Dass sie sich in der axonalen Degeneration nicht von Wildtypmäusen unterscheiden, ist daher plausibel. Bei älteren Tieren (Alter 7-9 Monaten) wäre jedoch ein stärkeres Ausmaß und früheres Auftreten von Degenerationszeichen zu erwarten gewesen, da bei (Thy-1)-h[A30P] $\alpha$ SYN-Mäusen in diesem Alter $\alpha$ SYN-Aggregate beobachtet wurden. Dass erste klinische Zeichen einer Synucleinopathie erst in einem Alter von $\geq 12$ Monaten innerhalb dieses transgenen Tiermodells auftraten, lässt vermuten, dass betroffene Neurone in einem moderaten $\alpha$ SYN-Aggregationsstadium über ausreichende Kompensationsmechanismen verfügen und sich deshalb auch in unseren Experimenten als widerstandsfähig gegenüber dem induzierten Kalziumein- 
strom erwiesen haben. Aus diesem Grund wäre eine Live-Imaging-Reihe mit (Thy-1)$\mathrm{h}[\mathrm{A} 30 \mathrm{P}] \alpha \mathrm{SYN}-$ Tieren im Alter von $\geq 12$ Monaten sinnvoll zu ergänzen.

Die oben vorgestellten Studien korrelierten die klinische Symptomatik mit dem histopathologischen Nachweis von $\alpha$ SYN-Aggregaten. Die aktuelle Studienlage weist jedoch darauf hin, dass vor allem oligomere Formen des $\alpha \mathrm{SYN}$ eine neurotoxische Wirkung entfalten und somit den Krankheitsprozess bestimmen: Ratten, die $\alpha$ SYNMutationen mit hoher Tendenz zur Formierung von Oligomeren exprimierten, zeigten sich stärker betroffen von pathologischen Veränderungen als Tiere, die fibrillogene $\alpha$ SYN-Formen exprimierten (Winner et al. 2011). [A30P] $\alpha$ SYN und [A53T] $\alpha$ SYN wurden in dieser Studie den fibrillogenen $\alpha \mathrm{SYN}$-Spezies zugeordnet, jedoch zeigte [A30P] $\alpha$ SYN eine schwächere Tendenz zur Fibrillenbildung als [A53T] $\alpha$ SYN und erwies sich insgesamt als toxischer. Dieser Effekt ist früher bereits zellunabhängig gezeigt worden (Conway et al. 2000). Die geringer aufgeprägte Fibrillogenität von [A30P] $\alpha$ SYN passt zwar zum späteren Auftreten histopathologischer Veränderungen bei den oben beschriebenen (Thy-1)-h[A30P] $\alpha$ SYN-Mäusen (Kahle et al. 2000; Freichel et al. 2007), jedoch nicht zum milderen klinischen Phänotyp dieser Tiere im Vergleich zu [A53T] $\alpha$ SYN-Mäusen und steht somit auch im Gegensatz zu unseren Beobachtungen. Neben Unterschieden in der Neigung zur Aggregation wurden Differenzen der $\alpha$ SYN-Mutanten bezüglich der Aktivierung von Mikroglia nachgewiesen: Im Vergleich zum [WT] $\alpha$ SYN induzieren beide $\alpha$ SYN-Mutanten im zellbasierten Modell eine mikrogliale Umgebungsreaktion mit Freisetzung von Entzündungsmediatoren, [A53T] $\alpha$ SYN mehr als [A30P] $\alpha$ SYN (Hoenen et al. 2016). Ebenfalls wurde im Zellmodell in Anwesenheit von monomerem [A53T] $\alpha$ SYN eine Steigerung der mikroglialen Phagozytose festgestellt, während diese in Anwesenheit von monomerem [A30P] $\alpha$ SYN gehemmt war (Roodveldt et al. 2010).

Insgesamt decken sich die Ergebnisse unserer Studie mit den Beobachtungen, die derzeit zu den verwendeten Tiermodellen vorliegen. Bisher wurden in den besagten Tiermodellen vor allem histopathologische Veränderungen mit behavioralen Beobachtungen korreliert. Da jedoch nicht das Vorliegen von $\alpha$ SYN-Monomeren oder Fibrillen, sondern die intrazelluläre Konzentration von Mono- und Oligomeren für den Krankheitsprozess relevant erscheint, ist es sinnvoll, in weiteren Studien das Auftreten von axonaler Degeneration in Live-Imaging-Experimenten mit dem Auftreten 
von $\alpha$ SYN-Mono- und Oligomeren zu korrelieren. Bezogen auf die Frage, welche $\alpha \mathrm{SYN}-$ Mutation den toxischeren Effekt hat, ist die Studienlage heterogen. Es bleibt zu klären, ob der in der vorliegenden Arbeit und vergangenen tierexperimentellen Studien festgestellte Unterschied zwischen den beiden Tiermodellen auf ein unterschiedliches Expressionsniveau von $\alpha$ SYN zurückzuführen ist, oder ob er durch einen Unterschied in der Toxizität erklärt werden kann.

\subsubsection{Das Alter der Versuchstiere beeinflusste nicht das Ausmaß und den Ablauf der axonalen Degeneration}

In der vorliegenden Arbeit ergab sich kein Unterschied in Degenerationsverlauf und Ausmaß zwischen jungen und alten Tieren innerhalb der jeweiligen Genotypen. Dies war unerwartet im Kontext der tierexperimentellen Studien, die zu den verwendeten transgenen Tiermodellen veröffentlicht und im vorherigen Abschnitt bereits vorgestellt wurden. Insgesamt wäre eine zeitabhängige kumulative Schädigung der Axone durch $\alpha$ SYN zu erwarten, die bei älteren Mäusen zu einer höheren Empfindlichkeit der Axone gegenüber dem toxischen Stimulus des Kalzium-Ionophor-vermittelten Kalzium-Einstroms führen müsste. Warum sich ein solcher Effekt in der vorliegenden Arbeit nicht zeigte, bleibt Gegenstand zukünftiger Untersuchungen. Es ist möglich, dass nicht alle Axone gleich empfindlich auf $\alpha \mathrm{SYN}$ als toxischen Stimulus reagierten. Besonders empfindliche Axone waren ggf. zum Zeitpunkt des Live-Imagings bereits degeneriert, diese besonders empfindlichen Axone wurden in der Folge bei der Messung der Bulb-Verteilungsdichte als Maß der axonalen Degeneration nicht erfasst. Von diesem Phänomen sind natürlich insbesondere die Live-Imagings der alten Tiere betroffen und könnten so den kumulativen axonalen Schaden durch $\alpha S Y N$ verschleiern. Immunhistologische Untersuchungen der axonalen Dichte in den ON junger und alter Versuchstiere könnten diesen Effekt aufdecken. 


\subsection{Ausblick}

Die vorliegende Arbeit zeigt nicht nur, dass $\alpha$ SYN axonale Degeneration beeinflusst, sie weist diesen Effekt auch erstmals in vivo nach. Hierbei handelt es sich um eine rein morphologische Beobachtung, deren Ursachen auf Zellebene noch nicht hinreichend erklärt sind. Gerade die Wechselwirkung zwischen intrazellulärem Kalziumspiegel und $\alpha \mathrm{SYN}$ ist dabei interessant (für Kontextliteratur siehe Kapitel: 4.2.4) und eröffnet mitunter pharmakologische Therapieansätze, deren Wirksamkeit mit dem in dieser Arbeit etablierten transgenen Live-Imaging-Modell überprüft werden können.

Die in dieser Arbeit verwendete Messgröße der Bulb-Verteilungsdichte dient als Maß der Axonalen Degeneration, da die Bulb-Formierung nachgewiesener Bestandteil des axonalen Degenerationsverlaufs ist (Knöferle et al. 2010; Koch et al. 2010). Knöferle et al. Und Koch et al. postulieren als eine von mehreren Prozessen der Degenerationskaskade Störungen des axonalen Transports, z. B. von Zellorganellen, deren Akkumulation zur Bulb-Formierung beiträgt. Als Folgestudie sind daher der Nachweis und die Visualisierung einer Transportstörung in vivo interessant, z. B. mit Fluoreszenz-markierten Mitochondrien. Auch ein solches Modell ermöglicht die Testung pharmakologischer Ansätze. Außerdem sollte die molekulare Grundlage der differentiellen Effekte der $\alpha$ SYN-Varianten auf die Bulb-Größe weiter untersucht werden. Hierzu würden sich z. B. hoch-auflösende moderne Mikroskopie-Verfahren wie STED eignen. 


\section{$5 \quad$ Zusammenfassung}

Axonale Degeneration spielt eine Schlüsselrolle in der Pathogenese des Morbus Parkinson. Das Protein $\alpha$-Synuclein $(\alpha \mathrm{SYN})$ und seine mutierten Formen [A53T] $\alpha$ SYN und $[\mathrm{A} 30 \mathrm{P}] \alpha \mathrm{SYN}$ sind entscheidend an diesem degenerativen Prozess beteiligt. Ziel der vorliegenden Arbeit war es, den Einfluss von [A53T] $\alpha$ SYN und [A30P] $\alpha$ SYN auf das Ausmaß und den zeitlichen Ablauf von Kalzium-induzierter axonaler Degeneration in vivo zu untersuchen.

Dazu wurde ein Live-Imaging-Verfahren am optischen Nerven von transgenen [A53T] $\alpha$ SYN und [A30P] $\alpha$ SYN Mäusen etabliert. Durch Applikation eines KalziumIonophors wurde axonale Degeneration induziert. Anschließend wurden morphologische Veränderungen von Fluoreszenz-markierten Axonen des optischen Nervs über einen Zeitraum von 5 Stunden beobachtet. [A53T] $\alpha$ SYN-, [A30P] $\alpha$ SYN- und Wildtypmäusen wurden jeweils in zwei Altersgruppen untersucht (3-5 bzw. 7-9 Monate).

In beiden Altersgruppen entwickelten [A53T] $\alpha$ SYN-Mäuse eine höhere Anzahl axonaler Bulbs als Wildtyp-Tiere. [A30P] $\alpha$ SYN-Mäuse unterschieden sich nicht signifikant von Wildtyp-Mäusen. In keiner der Versuchsgruppen zeigte sich ein signifikanter Unterschied zwischen der Anzahl an Bulbs im Alter von 3-5 und 7-9 Monaten. Im Alter von 3-5 Monaten hatten axonale Bulbs der [A53T] $\alpha$ SYN-Mäuse einen signifikant geringeren Durchmesser als Bulbs der Wildtyp- und [A30P] $\alpha$ SYN-Mäuse. Im Alter von 7-9 Monaten ergab sich kein Unterschied zwischen den verschiedenen Versuchsgruppen. Humanes $\alpha \mathrm{SYN}$ war im optischen Nerven von beiden transgenen Mausmodellen exprimiert. [A53T] $\alpha$ SYN-Mäuse zeigten jedoch im Vergleich zu [A30P] $\alpha$ SYNMäusen eine signifikant höhere Expression.

Insgesamt konnte in dieser Arbeit der neurotoxische Effekt von $\alpha \mathrm{SYN}$ erstmals in vivo gezeigt werden. Die für diese Arbeit etablierte Live-Imaging-Technik für Mäuse kann auch in Zukunft bei vielen anderen transgenen Mausmodellen neurodegenerativer Erkrankungen zur Anwendung kommen und bietet zudem einen Testrahmen für pharmakologische Therapieansätze. 


\section{Literaturverzeichnis}

Abbott BJ, Fukuda DS, Dorman DE (1979): Microbial transformation of A23187, a divalent cation ionophore antibiotic.; in: Antimicrobial Agents and Chemotherapy., 808-812

Abeliovich A, Schmitz Y, Fariñas I, Choi-Lundberg D, Ho WH, Castillo PE, Shinsky N, Verdugo JM, Armanini M, Ryan A, et al. (2000): Mice lacking alpha-synuclein display functional deficits in the nigrostriatal dopamine system. Neuron $\underline{25}$, 239-252

Adamczyk A, Strosznajder JB (2006): Alpha-synuclein potentiates Ca2+ influx through voltage-dependent Ca2+ channels: Neuroreport 17, 1883-1886

Ahn T-B, Kim SY, Kim JY, Park S-S, Lee DS, Min HJ, Kim YK, Kim SE, Kim J-M, Kim H-J, et al. (2008): alpha-Synuclein gene duplication is present in sporadic Parkinson disease. Neurology 70, 43-49

Altintaş O, Işeri P, Ozkan B, Cağlar Y (2008): Correlation between retinal morphological and functional findings and clinical severity in Parkinson's disease. Doc Ophthalmol Adv Ophthalmol 116, 137-146

Beach TG, Adler CH, Sue LI, Peirce JB, Bachalakuri J, Dalsing-Hernandez JE, Lue LF, Caviness JN, Connor DJ, Sabbagh MN, Walker DG (2008): Reduced striatal tyrosine hydroxylase in incidental Lewy body disease. Acta Neuropathol (Berl) $\underline{115}, 445-451$

Beach TG, White CL, Hladik CL, Sabbagh MN, Connor DJ, Shill HA, Sue LI, Sasse J, Bachalakuri J, Henry-Watson J, et al. (2009): Olfactory bulb $\alpha$-synucleinopathy has high specificity and sensitivity for Lewy body disorders. Acta Neuropathol (Berl) 117, 169-174

Beach TG, Carew J, Serrano G, Adler CH, Shill HA, Sue LI, Sabbagh MN, Akiyama H, Cuenca N, Arizona Parkinson's Disease Consortium (2014): Phosphorylated $\alpha$ synuclein-immunoreactive retinal neuronal elements in Parkinson's disease subjects. Neurosci Lett $\underline{571}, 34-38$

Bernheimer H, Birkmayer W, Hornykiewicz O, Jellinger K, Seitelberger F (1973): Brain dopamine and the syndromes of Parkinson and Huntington. Clinical, morphological and neurochemical correlations. J Neurol Sci 20, 415-455

Bodis-Wollner I, Yahr M.D, Thornton J (1981): Visual evoked potentials and the severity of Parkinson's disease. Buchkapitel in Research Progress in Parkinson's Disease von Rose F C und Capildeo R (Hrsg.), 126-137

Bodis-Wollner I, Kozlowski PB, Glazman S, Miri S (2014): $\alpha$-synuclein in the inner retina in parkinson disease. Ann Neurol 75, 964-966

Bonifati V, Rizzu P, van Baren MJ, Schaap O, Breedveld GJ, Krieger E, Dekker MCJ, Squitieri F, Ibanez P, Joosse M, et al. (2003): Mutations in the DJ-1 gene associated with autosomal recessive early-onset parkinsonism. Science $\underline{299}$, 256259 
Braak H, Rüb U, Sandmann-Keil D, Gai WP, de Vos RA, Jansen Steur EN, Arai K, Braak E (2000): Parkinson's disease: affection of brain stem nuclei controlling premotor and motor neurons of the somatomotor system. Acta Neuropathol (Berl) 99, 489-495

Braak H, Del Tredici K, Bratzke H, Hamm-Clement J, Sandmann-Keil D, Rüb U (2002): Staging of the intracerebral inclusion body pathology associated with idiopathic Parkinson's disease (preclinical and clinical stages). J Neurol 249 Suppl 3. III/1-5

Braak H, Rüb U, Gai WP, Del Tredici K (2003a): Idiopathic Parkinson's disease: possible routes by which vulnerable neuronal types may be subject to neuroinvasion by an unknown pathogen. J Neural Transm 110, 517-536

Braak H, Del Tredici K, Rüb U, de Vos RAI, Jansen Steur ENH, Braak E (2003b): Staging of brain pathology related to sporadic Parkinson's disease. Neurobiol Aging $\underline{24}$, 197-211

Braak H, de Vos RAI, Bohl J, Del Tredici K (2006): Gastric $\alpha$-synuclein immunoreactive inclusions in Meissner's and Auerbach's plexuses in cases staged for Parkinson's disease-related brain pathology. Neurosci Lett $\underline{396}, 67-72$

Bussell R, Eliezer D (2003): A structural and functional role for 11-mer repeats in alpha-synuclein and other exchangeable lipid binding proteins. J Mol Biol $\underline{329}$ 763-778

Bussell R, Ramlall TF, Eliezer D (2005): Helix periodicity, topology, and dynamics of membrane-associated alpha-synuclein. Protein Sci 14, 862-872

Cersosimo MG, Benarroch EE (2012): Pathological correlates of gastrointestinal dysfunction in Parkinson's disease. Neurobiol Dis $\underline{46}, 559-564$

Chaney MO, Jones ND, Debono M (1976): The structure of the calcium complex of A23187, a divalent cation ionophore antibiotic. J Antibiot (Tokyo) 29, 424-427

Conway KA, Lee SJ, Rochet JC, Ding TT, Williamson RE, Lansbury PT (2000): Acceleration of oligomerization, not fibrillization, is a shared property of both alphasynuclein mutations linked to early-onset Parkinson's disease: implications for pathogenesis and therapy. Proc Natl Acad Sci U S A 97, 571-576

Coskuner 0, Wise-Scira 0 (2013): Structures and free energy landscapes of the A53T mutant-type $\alpha$-synuclein protein and impact of A53T mutation on the structures of the wild-type $\alpha$-synuclein protein with dynamics. ACS Chem Neurosci 4, 1101-1113

Damier P, Hirsch EC, Agid Y, Graybiel AM (1999): The substantia nigra of the human brain. II. Patterns of loss of dopamine-containing neurons in Parkinson's disease. Brain 122, 1437-1448

Danzer KM, Haasen D, Karow AR, Moussaud S, Habeck M, Giese A, Kretzschmar H, Hengerer B, Kostka M (2007): Different Species of -Synuclein Oligomers Induce Calcium Influx and Seeding. J Neurosci 27, 9220-9232 
Danzer KM, Kranich LR, Ruf WP, Cagsal-Getkin O, Winslow AR, Zhu L, Vanderburg CR, McLean PJ (2012): Exosomal cell-to-cell transmission of alpha synuclein oligomers. Mol Neurodegener $\underline{7}, 42$

Dauer W, Przedborski S (2003): Parkinson's disease: mechanisms and models. Neuron $\underline{39}, 889-909$

Davidson WS, Jonas A, Clayton DF, George JM (1998): Stabilization of alpha-synuclein secondary structure upon binding to synthetic membranes. J Biol Chem $\underline{273}$, 9443-9449

Decressac M, Mattsson B, Lundblad M, Weikop P, Björklund A (2012): Progressive neurodegenerative and behavioural changes induced by AAV-mediated overexpression of $\alpha$-synuclein in midbrain dopamine neurons. Neurobiol Dis $\underline{45}$, 939-953

de Lau LM, Breteler MM (2006): Epidemiology of Parkinson's disease. Lancet Neurol 5, 525-535

Del Tredici K, Braak H (2016): Review: Sporadic Parkinson's disease: development and distribution of $\alpha$-synuclein pathology. Neuropathol Appl Neurobiol $\underline{42}$ $33-50$

Del Tredici K, Rüb U, De Vos RAI, Bohl JRE, Braak H (2002): Where does parkinson disease pathology begin in the brain? J Neuropathol Exp Neurol 61, 413-426

DelleDonne A, Klos KJ, Fujishiro H, Ahmed Z, Parisi JE, Josephs KA, Frigerio R, Burnett M, Wszolek ZK, Uitti RJ, et al. (2008): Incidental Lewy body disease and preclinical Parkinson disease. Arch Neurol 65, 1074-1080

Desplats P, Lee H-J, Bae E-J, Patrick C, Rockenstein E, Crews L, Spencer B, Masliah E, Lee S-J (2009): Inclusion formation and neuronal cell death through neuronto-neuron transmission of -synuclein. Proc Natl Acad Sci USA 106, 1301013015

Dexter DT, Jenner P (2013): Parkinson disease: from pathology to molecular disease mechanisms. Free Radic Biol Med 62, 132-144

Djelloul M, Holmqvist S, Boza-Serrano A, Azevedo C, Yeung MS, Goldwurm S, Frisén J, Deierborg T, Roybon L (2015): Alpha-Synuclein Expression in the Oligodendrocyte Lineage: an In Vitro and In Vivo Study Using Rodent and $\mathrm{Hu}-$ man Models. Stem Cell Rep $\underline{5}$, 174-184

Doty RL (2012): Olfaction in Parkinson's disease and related disorders. Neurobiol Dis $\underline{46}, 527-552$

Duda JE, Giasson BI, Mabon ME, Lee VM-Y, Trojanowski JQ (2002): Novel antibodies to synuclein show abundant striatal pathology in Lewy body diseases. Ann Neurol $\underline{52}, 205-210$

Emmanouilidou E, Melachroinou K, Roumeliotis T, Garbis SD, Ntzouni M, Margaritis LH, Stefanis L, Vekrellis K (2010): Cell-Produced $\alpha$-Synuclein Is Secreted in a 
Calcium-Dependent Manner by Exosomes and Impacts Neuronal Survival. J Neurosci $\underline{30}$, 6838-6851

Fagerqvist T, Lindström V, Nordström E, Lord A, Tucker SME, Su X, Sahlin C, Kasrayan A, Andersson J, Welander H, et al. (2013): Monoclonal antibodies selective for $\alpha$-synuclein oligomers/protofibrils recognize brain pathology in Lewy body disorders and $\alpha$-synuclein transgenic mice with the disease-causing A30P mutation. J Neurochem 126, 131-144

Fearnley JM, Lees AJ (1991): Ageing and Parkinson's disease: substantia nigra regional selectivity. Brain 114, 2283-2301

Freichel C, Neumann M, Ballard T, Müller V, Woolley M, Ozmen L, Borroni E, Kretzschmar HA, Haass C, Spooren W, Kahle PJ (2007): Age-dependent cognitive decline and amygdala pathology in alpha-synuclein transgenic mice. Neurobiol Aging 28, 1421-1435

Gerstenberger J, Bauer A, Helmschrodt C, Richter A, Richter F (2016): The novel adaptive rotating beam test unmasks sensorimotor impairments in a transgenic mouse model of Parkinson's disease. Behav Brain Res $\underline{304}$, 102-110

Giasson BI, Duda JE, Quinn SM, Zhang B, Trojanowski JQ, Lee VM-Y (2002): Neuronal alpha-synucleinopathy with severe movement disorder in mice expressing A53T human alpha-synuclein. Neuron $\underline{34}$, 521-533

Hansen C, Angot E, Bergström A-L, Steiner JA, Pieri L, Paul G, Outeiro TF, Melki R, Kallunki P, Fog K, et al. (2011): $\alpha$-Synuclein propagates from mouse brain to grafted dopaminergic neurons and seeds aggregation in cultured human cells. J Clin Invest 121, 715-725

Hawkes CH, Del Tredici K, Braak H (2007): Parkinson's disease: a dual-hit hypothesis. Neuropathol Appl Neurobiol 33, 599-614

Hawkes CH, Del Tredici K, Braak H (2009): Parkinson's Disease: The Dual Hit Theory Revisited. Ann N Y Acad Sci 1170, 615-622

Hellström M, Ruitenberg MJ, Pollett MA, Ehlert EME, Twisk J, Verhaagen J, Harvey AR (2009): Cellular tropism and transduction properties of seven adenoassociated viral vector serotypes in adult retina after intravitreal injection. Gene Ther 16, 521-532

Hoenen C, Gustin A, Birck C, Kirchmeyer M, Beaume N, Felten P, Grandbarbe L, Heuschling P, Heurtaux T (2016): Alpha-Synuclein Proteins Promote ProInflammatory Cascades in Microglia: Stronger Effects of the A53T Mutant. PloS One $\underline{11}$, e0162717

Holstege G (1992): The emotional motor system. Eur J Morphol $\underline{30}$ 67-79

Holstege G (1996): The somatic motor system. Prog Brain Res 107, 9-26 
Hoyer W, Cherny D, Subramaniam V, Jovin TM (2004): Impact of the acidic C-terminal region comprising amino acids 109-140 on alpha-synuclein aggregation in vitro. Biochemistry $\underline{43}, 16233-16242$

Iacono D, Geraci-Erck M, Rabin ML, Adler CH, Serrano G, Beach TG, Kurlan R (2015): Parkinson disease and incidental Lewy body disease: Just a question of time? Neurology 85, 1670-1679

Ikeda H, Head GM, Ellis CJ (1994): Electrophysiological signs of retinal dopamine deficiency in recently diagnosed Parkinson's disease and a follow up study. Vision Res $\underline{34}$, 2629-2638

Inzelberg R, Ramirez JA, Nisipeanu P, Ophir A (2004): Retinal nerve fiber layer thinning in Parkinson disease. Vision Res 44, 2793-2797

Ishizawa T, Mattila P, Davies P, Wang D, Dickson DW (2003): Colocalization of Tau and Alpha-Synuclein Epitopes in Lewy Bodies. J Neuropathol Exp Neurol $\underline{62}$, 389-397

Jakes R, Spillantini MG, Goedert M (1994): Identification of two distinct synucleins from human brain. FEBS Lett $\underline{345}, 27-32$

Kahle PJ, Neumann M, Ozmen L, Müller V, Jacobsen H, Schindzielorz A, Okochi M, Leimer U, van der Putten H, Probst A, et al. (2000): Subcellular Localization of Wild-Type and Parkinson's Disease-Associated Mutant $\alpha$-Synuclein in Human and Transgenic Mouse Brain. J Neurosci 20, 6365-6373

Kemshead JT, Ritter MA, Cotmore SF, Greaves MF (1982): Human Thy-1: expression on the cell surface of neuronal and glial cells. Brain Res $\underline{236}$ 451-461

Kerschensteiner M, Schwab ME, Lichtman JW, Misgeld T (2005): In vivo imaging of axonal degeneration and regeneration in the injured spinal cord. Nat Med $\underline{11}$, 572-577

Kish SJ, Shannak K, Hornykiewicz O (1988): Uneven pattern of dopamine loss in the striatum of patients with idiopathic Parkinson's disease. Pathophysiologic and clinical implications. N Engl J Med $\underline{318}, 876-880$

Kitada T, Asakawa S, Hattori N, Matsumine H, Yamamura Y, Minoshima S, Yokochi M, Mizuno Y, Shimizu N (1998): Mutations in the parkin gene cause autosomal recessive juvenile parkinsonism. Nature $\underline{392}, 605-608$

Knöferle J, Koch JC, Ostendorf T, Michel U, Planchamp V, Vutova P, Tonges L, Stadelmann C, Bruck W, Bahr M, Lingor P (2010): Mechanisms of acute axonal degeneration in the optic nerve in vivo. Proc Natl Acad Sci USA 107, 60646069

Koch JC, Knöferle J, Tönges L, Ostendorf T, Bähr M, Lingor P (2010): Acute axonal degeneration in vivo is attenuated by inhibition of autophagy in a calciumdependent manner. Autophagy $\underline{6}$, 658-659 
Konno T, Ross OA, Puschmann A, Dickson DW, Wszolek ZK (2016): Autosomal dominant Parkinson's disease caused by SNCA duplications. Parkinsonism Relat Disord 22 Suppl 1, S1-S6

Krüger R, Kuhn W, Müller T, Woitalla D, Graeber M, Kösel S, Przuntek H, Epplen JT, Schöls L, Riess O (1998): Ala30Pro mutation in the gene encoding alphasynuclein in Parkinson's disease. Nat Genet 18, 106-108

Kügler S, Lingor P, Schöll U, Zolotukhin S, Bähr M (2003): Differential transgene expression in brain cells in vivo and in vitro from AAV-2 vectors with small transcriptional control units. Virology $\underline{311,89-95}$

Laurens B, Vergnet S, Lopez MC, Foubert-Samier A, Tison F, Fernagut P-O, Meissner WG (2017): Multiple System Atrophy - State of the Art. Curr Neurol Neurosci Rep 17, 41

Lee H-J (2005): Intravesicular Localization and Exocytosis of -Synuclein and its Aggregates. J Neurosci $25,6016-6024$

Lee H-J, Suk J-E, Bae E-J, Lee J-H, Paik SR, Lee S-J (2008): Assembly-dependent endocytosis and clearance of extracellular a-synuclein. Int J Biochem Cell Biol $\underline{40}$ 1835-1849

Lee MK, Stirling W, Xu Y, Xu X, Qui D, Mandir AS, Dawson TM, Copeland NG, Jenkins NA, Price DL (2002): Human -synuclein-harboring familial Parkinson's disease-linked Ala-53 - Thr mutation causes neurodegenerative disease with synuclein aggregation in transgenic mice. Proc Natl Acad Sci USA 99, 89688973

Lee S-J, Jeon H, Kandror KV (2008): Alpha-synuclein is localized in a subpopulation of rat brain synaptic vesicles. Acta Neurobiol Exp (Warsz) 68, 509-515

Lees AJ, Hardy J, Revesz T (2009): Parkinson’s Disease. Lancet 2055-2066

Leger F, Fernagut P-0, Canron M-H, Léoni S, Vital C, Tison F, Bezard E, Vital A (2011): Protein aggregation in the aging retina. J Neuropathol Exp Neurol 70, 63-68

Lindström V, Fagerqvist T, Nordström E, Eriksson F, Lord A, Tucker S, Andersson J, Johannesson M, Schell H, Kahle PJ, et al. (2014): Immunotherapy targeting $\alpha$ synuclein protofibrils reduced pathology in (Thy-1)-h[A30P] $\alpha$-synuclein mice. Neurobiol Dis $\underline{69}, 134-143$

Lindström V, Gustafsson G, Sanders LH, Howlett EH, Sigvardson J, Kasrayan A, Ingelsson M, Bergström J, Erlandsson A (2017): Extensive uptake of $\alpha$ synuclein oligomers in astrocytes results in sustained intracellular deposits and mitochondrial damage. Mol Cell Neurosci $\underline{82}, 143-156$

Lingor P, Koch JC, Tönges L, Bähr M (2012): Axonal degeneration as a therapeutic target in the CNS. Cell Tissue Res $\underline{349}$,289-311

Luk KC, Song C, O’Brien P, Stieber A, Branch JR, Brunden KR, Trojanowski JQ, Lee VMY (2009): Exogenous -synuclein fibrils seed the formation of Lewy body-like 
intracellular inclusions in cultured cells. Proc Natl Acad Sci USA $\underline{106}$, 2005120056

Ma M (2013): Role of calpains in the injury-induced dysfunction and degeneration of the mammalian axon. Neurobiol Dis $\underline{60}, 61-79$

Martin KRG, Klein RL, Quigley HA (2002): Gene delivery to the eye using adenoassociated viral vectors. Methods 28, 267-275

Masliah E, Rockenstein E, Veinbergs I, Mallory M, Hashimoto M, Takeda A, Sagara Y, Sisk A, Mucke L (2000): Dopaminergic loss and inclusion body formation in alpha-synuclein mice: implications for neurodegenerative disorders. Science 287, 1265-1269

Moechars D, Dewachter I, Lorent K, Reversé D, Baekelandt V, Naidu A, Tesseur I, Spittaels K, Haute CV, Checler F, et al. (1999): Early phenotypic changes in transgenic mice that overexpress different mutants of amyloid precursor protein in brain. J Biol Chem 274, 6483-6492

Moschos MM, Tagaris G, Markopoulos I, Margetis I, Tsapakis S, Kanakis M, Koutsandrea C (2011): Morphologic changes and functional retinal impairment in patients with Parkinson disease without visual loss. Eur J Ophthalmol $\underline{21}, 24-29$

Nath S, Goodwin J, Engelborghs Y, Pountney DL (2011): Raised calcium promotes $\alpha$ synuclein aggregate formation. Mol Cell Neurosci $\underline{46}$, 516-526

Neumann M, Kahle PJ, Giasson BI, Ozmen L, Borroni E, Spooren W, Müller V, Odoy S, Fujiwara H, Hasegawa M, et al. (2002): Misfolded proteinase K-resistant hyperphosphorylated alpha-synuclein in aged transgenic mice with locomotor deterioration and in human alpha-synucleinopathies. J Clin Invest 110, 14291439

Nieuwenhuys R (1996): The greater limbic system, the emotional motor system and the brain. Prog Brain Res 107, 551-580

Nuytemans K, Theuns J, Cruts M, Van Broeckhoven C (2010): Genetic etiology of Parkinson disease associated with mutations in the SNCA, PARK2, PINK1, PARK7, and LRRK2 genes: a mutation update. Hum Mutat $\underline{31}$, 763-780

Palmowski-Wolfe AM, Perez MT, Behnke S, Fuss G, Martziniak M, Ruprecht KW (2006): Influence of dopamine deficiency in early Parkinson's disease on the slow stimulation multifocal-ERG. Doc Ophthalmol Adv Ophthalmol 112, 209215

Pan-Montojo F, Schwarz M, Winkler C, Arnhold M, O'Sullivan GA, Pal A, Said J, Marsico G, Verbavatz J-M, Rodrigo-Angulo M, et al. (2012): Environmental toxins trigger PD-like progression via increased alpha-synuclein release from enteric neurons in mice. Sci Rep $\underline{2}, 898$ 
Park SM, Jung HY, Kim TD, Park JH, Yang C-H, Kim J (2002): Distinct roles of the Nterminal-binding domain and the C-terminal-solubilizing domain of alphasynuclein, a molecular chaperone. J Biol Chem 277, 28512-28520

Pasanen P, Myllykangas L, Siitonen M, Raunio A, Kaakkola S, Lyytinen J, Tienari PJ, Pöyhönen M, Paetau A (2014): Novel $\alpha$-synuclein mutation A53E associated with atypical multiple system atrophy and Parkinson's disease-type pathology. Neurobiol Aging 35, 2180.e1-5

Pearce RK, Hawkes CH, Daniel SE (1995): The anterior olfactory nucleus in Parkinson's disease. Mov Disord 10, 283-287

Peppe A, Stanzione P, Pierelli F, Stefano E, Rizzo PA, Tagliati M, Morocutti C (1992): Low contrast stimuli enhance PERG sensitivity to the visual dysfunction in Parkinson's disease. Electroencephalogr Clin Neurophysiol 82, 453-457

Pfeiffer RF (2011): Gastrointestinal dysfunction in Parkinson's disease. Parkinsonism Relat Disord 17, 10-15

Polymeropoulos MH, Lavedan C, Leroy E, Ide SE, Dehejia A, Dutra A, Pike B, Root H, Rubenstein J, Boyer R, et al. (1997): Mutation in the alpha-synuclein gene identified in families with Parkinson's disease. Science 276, 2045-2047

Pressman BC (1976): Biological Applications of Ionophores. Annu Rev Biochem 45 , 501-530

Proukakis C, Dudzik CG, Brier T, MacKay DS, Cooper JM, Millhauser GL, Houlden H, Schapira AH (2013): A novel $\alpha$-synuclein missense mutation in Parkinson disease. Neurology $\underline{80}, 1062-1064$

Rabinowitz JE, Bowles DE, Faust SM, Ledford JG, Cunningham SE, Samulski RJ (2004): Cross-Dressing the Virion: the Transcapsidation of Adeno-Associated Virus Serotypes Functionally Defines Subgroups. J Virol 78, 4421-4432

Ratican SE, Osborne A, Martin KR (2018): Progress in Gene Therapy to Prevent Retinal Ganglion Cell Loss in Glaucoma and Leber's Hereditary Optic Neuropathy. Neural Plast $\underline{2018}, 7108948$

Ribas VT, Schnepf B, Challagundla M, Koch JC, Bähr M, Lingor P (2015): Early and Sustained Activation of Autophagy in Degenerating Axons after Spinal Cord Injury: Autophagy Activation in Spinal Cord Damaged Axons. Brain Pathol 25, 157170

Ribas VT, Koch JC, Michel U, Bähr M, Lingor P (2016): Attenuation of Axonal Degeneration by Calcium Channel Inhibitors Improves Retinal Ganglion Cell Survival and Regeneration After Optic Nerve Crush. Mol Neurobiol 54 (1), 72-86

Roodveldt C, Labrador-Garrido A, Gonzalez-Rey E, Fernandez-Montesinos R, Caro M, Lachaud CC, Waudby CA, Delgado M, Dobson CM, Pozo D (2010): Glial innate immunity generated by non-aggregated alpha-synuclein in mouse: differences between wild-type and Parkinson's disease-linked mutants. PloS One $\underline{5}$, e13481 
Ross GW, Petrovitch H, Abbott RD, Nelson J, Markesbery W, Davis D, Hardman J, Launer L, Masaki K, Tanner CM, White LR (2004): Parkinsonian signs and substantia nigra neuron density in decendents elders without PD. Ann Neurol 56, 532-539

Roth NM, Saidha S, Zimmermann H, Brandt AU, Isensee J, Benkhellouf-Rutkowska A, Dornauer M, Kühn AA, Müller T, Calabresi PA, Paul F (2014): Photoreceptor layer thinning in idiopathic Parkinson's disease. Mov Disord 29, 1163-1170

Sartucci F, Orlandi G, Bonuccelli U, Borghetti D, Murri L, Orsini C, Domenici L, Porciatti V (2006): Chromatic pattern-reversal electroretinograms (ChPERGs) are spared in multiple system atrophy compared with Parkinson's disease. Neurol Sci $\underline{26}, 395-401$

Scherman D, Desnos C, Darchen F, Pollak P, Javoy-Agid F, Agid Y (1989): Striatal dopamine deficiency in Parkinson's disease: role of aging. Ann Neurol 26, 551557

Shevtsova Z, Malik JMI, Michel U, Bähr M, Kügler S (2005): Promoters and serotypes: targeting of adeno-associated virus vectors for gene transfer in the rat central nervous system in vitro and in vivo. Exp Physiol 90, 53-59

Shoji M (2000): Accumulation of NACP/alpha -synuclein in Lewy body disease and multiple system atrophy. J Neurol Neurosurg Psychiatry $\underline{68}$, 605-608

Singleton AB, Farrer M, Johnson J, Singleton A, Hague S, Kachergus J, Hulihan M, Peuralinna T, Dutra A, Nussbaum R, et al. (2003): alpha-Synuclein locus triplication causes Parkinson's disease. Science $\underline{302}, 841$

Stagi M, Gorlovoy P, Larionov S, Takahashi K, Neumann H (2006): Unloading kinesin transported cargoes from the tubulin track via the inflammatory c-Jun Nterminal kinase pathway. FASEB J 20, 2573-2575

Surmeier DJ (2007): Calcium, ageing, and neuronal vulnerability in Parkinson's disease. Lancet Neurol 6, 933-938

Tagliati M, Bodis-Wollner I, Yahr MD (1996): The pattern electroretinogram in Parkinson's disease reveals lack of retinal spatial tuning. Electroencephalogr Clin Neurophysiol 100, 1-11

Tamamizu-Kato S, Kosaraju MG, Kato H, Raussens V, Ruysschaert J-M, Narayanaswami V (2006): Calcium-Triggered Membrane Interaction of the $\alpha$ Synuclein Acidic Tail †. Biochemistry $\underline{45}$, 10947-10956

Touma E, Kato S, Fukui K, Koike T (2007): Calpain-mediated cleavage of collapsin response mediator protein(CRMP)-2 during neurite degeneration in mice. Eur J Neurosci 26, 3368-3381

Tshilenge K-T, Ameline B, Weber M, Mendes-Madeira A, Nedellec S, Biget M, Provost N, Libeau L, Blouin V, Deschamps J-Y, et al. (2016): Vitrectomy Before Intravitreal Injection of AAV2/2 Vector Promotes Efficient Transduction of 
Retinal Ganglion Cells in Dogs and Nonhuman Primates. Hum Gene Ther Methods $\underline{27}, 122-134$

Ulmer TS, Bax A, Cole NB, Nussbaum RL (2005): Structure and dynamics of micellebound human alpha-synuclein. J Biol Chem 280, 9595-9603

Valente EM, Abou-Sleiman PM, Caputo V, Muqit MMK, Harvey K, Gispert S, Ali Z, Del Turco D, Bentivoglio AR, Healy DG, et al. (2004): Hereditary early-onset Parkinson's disease caused by mutations in PINK1. Science 304, 1158-1160

van der Putten H, Wiederhold KH, Probst A, Barbieri S, Mistl C, Danner S, Kauffmann S, Hofele K, Spooren WP, Ruegg MA, et al. (2000): Neuropathology in mice expressing human alpha-synuclein. J Neurosci 20, 6021-6029

Vosler PS, Brennan CS, Chen J (2008): Calpain-Mediated Signaling Mechanisms in Neuronal Injury and Neurodegeneration. Mol Neurobiol 38, 78-100

Wakabayashi K, Tanji K, Mori F, Takahashi H (2007): The Lewy body in Parkinson's disease: molecules implicated in the formation and degradation of alphasynuclein aggregates. Neuropathology 27, 494-506

Winner B, Jappelli R, Maji SK, Desplats PA, Boyer L, Aigner S, Hetzer C, Loher T, Vilar $\mathrm{M}$, Campioni $\mathrm{S}$, et al. (2011): In vivo demonstration that $\alpha$-synuclein oligomers are toxic. Proc Natl Acad Sci U S A 108, 4194-4199

Wirtschafter JD (1983): Optic nerve axons and acquired alterations in the appearance of the optic disc. Trans Am Ophthalmol Soc 81, 1034-1091

Wise-Scira O, Aloglu AK, Dunn A, Sakallioglu IT, Coskuner O (2013a): Structures and free energy landscapes of the wild-type and A30P mutant-type $\alpha$-synuclein proteins with dynamics. ACS Chem Neurosci $\underline{4}$, 486-497

Wise-Scira O, Dunn A, Aloglu AK, Sakallioglu IT, Coskuner O (2013b): Structures of the E46K mutant-type $\alpha$-synuclein protein and impact of E46K mutation on the structures of the wild-type $\alpha$-synuclein protein. ACS Chem Neurosci $\underline{4}$, 498508

Zarranz JJ, Alegre J, Gómez-Esteban JC, Lezcano E, Ros R, Ampuero I, Vidal L, Hoenicka J, Rodriguez 0, Atarés B, et al. (2004): The new mutation, E46K, of alphasynuclein causes Parkinson and Lewy body dementia. Ann Neurol $\underline{55}, 164-173$

Zhang J-N, Michel U, Lenz C, Friedel CC, Köster S, d'Hedouville Z, Tönges L, Urlaub H, Bähr M, Lingor P, Koch JC (2016): Calpain-mediated cleavage of collapsin response mediator protein-2 drives acute axonal degeneration. Sci Rep $\underline{6}, 37050$

Zhang L, Zhang C, Zhu Y, Cai Q, Chan P, Uéda K, Yu S, Yang H (2008): Semi-quantitative analysis of $\alpha$-synuclein in subcellular pools of rat brain neurons: An immunogold electron microscopic study using a C-terminal specific monoclonal antibody. Brain Res 1244, 40-52 
Zimprich A, Biskup S, Leitner P, Lichtner P, Farrer M, Lincoln S, Kachergus J, Hulihan M, Uitti RJ, Calne DB, et al. (2004): Mutations in LRRK2 cause autosomaldominant parkinsonism with pleomorphic pathology. Neuron 44 , 601-607 


\section{Danksagung}

Die vorliegende Arbeit wäre nicht möglich gewesen ohne das beste und kollegialste Team, das sich ein Medizindoktorand nur wünschen kann! Vielen Dank an alle, die mich mit ihrer langjährigen Laborerfahrung, ihrem Fachwissen und ihrer Geduld während der letzten Jahre begleitet und unterstützt haben.

Im Einzelnen danke ich: Vivian Dambeck und Lisa Barski für ihre helfende Hand im Labor und ihre Beratung bei methodischen Fragen, Dr. rer. nat. Lars Tatenhorst, Dr. rer. nat. Eleonora Carboni und Dr. rer. nat. Anna Elisa Roser sowie den Tierärzten der Zentralen Tierexperimentellen Einrichtung für ihr offenes Ohr bei tierexperimentellen Fragen und der gesamten Arbeitsgruppe Lingor für eine unvergessliche Zeit.

Spezieller Dank gebührt Dr. med. Alexander Böcker für sein unglaubliches Engagement als mein wissenschaftlicher Betreuer, sei es in der Anfangsphase bei langen Nächten im Labor oder später bei der Beantwortung langer Emails mit fachlichen Fragen.

Zuletzt möchte ich mich bei meinen Doktorvätern PD Dr. med. Jan C. Koch und zuvor Prof. Dr. med. Paul Lingor bedanken, die mir beide stets beratend zur Seite standen und mich über die letzten Jahre gefördert haben. 